\title{
FINITE ELEMENT ANALYSIS OF FREEZING EFFECT ON SOIL NAIL WALL
}

\author{
by \\ Milad Babaei \\ B.Sc., Shahid Chamran University, Iran, 2008 \\ M.Sc., Shahid Chamran University, Iran, 2012 \\ A thesis
presented to Ryerson University \\ in partial fulfillment of the \\ requirements for the degree of \\ Master of Applied Science \\ in the program of \\ Civil Engineering
}

Toronto, Ontario, Canada, 2016

(C) (Milad Babaei) 2016 


\section{AUTHOR'S DECLARATION}

I hereby declare that I am the sole author of this thesis. This is a true copy of the thesis, including any required final revisions, as accepted by my examiners.

I authorize Ryerson University to lend this thesis to other institutions or individuals for the purpose of scholarly research.

I further authorize Ryerson University to reproduce this thesis by photocopying or by other means, in total or in part, at the request of other institutions or individuals for the purpose of scholarly research.

I understand that my thesis may be made electronically available to the public. 


\title{
FINITE ELEMENT ANALYSIS OF FREEZING EFFECT ON SOIL NAIL WALL
}

\author{
Milad Babaei \\ Master of Applied Science 2016 \\ Department of Civil Engineering \\ Ryerson University, Toronto, Canada
}

\begin{abstract}
This study presents a finite element analysis on the behavior of soil nail walls subjected to different freezing and thawing conditions. Thermo-mechanical coupled analysis has become increasingly important due to the increasing number of geotechnical structures built in cold regions. Soil nailing is a relatively new technique of reinforcing existing slopes or supporting new excavations. Its performance has been proven through decades of successful applications throughout the world. However, its applications in cold regions are still very limited due to sparse research available on its behavior in cold regions. In addition, soil may dramatically change its properties after experiencing freezing and thawing cycles. A two-dimensional finite element analysis using ABAQUS software is conducted to investigate the frost penetration depth in the soil and the resulting influence on the performance of the soil nail walls in Northern Ontario. The numerical model is verified against the field measurements obtained from a research program done in Brunswick, Maine, U.S. (Duchesne, 2003). The change of thermally induced stress along soil nails as well as the increase of displacements and earth pressure on the facing of the walls is investigated under freezing conditions. A parametric study is also conducted to probe the effect of thermal insulation systems on the wall facing and nails. This study provides valuable insight into the behavior of soil nailed structures in cold regions.
\end{abstract}




\section{DEDICATION}

To my family in Iran

for their love and support 


\section{ACKNOWLEDGEMENTS}

First and foremost, I would like to express my sincere appreciation to my advisor, Dr. Jinyuan Liu, for his guidance, assistance and patience throughout the research and writing phases of this thesis. His constructive comments and suggestions to countless questions and challenges that this study faced is greatly appreciated. I hope that I can continue my professional relations with him.

I am also grateful to Dr. Tareq Salloum, my co-supervisor who has shared his expertise and contributed time and effort in various ways in the production of this research.

The research described in this dissertation is made possible by the funding from Ministry of Transportation of Ontario. Their financial supports are gratefully appreciated. I also wish to thank Mr. David Staseff for his time and support at the beginning of this research study.

Next, I would especially like to express my gratitude to my fellow graduate students for their friendship, encouragement and support.

Last, but by no means least, I would like to acknowledge the tremendous understanding, patience, and love provided by my parents and my siblings through my study. 


\section{TABLE OF CONTENTS}

AUTHOR'S DECLARATION ..................................................................................................... ii

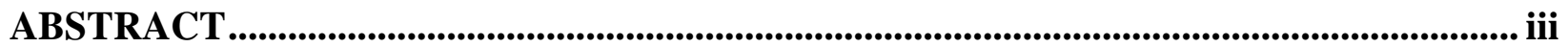

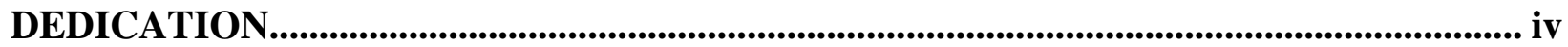

ACKNOWLEDGEMENTS ……..........................................................................................................

TABLE OF CONTENTS …........................................................................................................ vi

LIST OF TABLES ....................................................................................................................... viii

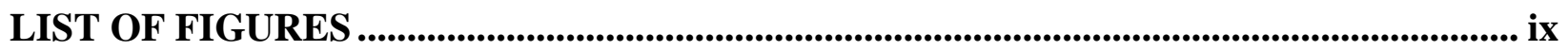

Chapter 1 : Introduction .......................................................................................................................1

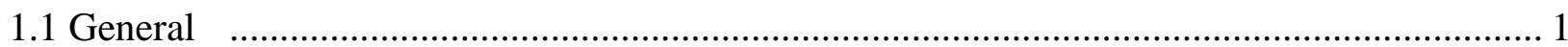

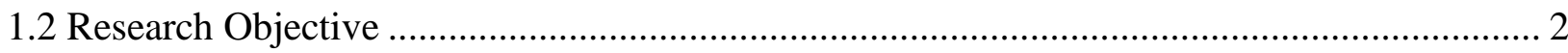

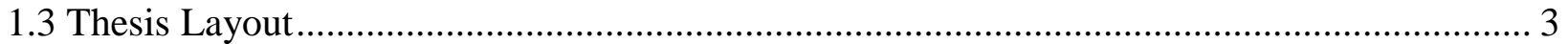

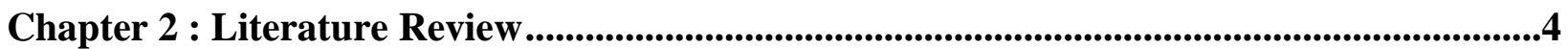

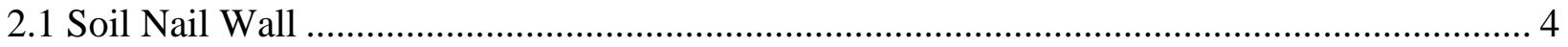

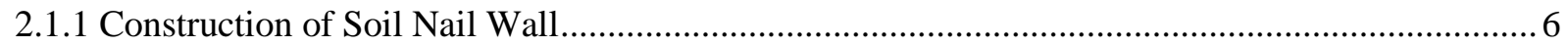

2.1.2 Typical Applications in Highway Construction......................................................................

2.1.3 Application of Retaining Systems in Cold Regions ................................................................ 10

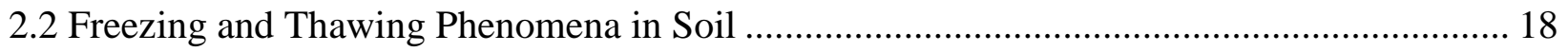

2.2.1 Mechanisms of Heat Transfer in Soil................................................................................. 19

2.2.2 Temperature Profile in Ground ............................................................................................ 20

2.2.3 Ground Freezing and Frost Penetration ...................................................................................22

2.2.4 Thaw Consolidation and Thaw Settlement in Soil................................................................... 30

2.2.5 Previous Investigation on Freezing and Thawing Behavior of Soil............................................ 31

2.3 Numerical Modelling of Heat Transfer in Soil ................................................................... 33

2.3.1 Theoretical Background of Heat Transfer in Soil Nail Walls .......................................................... 33

2.3.2 Transient Heat Transfer Model in Freezing and Thawing Soil........................................................ 34

2.3.3 Frost Penetration Prediction Models.......................................................................................... 35

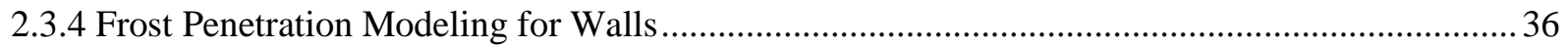

2.4 Mitigation Measures for Preventing Frost Damage on Retaining Structures .......................... 36

2.5 Constitutive Models for Freezing and Thawing Soil ............................................................ 40

Chapter 3 : Numerical Modeling and Model Verification ............................................................44

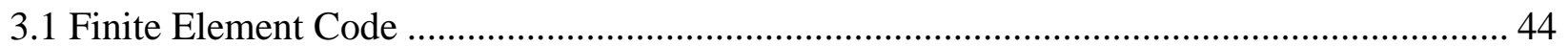

3.2 Details of Finite Element Model for Freezing and Thawing Study ....................................... 45

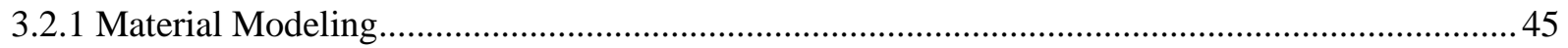




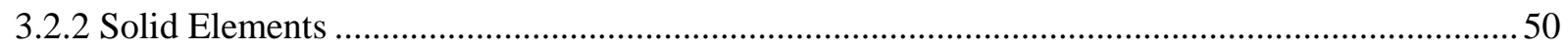

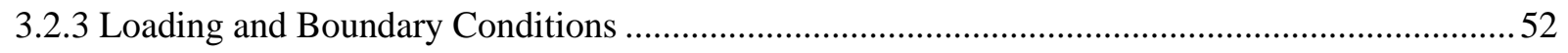

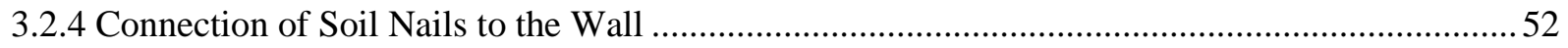

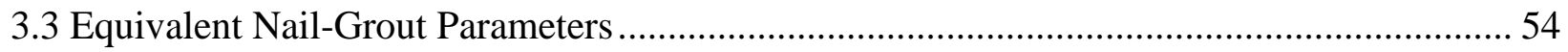

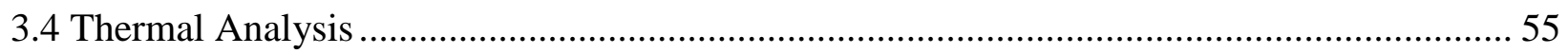

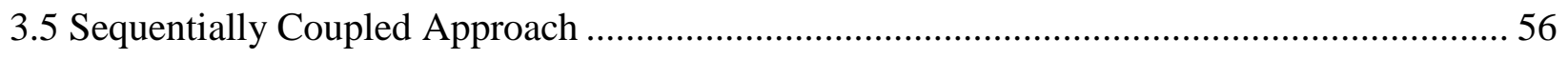

3.5.1 Transferring the Heat Transfer Results to the Mechanical Analysis.........................................57

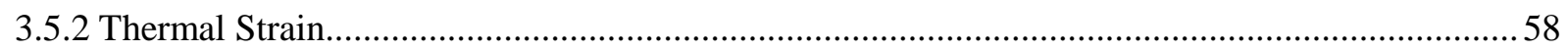

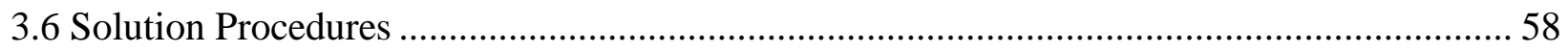

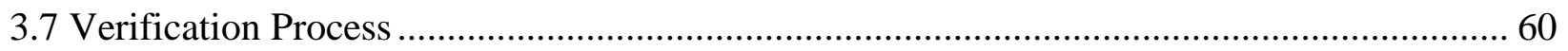

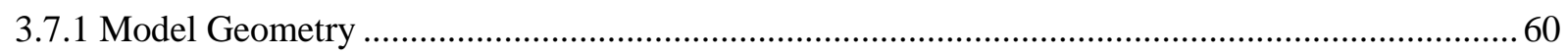

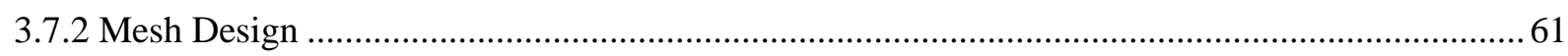

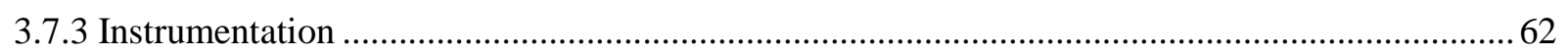

3.7.4 Effects of Freezing and Thawing on Material Properties ....................................................... 63

Chapter 4 : Mitigation Measures-Parametric Study .............................................................71

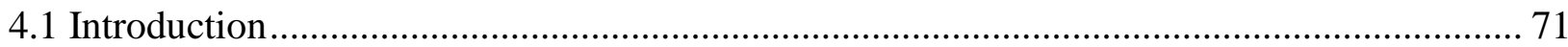

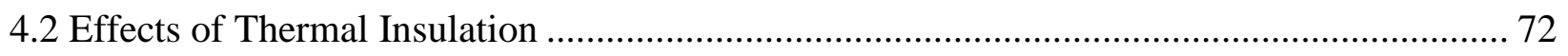

4.3 Performance of a Hypothetical Soil Nail Wall in Timmins, Ontario ................................. 73

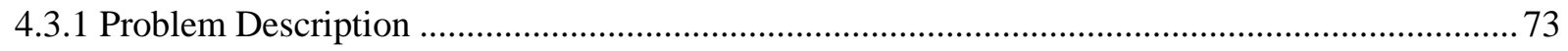

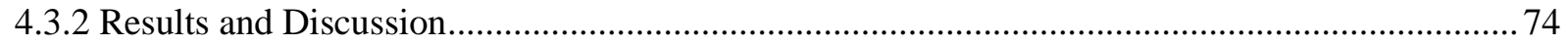

4.4 Performance of a Hypothetical Soil Nail Wall in Toronto, Ontario ..................................... 86

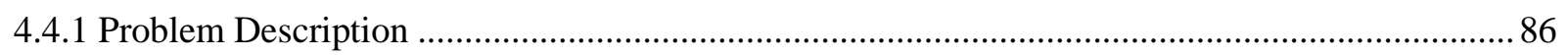

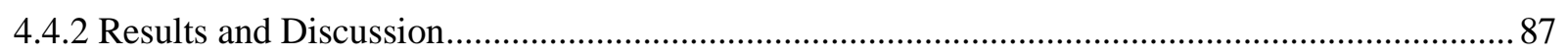

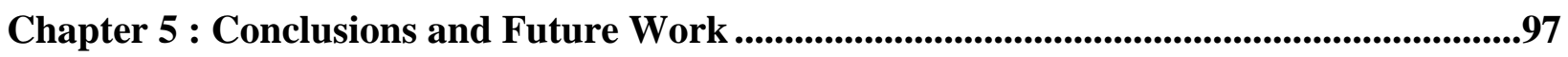

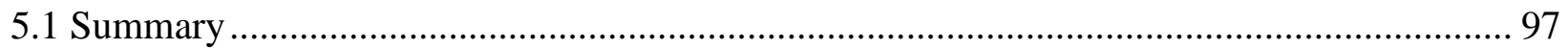

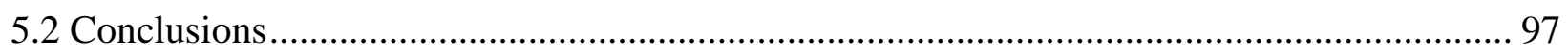

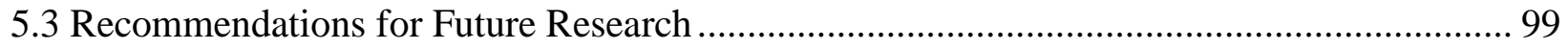

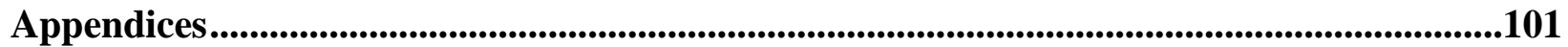

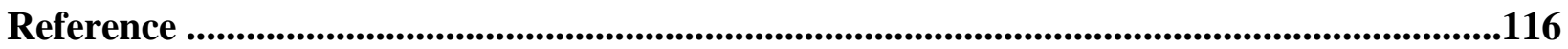




\section{LIST OF TABLES}

Table 2-1 U.S. Corps of Engineers frost susceptibility criteria based on soil type (Freitag and

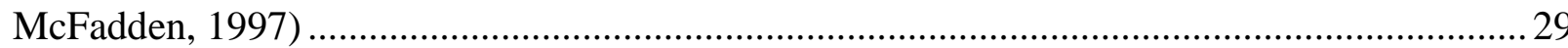

Table 2-2 Classification of frost susceptibility based on laboratory test (Freitag and McFadden,

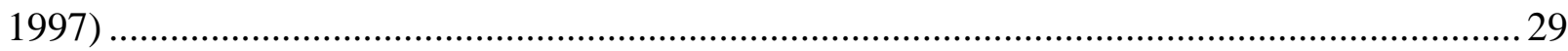

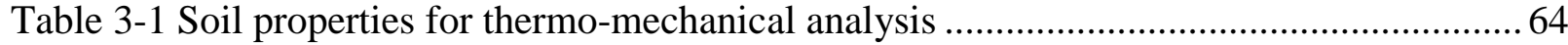

Table 3-2 Nail and wall properties for thermo-mechanical analysis ...................................6 64

Table 4-1 Material properties of insulation layer and LFC ................................................ 73 


\section{LIST OF FIGURES}

Figure 2-1 Soil nail wall (Source: https://seminarlinks.blogspot.ca)......................................4

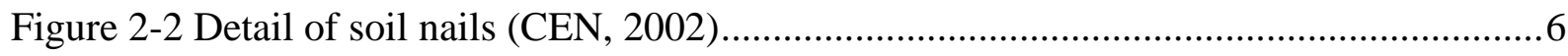

Figure 2-3 Typical soil nail wall construction sequence (Porterfield et al., 1994) .....................9

Figure 2-4 Schematic representation of slope facing reconstruction using geosynthetics (after Alston, 1994)

Figure 2-5 Predominant heat transfer mechanisms by grain size and degree of saturation (Loveridge, 2012, redrawn from Farouki, 1986) 20

Figure 2-6 Air freezing index map for Canada based on the period 1931 to 1960 (Boyd, 1973)

Figure 2-7 Whiplash curve for distribution of ground temperature over depth (Phukan, 1985) .22

Figure 2-8 Map of frost penetration depth in Ontario.........................................................25

Figure 2-9 Waves and potholes in a pavement caused by frost action (Source:

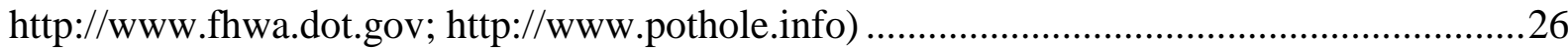

Figure 2-10 Frost heave process (Mitchell, 1976) …………………………………….........2

Figure 2-11 Freezing soil zones (Zhu, 2006) .......................................................................28

Figure 2-12 Thaw consolidation test result (Tsytovich, 1960) .................................................31

Figure 2-13 Typical details for a weep hole in a steep soil nail slope (FHWA, 2015).............39

Figure 2-14 The interaction mechanisms in a coupled thermal-mechanical-fluid flow system

(Neaupane et al., 1999) .....................................................................................................41

Figure 3-1 Mohr's circles of effective stress (Ports and Zdravkovic, 2001) ...........................48

Figure 3-2 Mohr-Coulomb failure criterion: pyramidal surface in principal stress space and, in a detail, the cross-section in the equipressure plane (Labuz and Zang, 2012)..........................49

Figure 3-3 The tensile and compressive stress-strain curve of steel (Wulff, 1965) .................50

Figure 3-4 Node ordering, face numbering, and element numbering of integration points for 4node reduced integration element (ABAQUS, 2010) ...............................................................51

Figure 3-5 Soil nail wall with surcharge load at the top of embankment .................................52

Figure 3-6 Steps for sequentially coupled approach (Aziz and Tao, 2012)..............................57

Figure $3-7$ Geometry and boundary conditions .....................................................................61 
Figure 3-8 Initial temperature distribution

Figure 3-9 Finite element mesh and the locations of the strain gages and pressure cell

Figure 3-10 Temperature distribution for both warm and cold seasons

Figure 3-11 Comparison of thermally induced stresses with time on nails between finite element model and field measurement .67

Figure 3-12 Comparison of the heaving pressure on wall versus time ................................68

Figure 3-13 Horizontal displacement profile of the soil nail wall in Maine, U.S...................69

Figure 3-14 Vertical displacement profile of the soil nail wall in Maine, U.S.......................70

Figure 4-1 Insulation layer placement for the soil nail wall model ....................................72

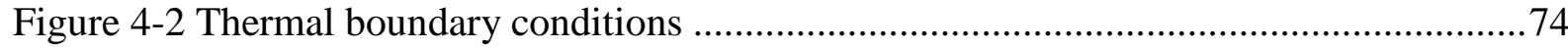

Figure 4-3 Temperature distribution for cold season in Timmins, Ontario...........................77

Figure 4-4 Temperature distribution for warm season in Timmins, Ontario.........................78

Figure 4-5 Thermally induced stress versus time for instrumented nails ...........................81

Figure 4-6 Lateral earth pressure increase on the wall versus time due to heaving ...............82

Figure 4-7 Horizontal displacement of a hypothetical soil nail wall in Timmins, Ontario

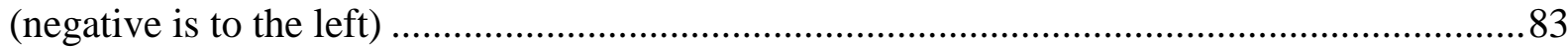

Figure 4-8 Vertical displacement of a hypothetical soil nail wall in Timmins, Ontari.........85

Figure 4-9 Thermal boundary conditions for a soil nail wall in Toronto, ON.......................86

Figure 4-10 Temperature distribution for cold season in Toronto, ON ..............................89

Figure 4-11 Temperature distribution for warm season in Toronto, ON ..............................90

Figure 4-12 Thermally induced stress change versus time for a hypnotical soil nail wall in

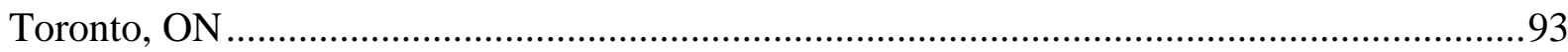

Figure 4-13 Lateral earth pressure increase on the wall versus time in Toronto, ON ............94

Figure 4-14 Horizontal displacement profile of a hypothetical soil nail wall in Toronto, ON.95

Figure 4-15 Vertical displacement of a hypothetical soil nail wall in Toronto, ON ..............96

Figure B.1 Horizontal displacement profile of a hypothetical soil nail wall in Timmins,

$\mathrm{ON}$

Figure B.2 Horizontal displacement profile of a hypothetical soil nail wall in Toronto,

ON. 
Figure B.3 Vertical displacement profile of a hypothetical soil nail wall in Timmins,

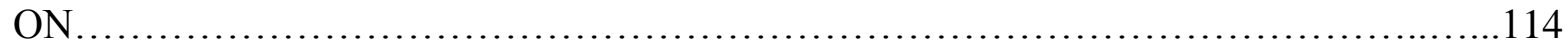

Figure B.4 Vertical displacement profile of a hypothetical soil nail wall in Toronto,

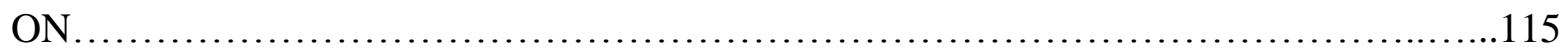




\section{Chapter 1 : Introduction}

\subsection{General}

A soil nail is a structural element which transferred loads to the ground to retain excavated or existing slopes. The "nail" may simply contain a steel tendon, but generally, the tendon is encapsulated in a cement grout in order to enhance load transfer and corrosion protection. Soil nailing is used for both temporary and permanent applications. The nail reinforcement developed stability of a slope, by improving the normal force and the soil shear resistance along the potential slip surfaces. This decreases the driving force along potential sliding surfaces in the soil. Finally, after the installation of the soil nails, a layer shotcrete is applied, which is typically shotcrete reinforced by Welded Wire Mesh (WWM). The application of soil nailing is extended to a wide variety of ground types, ranging from soils to weathered and unweathered rock.

The cold weather conditions in Canada, particularly in Northern Ontario, posed a unique challenge in assessing the feasibility of soil nail walls (SNWs). The prolonged exposure to freezing temperature may weaken the facing materials, diminish the bonding strength between at the groutsoil interface, and the adhesion between the shotcrete and the soil. Furthermore, this may create additional long-term deformation, and generate excessive stresses on the nails. Moreover, the intensity of thermal loading depends not only on the temperature fluctuation itself, but also on the type of soils at the site. The propagation of thermal energy inside soil mass, and its associated strain and strength change, is a very complicated phenomenon. Additionally, both unsaturated and saturated soils may revolve their engineering behaviours due to temperature variations (Gens, 2010). To minimize these detrimental effects, freeze-thaw cycles should be considered in the SNW design. 


\subsection{Research Objective}

The performance of SNWs is proven economically attractive and technically feasible after four decades of use in Europe, United States, and other places in the world. Nonetheless, there is a lack of proper categorized research regarding the performance and design of soil nail structures in cold regions, such as Northern Ontario. This highlighted a need for further studies to provide better understanding of the behaviour of SNWs in frost prone areas.

The intent of this research is to provide a numerical investigation on the influence of freezing conditions on the performance and durability of a soil nailed structure in frost prone areas. The Finite Element Method (FEM) is used in the study of SNWs by many researchers (Briaud and Lim, 1997; Smith and Su, 1997; Kingsbury at al., 2002; Zhou et al., 2009). The FE suite, ABAQUS, is utilized in this research due to its powerful and complete solutions for both routine and sophisticated engineering problems.

The objectives of this study include the following:

$>$ Numerically model the thermo-mechanical coupling phenomena and predict the frost penetration depth

$>$ Predict the frost penetration along the soil nails

$>$ Determine the thermally induced stresses on the nails

Investigate the frost induced lateral earth pressure on the wall facing

$>$ Determine the magnitude of the wall displacements during the course of cold season

$>$ Investigate the efficiency of various frost protection measures; and

$>$ Develop recommendations for implementing SNWs in cold regions.

The findings of this study would help implement this innovative retaining technique in Northern Ontario. 


\subsection{Thesis Layout}

This study presents a numerical simulation of the freezing and thawing cycle on SNWs, followed by recommendations for implementing SNWs in cold regions.

Following the introduction of the soil nailing technique and the objectives of this study in Chapter 1, Chapter 2 provides a literature review of SNW description and its application, freezing and thawing effects in soils and its influences on the performance of soil retention systems.

Chapter 3 presents a background on the FE modeling using ABAQUS, and the components of the thermo-mechanical modelling for simulating a SNW subjected to freezing and thawing cycle. This is followed by the model verification process versus measured field test data from instrumented SNW in Brunswick, Maine, U.S.

Chapter 4 reports the application of the developed FE model in the simulation of the hypothetical SNWs in Timmins, Ontario and Toronto, Ontario. The analysis results are presented in terms of frost penetration depth, thermally induced stresses on the nails, and pressure on the wall facing. It also contains the wall displacements caused by frost heaving, and the frost protection measures. The effectiveness of mitigation measures are also presented and discussed in this chapter.

Finally, Chapter 5 summarizes the research outcomes, conclusion of this research, and suggestions for further investigation. 


\section{Chapter 2 : Literature Review}

\subsection{Soil Nail Wall}

The main reinforcing mechanism of soil nailing is to reinforce and strengthen the existing ground by installing tension-resisting inclusions, such as steel bars or fiberglass rods, to reinforce and anchor an in situ soil mass and increase its stability. Soil nailing is used to stabilize slopes and landslides, provide earth retention for excavations for plants, parking structures, tunnels, deep cuts, and repair existing retaining walls as shown in Figure 2-1.

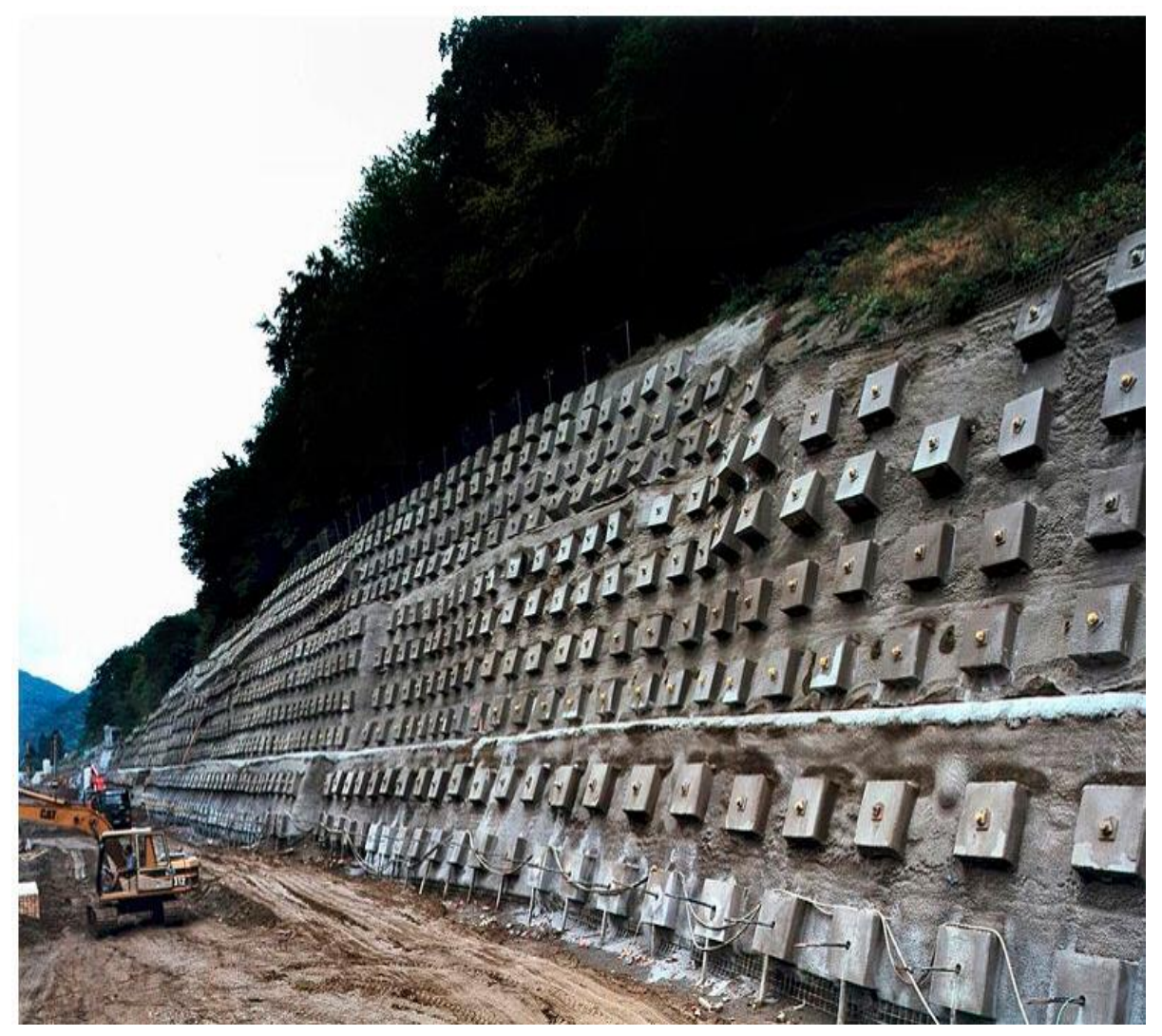

Figure 2-1 Soil nail wall (Source: HTTPS://SEMINARLINKS.BLOGSPOT.CA)

The insertion and grouting of steel reinforcement into the ground, combined with the application of shotcrete facing to provide support for excavation, is derived from the advanced system in rock- 
excavation support known as the "New Austrian Tunneling Method (NATM)" (Rabcewicz, 1965). The passive steel tendons are introduced as rock bolts in the tunnel industry. The concept of combining passive steel reinforcement and shotcrete extends subsequently to rock-slope stabilization projects (Lang, 1961). Soil nailing has been accepted as the generic terminology in all applications for ground installations.

The details of each individual soil nail are presented in Figure 2-2. The nails are typically placed in drilled boreholes and grouted along their entire length, although some contractors drive the nails into the ground (Byrne et al., 1993). However, drilled nails tend to have a higher capacity (Sieczkowski, 1989). In addition, for corrosion protection purpose in major projects, drilling and grouting has been the preferred technique in North America (Byrne et al., 1996).

Soil nailing technique, for specified conditions offers a feasible alternative in terms of technical feasibility, construction duration and cost as oppose to other retaining systems, such as ground anchor walls, and mechanically stabilized earth (MSE) techniques wall. 

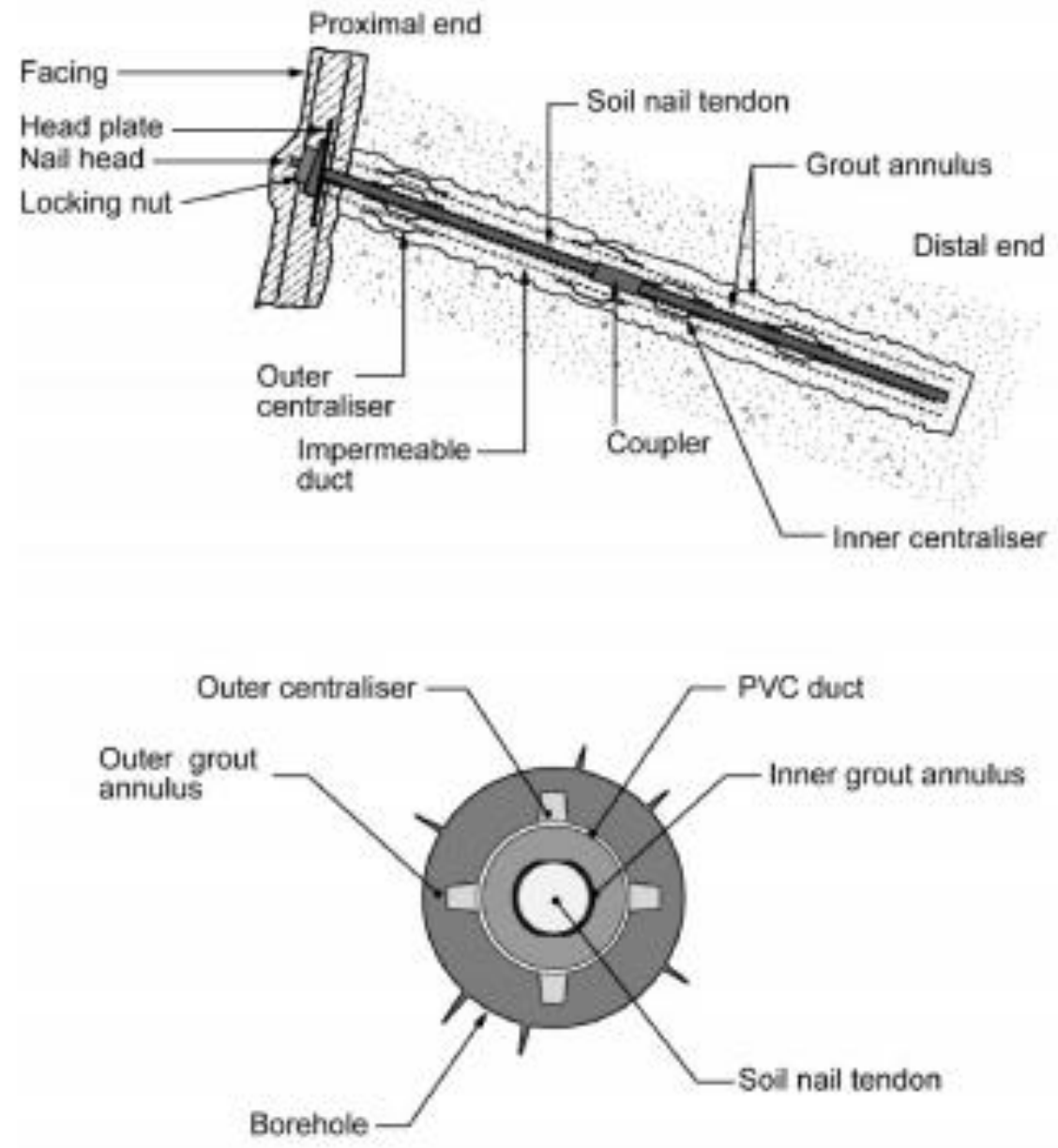

Section through soil nail

Note: Other systems may use flexible facing and/or may not use grout. impermeable duct or couplers

Figure 2-2 Detail of soil nails (CEN, 2002)

\subsubsection{Construction of Soil Nail Wall}

Soil nails are installed sub-horizontally in soft ground and weathered rock to retain slopes. The typical sequence of construction of a SNW is described below and illustrated in Figure 2-3.

Step 1. Excavation. The depth of the initial unsupported cut may range between 0.8 to $2 \mathrm{~m}$, and would reach roughly below the elevation where the first row of nails would be installed. The feasibility of this step is important because the excavation face must be able to remain unsupported, until the installation of nails and initial facing, generally one to two days. The type of soil that is 
excavated may limit the depth of the excavation. The excavated platform must provide safe access for the application of soil nail.

Step 2. Drilling Holes for Nails. Drill holes are carried out using drilling equipment that is managed from the excavated platform. The drill holes usually would stand without any supports.

Step 3. A) Installation and Grouting of Nails. Steel bars are installed in the drilled hole. A tremie pipe is inserted in the drill hole along with the steel bar for grouting; and then the hole is loaded with grout, under gravity or a nominal, low pressure (less than 34 to $69 \mathrm{kPa}$ ); depending on the inclination of the nails. In the case of the installing of the hollow bars, the drilling and grouting would occur in one operation. B) Installation of Drainage system. Strip drains are placed on the face of the excavation, from the top of the excavation area to slightly below the lower part of the excavation. The drainage systems are installed between adjoining nails and are opened downward to the next excavation section (FHWA, 2015).

Step 4. Initial Shotcrete Facing Construction. Before initializing the next excavation sector, an initial facing is constructed to the unsupported cut. The initial facing commonly contains a reinforced $0.1 \mathrm{~m}$ thick layer of shotcrete. The reinforcement comprised WWM that is installed in the middle of the facing thickness. Bending resistance is provided through the installation of horizontal and vertical bars around the nail heads. A bearing plate is installed over the nail head that is protruding from the drilled hole, at the time that shotcrete is curing. The steel bearing plate is placed with slight pressure into the fresh shotcrete. Hexagonal nuts and ishers are then used to secure the nail head and the bearing plate system. The Hexagonal nut should be wrench-tightened within 24 hours of the installment of the initial facing shotcrete. Before advancing to the subsequent excavation sector, in order to proof-load nails capacity or to verify the load-specified criterion, testing of some of the installed nails should be carried out. Additionally, the shotcrete should also achieve its minimum specified 3-day compressive strength. Curing period of the shotcrete for 72 hours should be considered for construction planning.

Step 5. Subsequent Levels Construction. Steps 1 through 4 are repeated for the remaining excavation. At each excavation sector, the strip drain is placed to the subsequent section. A new 
panel of WWM is then placed overlapping with the WWM panel above for at least one full mesh cell. The temporary shotcrete is then applied in connection with the previous shotcrete section.

Step 6. Final Facing Construction. After the last part of the excavation is completed and nails are installed, the final facing would build. Final facing may contain cast in place reinforced concrete, or prefabricated panels. Drainage systems are then installed for discharging any surplus water through the continuous drainage systems.

Alternation between steps described above could be inevitable in order to accommodate specific conditions at a site. For instance, shotcrete may be applied at each staged excavation, before nail installation, especially where the stability of the excavation face has been a concern. Another variation in nail installation could be placement of the tendon in the wet grout after grouting the drill hole. 


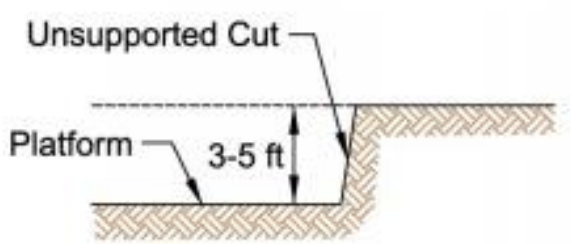

Step 1. Excavate Initial Lift

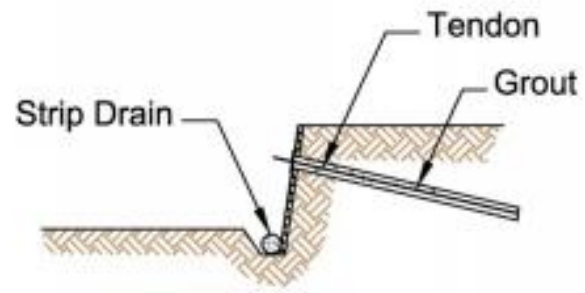

Step 3. Install and Grout Nail (Includes Strip Drain Installation)

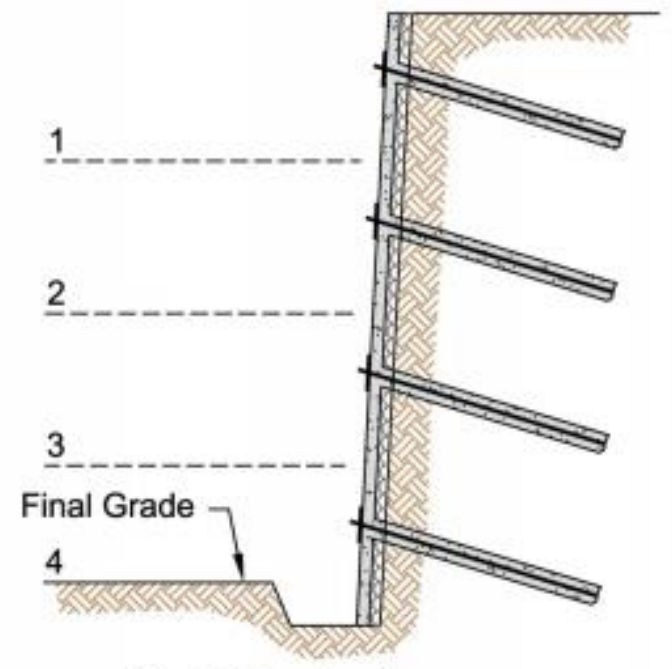

Step 5. Construction of Subsequent Levels

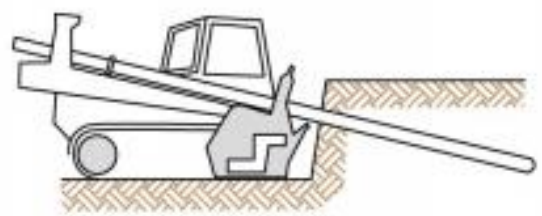

Step 2. Drill Nail Hole

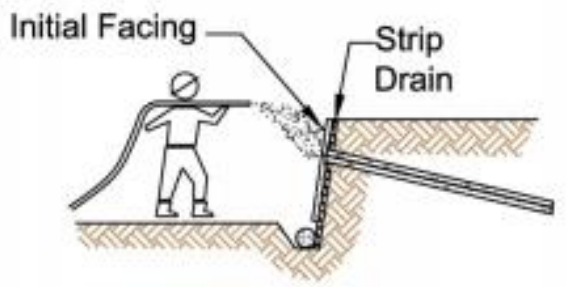

Step 4. Place Initial Facing (Includes Shotcrete, Reinforcement, Bearing Plate, Washer and Hex Nut Installation)

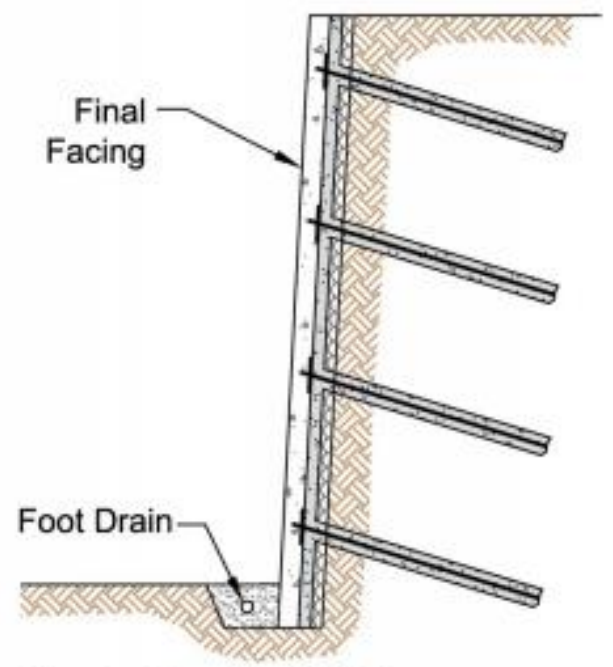

Step 6. Place Final Facing (Includes Building of Foot Drain)

Figure 2-3 Typical soil nail wall construction sequence (Porterfield et al., 1994)

\subsubsection{Typical Applications in Highway Construction}

Soil nailing is proven to be very cost-effective for shoring temporary excavation and stabilizing slopes. Related to highway construction, soil nailing is applied in many cases. Examples include 
the excavation of roadway cuts, widening of a road under an existing bridge, stabilization of cut tunnel portals, and repair/reconstruction of existing retaining structures.

The soil nailed structure performs similar to a composite gravity structure. However, there is a possibility for a slide surface to develop through the nails, especially, through the low-capacity tendons that are common with driven SNWs (Sieczkowski, 1989). Slopes ranging from $50^{\circ}$ to $90^{\circ}$ have been reinforced with the nails installed at $0^{\circ}$ to $30^{\circ}$ inclination below horizontal; most designs proposed the nails placement between $10^{\circ}$ and $20^{\circ}$ below horizontal. Parametric studies have revealed that increasing the number of nails in a wall would maximize the factor of safety by pushing the failure surface further back into the soil mass (Sieczkowski, 1989).

SNWs built in cold regions are prone to increased loads in the nails resulting from frost force. Byrne et al. (1998) revealed failure of soil nail facing, and the soil behind the wall may experience settlement after thawing. Elias and Juran (1991) conducted a survey on monitored SNWs subjected to frost action. They reported that nail loads are maximized in several conditions: 1) frost propagation depth; 2) freezing index; and 3) water sources in the vicinity of the wall facing. In a few cases, frost induced stresses increased to roughly twice the initial post-construction values are observed at the distance of 0 to $4 \mathrm{~m}$ behind the face of the SNWs.

When used in cold regions, SNWs would be exposed to a prolonged exposure of ambient freezing temperature. A field measurement conducted by Kingsbury et al. (2002) found that the force in the nail head caused by frost action could be 2.5 times larger than the maximum seasonal nail force without frost action.

\subsubsection{Application of Retaining Systems in Cold Regions}

Only a few case histories document the behavior of SNWs in cold climates and frost prone soils. However, well-documented measurements of seasonal stress cycles in other retaining wall systems may provide a model for understanding the seasonal stress increases in a SNW. 
In Canada, soil nailing started with a temporary excavation support in Vancouver, B.C. in the late 1960s. To date its application has been primarily in the temporary excavation shoring market in Western Canada. It has also been applied for a $20 \mathrm{~m}$ excavated cut in the Edmonton Light Rail Transit Project in Alberta. However, it has been relatively new in Ontario with only limited case histories available so far.

\subsubsection{Seasonal Stresses on Retaining Systems in Cold Regions}

McRostie and Schriever (1967) monitored the movement of a wall and the pre-stressing force in the steel bars as the soil froze behind a tied-back retaining structure. Frost pressures within the range of 14.4 to $28.7 \mathrm{kPa}$ are captured. The peak horizontal wall displacement resulting from frost force is nearly $21 \mathrm{~mm}$.

Pappas and Sexsmith (1968) measured significant strut load increases as a result of the ice lens creation behind the exposed sheeting in a strutted excavation in clay. Equivalently, the measurements of anchor forces in a sheet-pile wing wall by Eigenbrod and Burak (1992) revealed that the force cycled from an initial average of $5 \mathrm{kN}$ in the summer to an average of $50 \mathrm{kN}$ in the winter.

Smoltczyk et al. (1977) evaluated the earth pressures on ship hoists in German locks over a few years. They noted that wall displacement closely related to seasonal temperature fluctuations. According to the measurements, the backfill became progressively resistant to seasonal deformation with each new cycle. However, over time, the wall toe would displace outward continuously. In a double U-frame lock, which is constrained by a compacted wall backfill, the soil is subjected to an additional earth pressure with each new summer cycle. Similar temperatureinduced movement is reported by Broms and Ingelson (1971) in Sweden on cyclical earth movements in the bridge abutments constrained by a rigid frame.

Morgenstern and Sego (1981) reported on the frost action on a $7 \mathrm{~m}$ anchored tieback wall in Edmonton, Alberta. While aware of previous failures of tieback walls resulting from frost action (Sandegren et al. 1972; Stille 1976), the authors monitored an instrumented temporary wall. A 
cyclical pattern is distinctly appointed. The anchors experienced additional stresses as temperatures fell below freezing and lower stresses during warm season.

Long et al. (1984) presented a case history in which a section of a reinforced earth wall along the access road to Frejus Tunnel, failed in March 1981. The wall failure occurs due to a damaged manhole seepage which led to excessive heaving of the soil behind the wall. Several connections of tie strips failed due to frost action and formed a bulging displacement on the adjacent facing sectors. Without disturbing the traffic, the wall is restored after reconnecting the tie strips by pouring concrete into the failure areas. Soil nailing is used through the centers of existing concrete facing blocks in the deformed areas of the wall to repair the damage. The wall is instrumented by several means: temperature gages along the back and on top of the wall facing; load cells on the end of three of the nails; and leveling gages on the concrete facing panels, which are utilized to achieve a better insight into the performance of the wall under freezing conditions. According to measurements taken from the winter of 1981-82, the maximum frost depth reached $4.2 \mathrm{~m}$ behind the wall, near the top of the wall, and decreased to about $1.5 \mathrm{~m}$ at the lower part of wall. The nail peak stresses are captured on 23 February, prior to the deepest frost propagation on early march, while ambient temperatures has already started to increase. Tilting of the facing elements is minimal, even at the captured peak tensile loading.

Chen et al. (1996) conducted a full-scale experiment to investigate the prevention of frost damage to a retaining system by using geotextiles. The test results presented the backfill soil, heaved horizontally and compression of the soil is $0.3-0.9$ m away from the wall.

\subsubsection{Seasonal Stresses on Soil Nail Walls in Cold Regions}

The application of a soil nailing technique is reported by Guilloux et al. (1983). A technique is used to build temporary retaining walls for an underground structure at La Clusaz in the French Alps. The soil at the site is defined as compacted glacial till (with a density of $22 \mathrm{kN} / \mathrm{m}^{3}$ ). The application of soldier piles for a Berlin wall is not suitable due to the presence of large boulders and the density of the soil; hence, as an alternative solution, the soil nailing system is proposed to 
finish construction before winter begins. Finally, the Berlin wall is used for the east wall, while the soil nailing techniques are utilized for the north and south walls with a height of $14 \mathrm{~m}$. During the severe winter of 1980-81, frost penetrated to about $0.55 \mathrm{~m}$ from the exposed surface of the wall. The following observations are based on the installation of a wall monitoring system:

1) The stress distributions are not uniform along the soil nails, but the peak stress is a short distance behind the facing wall. The engineers noted a pattern of maximum forces in the strain gages along the nails, which roughly related to the development of a zone of active earth pressure behind the shotcrete facing. The gages located far from the wall facing showed a very small induced stress, even during the cold months.

2) The tensile stresses for most nails remained low, compared to their capacity, typically less than one quarter of the steel yield strength, apart from the area just behind the wall facing, which for some of nails tensile stresses reached the yield strength. The force for one nail, which is at a short distance behind the facing, increased from $20 \mathrm{kN}$ to $400 \mathrm{kN}$ during cold season. Due to the above-mention reason, the engineers released the tension in all of the nails to avoid plastic strain when the nail stresses continued to increase. Hence, an evaluation of the total magnitude of thermally-induced stresses is not possible.

3) The maximum horizontal movements of a wall are about $2 \mathrm{~cm}$ (approximately $0.1 \%$ of wall height), which this value is within the range for a SNW based on the survey by Juran and Elias (1987) on the performance of soil nailed wall in cold regions. They noted that wall displacement should not exceed $0.3 \%$ of wall height.

4) Thermally induced stresses on the nails increased frequently from December to the end of February, when the anchors on the nails are released to depress stresses. By end of April, the nail stresses has declined roughly to the initial values that are observed before the beginning of the cold season.

The measurements obtained from La Clusaz in 1980-81 are later employed by Unterreiner (1994) to calibrate his model for frost action. 
Nicholson (1986 a, b) reported the application of a $12 \mathrm{~m}$ high SNW in a tunnel project through the Cumberland Gap on the Kentucky-Tennessee border. The soil is described as a weathered shale and sandstone, which is underlain by the weathered bedrock. The wall is built for the Federal Highway Administration (FHWA) in U.S. as a project to illustrate its performance, and it is monitored with slope inclinometers, strain gages, load cells, and electronic distance measuring survey points on specific nails. During the colder months, an ice buildup is formed due to the seepage through the shotcrete wall facing. Installation of drainage strips on $4.6 \mathrm{~m}$ centers has proved inadequate for the actual amount of seepage. As a result, the author proposed the installation of drainage strips with $1.5 \mathrm{~m}$ centers for future soil nail projects. During January and February 1986 (four months following installation), the nail loads increased from 2000-2400 kN to $4000-5000 \mathrm{kN}$ due to heaving behind the facing. Upon spring thawing, the loads reduced again. The nails, which are designed conservatively, managed the thermally-induced loads without problems.

Juran and Elias (1987) monitored several instrumented soil nail projects based on performance criteria. They realized that displacements and ground movements in SNWs are normally limited to 0.2 to $0.3 \%$ of the wall height in non-plastic soils, since very little movement is required to mobilize the nail tension. They also indicated that, all nail loads reduced considerably upon spring thaw. However, the tension in sections directly behind the wall facing stayed permanently higher than initial values. For instance, data from strain gage at a point of $7.6 \mathrm{~cm}$ from the wall face, with a post-construction load of $20 \mathrm{kN}$, and a maximum captured load of $70 \mathrm{kN}$ in February 1986, reduced to a constant load of roughly $50 \mathrm{kN}$ in the spring of 1986 . The increased stresses in nails near the wall facing are attributed to soil expansions and local displacements, which are induced by frost force and constrained by the nail friction.

Schwing and Gudehus (1988) studied the performance of a $7 \mathrm{~m}$ high SNW with a $70^{\circ}$ slope, which is built for a road project in West Germany. The wall is built in three terraced sections. The terraces are filled with topsoil and planted to cover the shotcreted wall. The soil at the site contained several meters of loam (unit weight of $20 \mathrm{kN} / \mathrm{m}^{3}$ ) and is underlain by weathered marl. According to the results from the instrumentation, both the force and movement increased during the cold months. 
For the Cumberland Gap wall, the nail forces reached approximately double their initial values during the cold season, and then, the forces declined in the following spring but remained higher than their initial magnitudes. In the second freeze-thaw period, nail forces reached about the same peaks in the winter and minimums in the summer as in the previous year.

Alston (1991) designed a reinforced soil nailed slope in Cambridge, Ontario. In this project, a naturally stable hillside is transformed from a grade of vertical to horizontal ratio from 1:2 to 1:3 to allow building of a condominium in a river valley. The soil is described as a very dense glacial till (unit weight of $22.5 \mathrm{kN} / \mathrm{m}^{3}$ ), and highly frost susceptible. It is contaminated with many clay lenses, which created numerous water tables throughout the project area. The nailed slope is designed using the German limit equilibrium method as described in Stocker et al. (1979). The slope is reinforced through a 1.8 by $1.5 \mathrm{~m}$ grid with three different nail lengths ranging from 6.5 to $12 \mathrm{~m}$ depending on the height of slope.

The soil could stand at near-vertical inclinations for about 2 weeks without any support; as a result, shotcreting is not applied for the face stability, and the drainage qualities and aesthetics of shotcrete are not considered for this project. However, the wall is constructed with a flexible, permeable facing to withstand the estimated seasonal volume changes and load variations as a result of frost action. The permeable facing also assisted with the drainage of saturated areas along the wall.

A geotextile scheme is utilized over most of the wall for drainage, surface erosion control, and fines retention. A geogrid overlay transferred earth pressures to the soil nails. Additionally, to fill up the voids; slurry of sand, topsoil, and water is applied between the geotextile and the surrounding soil.

Severe seepage problems are observed in one area of the wall facing, which caused progressive slumping that could not be repaired before the winter begins. During the cold season, further damage appeared due to the freeze-thaw cycles and heavy precipitation alternating between rain and snow. Upon the spring thaw, this portion of the wall is repaired by a geotextile membrane, which is fixed in place by a timber grillage that is linked to the retaining structure. The damaged zone is rebuilt with a geogrid-reinforced "pillow" containing coarse-grained fill which placed in 
the zone between the scarp slope and the rest of the wall, whereas the facing is repaired with a geoweb filled with sand. Alston assumed in the design that the soil nailing techniques would retain the soil behind the scarp slope, as the reinforced facing would resist any forces generated by the pillow of reinforced fill in the active pressure wedge.

Horizontal geogrid strips are utilized to sculpt the rebuilt elements according to the rest of the wall and connected the new elements to angle bars tied to the soil nails; hence, most of the loads are translated back to the nails (Figure 2-4).

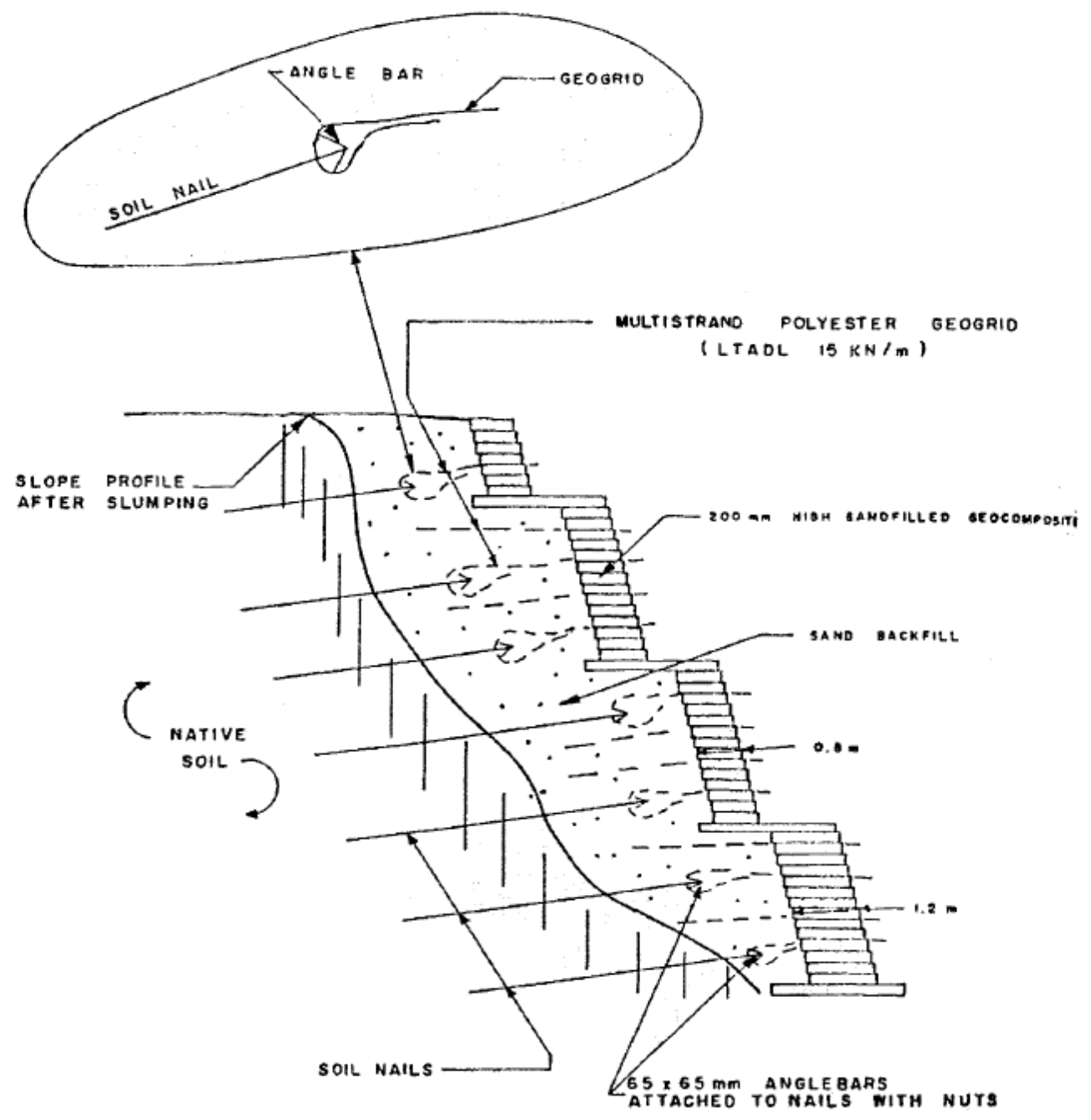

Figure 2-4 Schematic representation of slope facing reconstruction using geosynthetics (after Alston, 1994) 
In Northern Ontario's frost susceptible glacial tills, or in any case where additional protection against frost heave is warranted, French researcher Unterreiner (1994) developed a detailed model for the consideration of frost action in a SNW, which he calibrated and checked against actual measurements of frost displacement at La Clusaz (previously reported by Guilloux et al., 1981) and the CLOUTERRE full-scale demonstration walls. Based on the results from the model, he recommended two practical design alterations in order to take into account the seasonally increased stresses in SNWs:

1) Install short, $2 \mathrm{~m}$ long nails at typical intervals between the structural nails of $9 \mathrm{~m}$ length, hence contributing further reinforcement to the soil-nail mass structure.

2) Increase the free (ungrouted) length of the nail to the estimated frost penetration depth, which is measured from the nail head; thus, the freezing front would not influence the designed grout length on the nail.

Depending on the duration and intensity of the cold season, the free length could range from 0.5 $\mathrm{m}$ to $9 \mathrm{~m}$ and increase the design length of each soil nail. Unterreiner (1994) reported that this technique could lower the nail tensions by $21 \%$. The same development is obtained using the method with the additional short nails; hence, the designer should examine the most economical technique by considering the predicted frost conditions. When the additional length per nail is relatively small, the free length technique could be applied, otherwise the short nail method should be used (Unterreiner, 1994).

Kingsbury (1999) used numerical analysis with TEMP/W, a software module contained in the GEO-SLOPE software package, to predict frost penetration depths under varying thermal regimes. It allowed the solution of 2D transient heat transfer problems, while boundary conditions could be automatically created from imported climate data. The model is calibrated based on the data taken from an instrumented SNW in Moscow, Maine, United States during the winter of 1998-1999. Then, it is utilized to evaluate the performance of the wall under a variety of air temperatures, insulation thicknesses, and placements (insulated both face and top of the wall). He concluded 
based on the numerical analysis result that facial insulation would contribute to the reduction of frost penetration along a wall.

Other factors could also be taken into account in the design of a SNW in frost prone areas. For instance, the direction in which the wall is installed could also affect the frost penetration depth. North-facing walls may have 1.4 to 2 times the depth of frost penetration than south-facing walls, which are frequently exposed to sunlight. Drainage control measures should be considered to reduce infiltration and frost potential behind the wall.

Currently, there is not a design method which systematically addresses the design of SNWs in cold regions. Most authorities recommend prevention or mitigation of frost failure typically by one of the following: selecting a different construction method where the in situ soil is highly frost susceptible (FNRP, 1991; Byrne et al., 1993), or using insulation to reduce the frost penetration depth (FNRP, 1991; Byrne et al., 1996; Kingsbury, 1999). After five years of thorough study on the design and construction of SNWs, which ended up in a large document for design recommendations, FNRP (1991) made only a passing reference to potential source of wall failure in frost prone soils as a result of frost action. If the facing is sufficiently rigid to prevent such damage, the nails may fail in tension or the connection between the wall and the facing may rupture.

\subsection{Freezing and Thawing Phenomena in Soil}

Around a third of the Earth's surface could be considered as seasonal frost or permafrost (permanently frozen) regions. The Canadian climate results in freezing of the near-surface ground

for several months each winter almost everywhere in Canada. Ground freezing regularly results in volumetric expansion of the soil which causes heaving of structures located above or adjacent to the freezing soil. Spring thawing would release the excess pore water, generally weakening the soil and causing damage to the soil structure. This seasonal event could also cause serious problem for roads, buried pipelines and buildings, and very detrimental to infrastructures (Crawford, 1968; Penner and Crawford, 1983). 
Each soil has its own specific freezing characteristics, mainly depending on its texture and the dominant solute concentration. Fine-textured soils tend to create ice lenses at freezing conditions that could cause soil heaving. In coarse-grained soil, the ice is frequently distributed within the soil matrix. It is examined that freezing and thawing changes the engineering properties of soils. When soil freezes, its strength could be significantly increased because of the growth of ice component in the soil mixture. This attribute would diminish upon thawing.

\subsubsection{Mechanisms of Heat Transfer in Soil}

Heat transfer in soil occurs through three main mechanisms; conduction, convection, or radiation (Small, 1959). Heat conduction is the heat transfer from the more vigorous to the less vigorous atoms by electron collision and vibration. Convection is the process of heat flow by the movement of a fluid such as air or water from one place to another; carrying thermal energy with it. Radiation involves the transfer of thermal energy by emitting or absorbing electromagnetic waves. Soil is subjected predominantly to heat transfer by conduction, and heat transfer by convection of liquid water, and air is commonly insignificant in soils (Farouki, 1981). Heat transfer in form of radiation would contribute less than $1 \%$ to the total heat transfer in sand, and is even less in fine-grained soil (Farouki, 1981). Recently, analytic methods for thermal soil mechanics declined convection, and radiation, although these mechanisms may influence the final result slightly under various climatic conditions and soil type.

It also needs to mention that the process of geothermal heat energy typically provides only $10^{-4}$ of the magnitude of ambient heating/cooling at the ground surface, hence, it is neglected (Jumikis, 1977). However, in some cases, for instance if the soil is highly saturated with a large grain size, convection may become important as we should anticipate a considerable exposure of water through the soil particles. In unsaturated soils, moisture migration as a result of evaporation and subsequent condensation may be a major process as well, since it induces phase changes in the soil and thus influences its thermal properties, exclusively, by changing its saturation degree. Figure $2-5$, illustrates the previous statements, indicating some of the cases, agreeing with the degree of saturation and grain size of the soil, when convective or radiative heat transfer along with moisture migration become significant factor in heat transfer. 


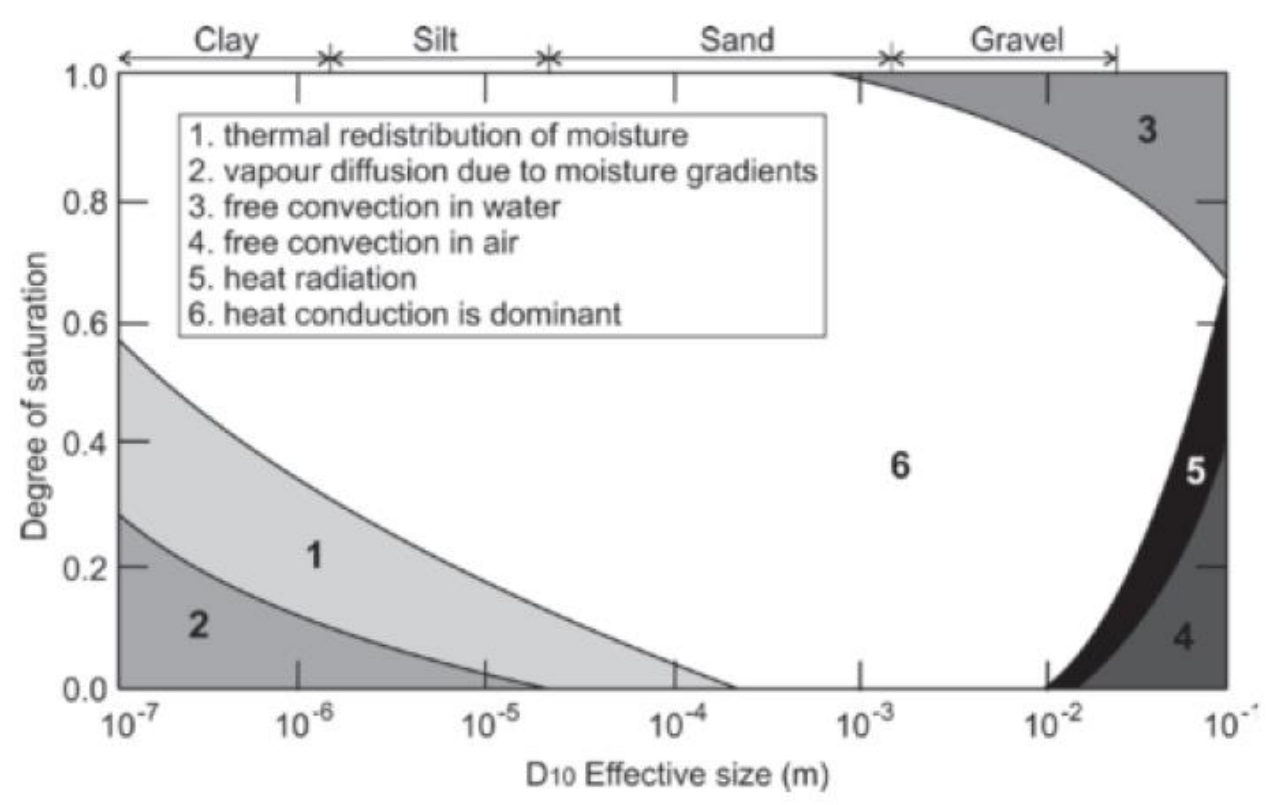

Figure 2-5 Predominant heat transfer mechanisms by grain size and degree of saturation (Loveridge, 2012, redrawn from Farouki, 1986)

As thermal conduction is the governing process of heat transfer through soils, it would be the focus of this research and taken into consideration in the thermal and thermo-mechanical analyses performed in Chapters 3 and 4.

\subsubsection{Temperature Profile in Ground}

In the northern hemisphere, the southern limit of cold regions expands down to about the $40^{\text {th }}$ parallel of latitude. An arbitrarily seasonal frost penetration depth of $0.3 \mathrm{~m}$ into the ground surface once in 10 years is typically considered as a criterion for the indication of this boundary (Smith, 1989). This frost penetration is illustrated roughly by a freezing index of $38^{\circ} \mathrm{C}$-days. The "Air Freezing Index (AFI)" is simply the total number of degree-days of freezing for a given winter (Zhang, 1998). The AFI map of Canada is shown in Figure 2-6. The cold regions are typically subdivided based on ground weather which is only seasonally frozen, whether permafrost occurs everywhere, or whether permafrost occurs only in some areas. It is commonly assumed that the 
mean annual ground surface temperature must be below about $-2.8^{\circ} \mathrm{C}$ for permanently frozen ground to exist.

The locations studied in this research are Timmins, and Toronto in Ontario. Their corresponding freezing indices are 1756 to 349 freezing degree days $\left({ }^{\circ} \mathrm{C}\right)$, respectively.

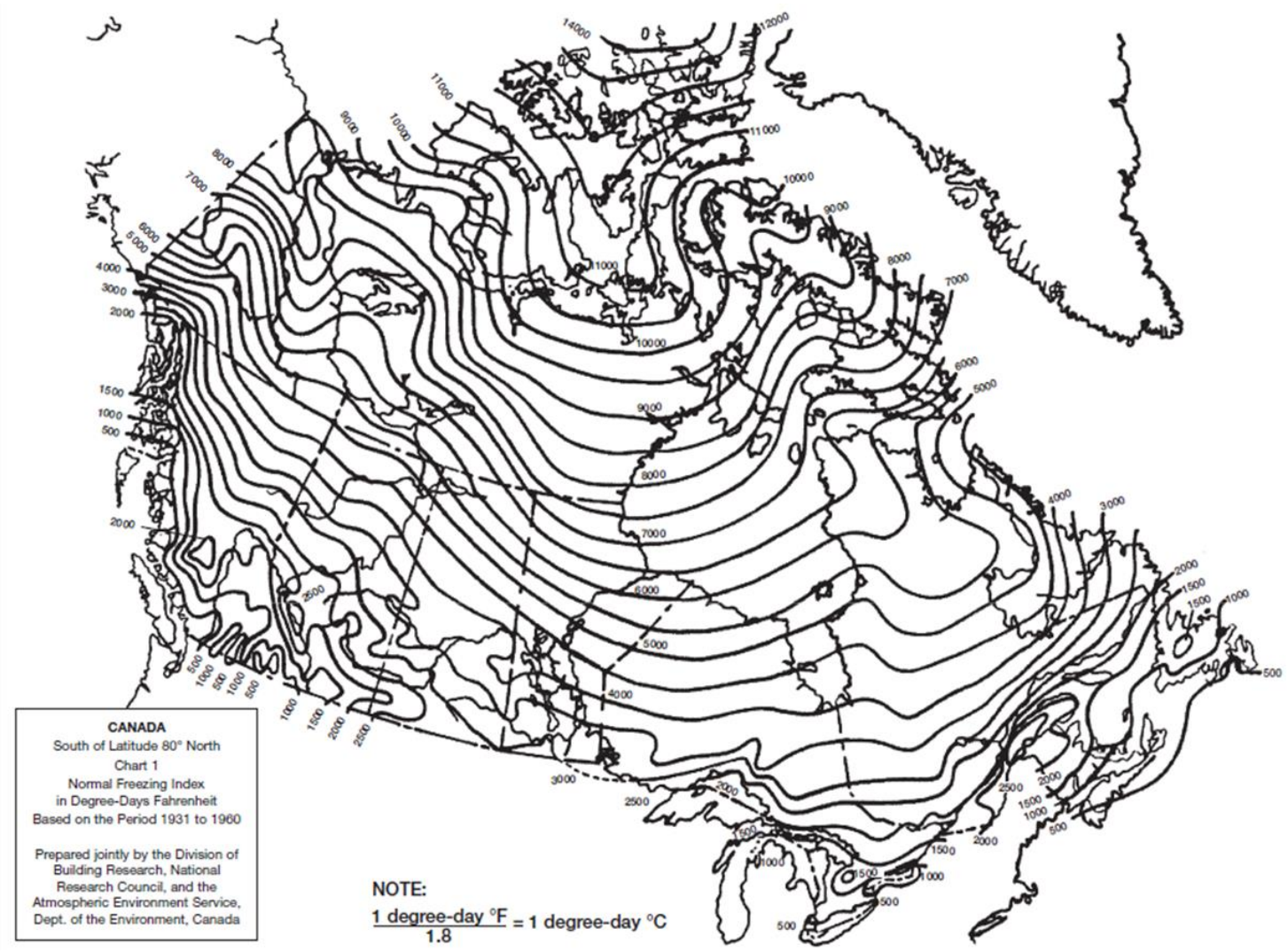

Figure 2-6 Air freezing index map for Canada based on the period 1931 to 1960 (Boyd, 1973)

The profile of instantaneous ground temperature as a function of depth is presented in Figure 2-7. The maximum and minimum of ground temperature over the course of one-year cycle are shown by the "trumpet curve." In the non-permafrost zones, the maximum freezing depth over the course of the winter is represented by the depth of "seasonal frost." In the permafrost zones, as illustrated on the left-hand side of the figure, the shape of the curves is similar but the origin is shifted to the 
right. The term "active layer" is referred to the maximum depth of thaw and, below this layer; there is a zone which remains frozen throughout the year.

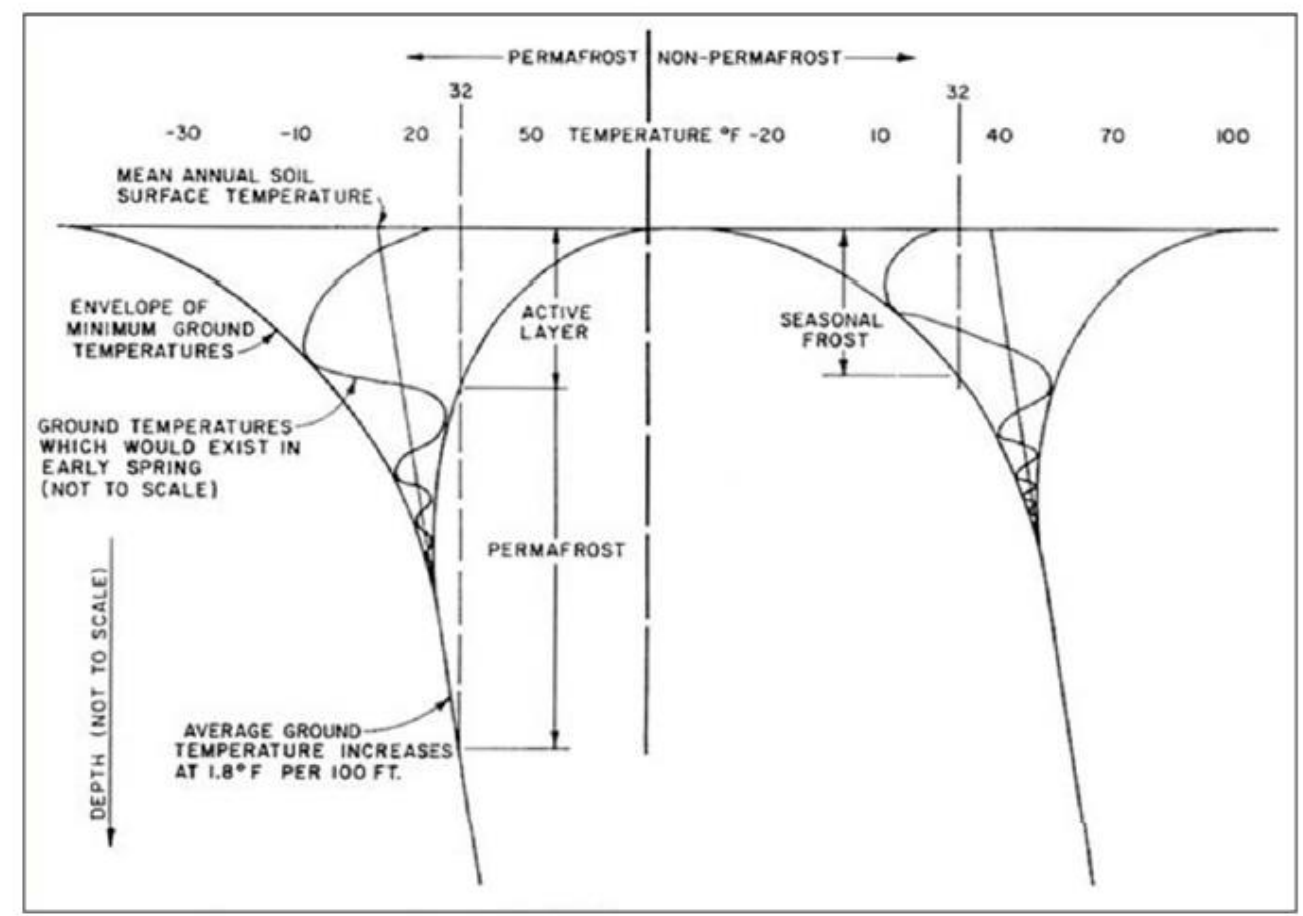

FIGURE 2-7 Whiplash curve for distribution of ground temperature over depth (Phukan, 1985)

\subsubsection{Ground Freezing and Frost Penetration}

The main process is the physical change of soil water from liquid to solid that makes the soil, a hard mass analogous to concrete. Its relatively high strength could be attributed in part to the binding together of soil particles with ice. Thermal properties, water content, and the ambient temperature are the main factors that influence the rate at which soil freezes.

In terms of frost penetration depth, as clay particles have a higher insulation value than silt or sand particles, and since clayey soils generally sustain more moisture than silts and sands, the frost penetrates deeper in silt and sandy soils than in clays, and silty clays. Information on real-time seasonal soil freezing depth is critical to a number of applications, for example construction codes that dictate the depth of building foundations (Burn, 1976; International Code Council, 2011). 
While a typical approximation of frost penetration depth could be made, often based on intense conditions, the advancement of the frost line, and its maximum depth in seasonally frozen ground could vary significantly from year to year.

There are direct approaches to obtain frost penetration depth, containing the excavation of a soil pit to observe the existence of ice crystals, the burying of moisture blocks, and the burying of thermocouples. Another way is the placement of frost tubes (McCool and Molnau, 1984; Hardy, et al., 2001). All of these approaches contain site observations.

The modest approach is the use of the AFI, where freezing degree days are accumulated and utilized as a substitute for frost depth (Burn, 1976; Berry, 1998; Hardy et al., 2001). Other procedures derive frost penetration depth based on the modeling of physical processes related to the freezing of soil, such as the Simultaneous Heat and Water (SHAW) model (Kennedy and Brenton, 1998; Kahimba et al., 2009), or soil-based heat flux balance approaches (Benoit and Mostaghimi, 1985), or hybrids (DeGaetano et al., 2001). Of these approaches presented in the literatures, the AFI remains the simplest method. However, the AFI is not the best indicator as it tends to over-predict frost penetration.

Frost penetration depths across Ontario are shown in Figure 2-8 (a) and (b). 


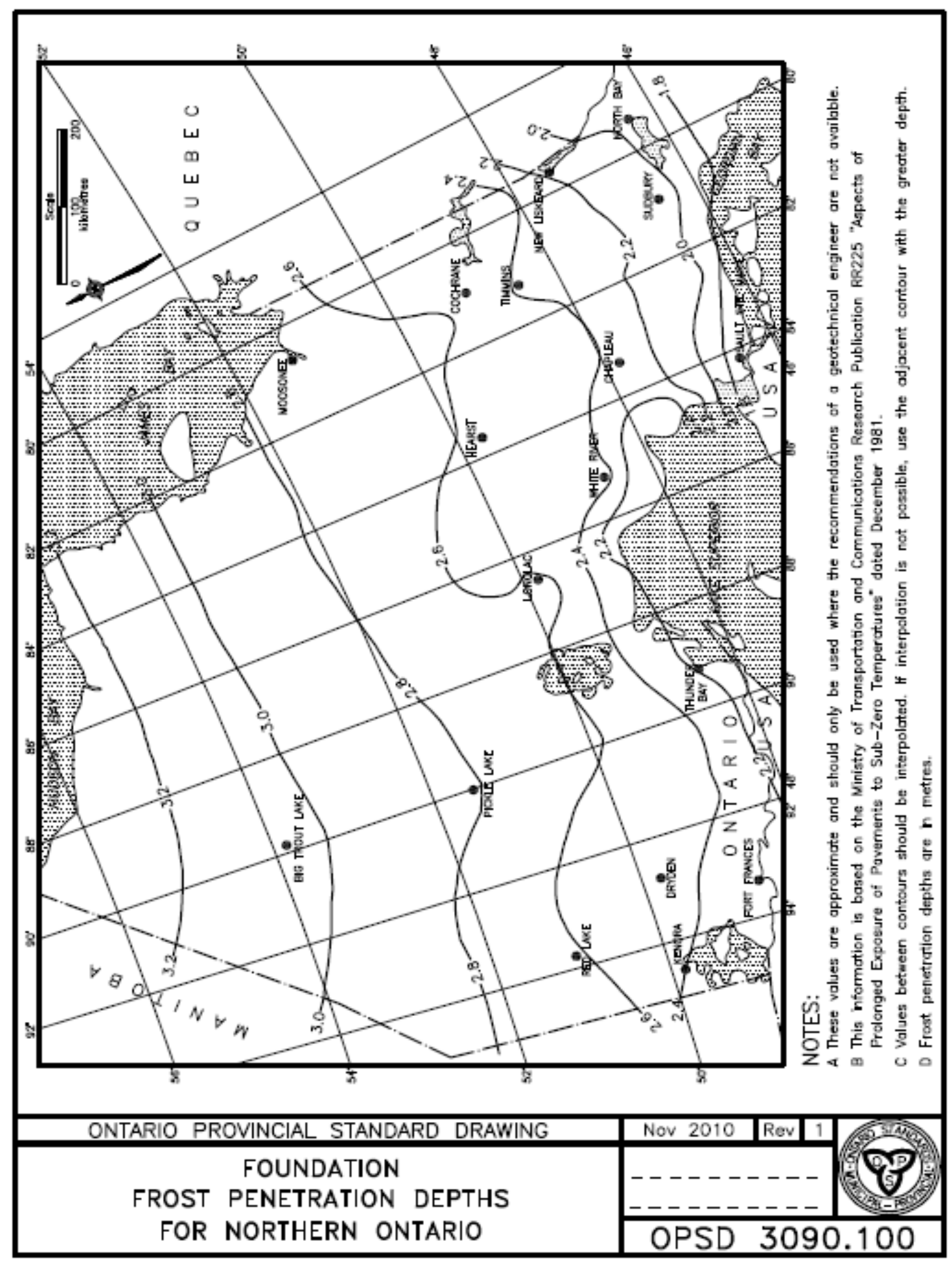

(a) Map of frost penetration depth in Northern Ontario 


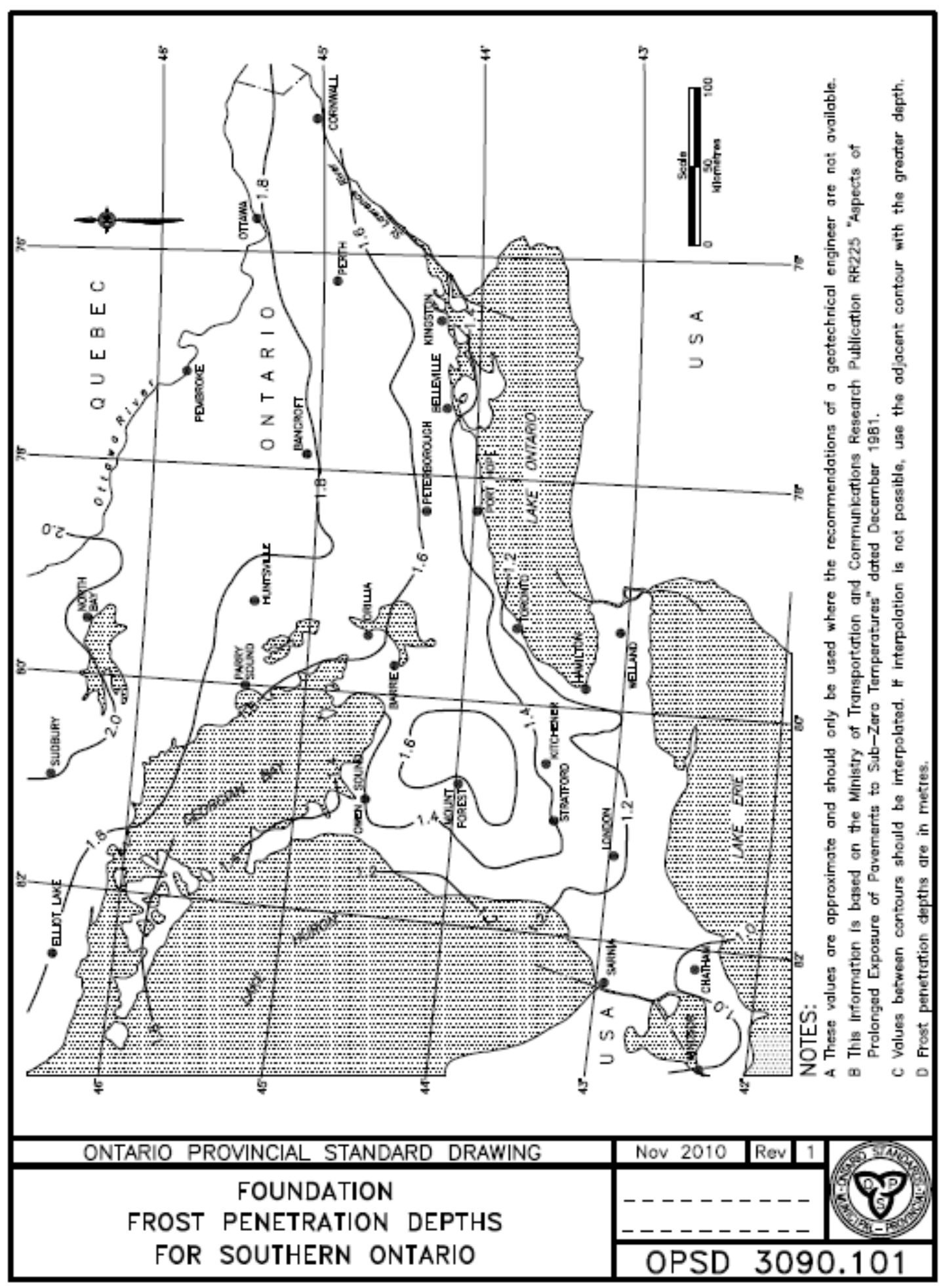

(b) Map of frost penetration depth in Southern Ontario

Figure 2-8 Map of frost penetration depth in Ontario 
Frost heave and thaw weakening are the major causes of damage to pavements in cold regions (Michalowski and Zhu, 2005a), as illustrated in Figure 2-9.
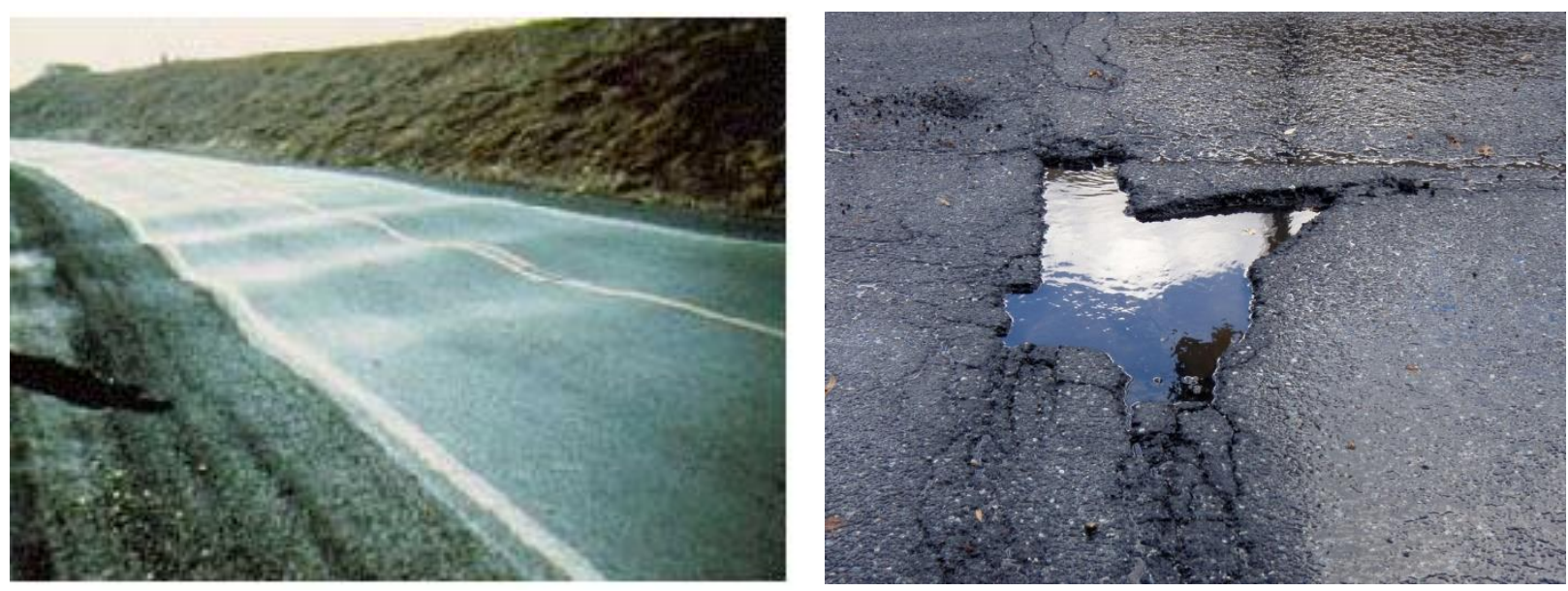

Figure 2-9 Waves and potholes in a pavement caused by frost action (Source: HTTP://WWW.FHWA.DOT.GOV; HTTP://WWW.POTHOLE.INFO)

When frozen, soils are generally very strong and almost impervious as a result of ice lenses formation which intend to wedge between soil particles (Hallin, 2004), however this event varies with the different types of soil. While many observations have illustrated that frost action occurs during seasonal freezing mainly in fine-grained sediments, it also shows that frost action occurs in permafrost areas in fairly coarse-grained particles, over long periods of time. Generally, it could be noted that coarse sands and clean gravels would not heave, while fine sand, and silts are very prone to heaving. Clays are very susceptible and produced large pressures during heaving, although they commonly heaved slowly. Silts are appeared to have a high heave rate, but much lower heaving pressures. A soil Mixture contains silts, sands or gravels with clay, presents high heaving rate, and heaving pressure becomes less expected (Penner, 1962).

A decrease in temperature generally results in an increase in strength of a frozen soil, however at the same time, it would lead to its brittleness, which would appear by a larger decline of strength after the peak and a surge in the ratio of compressive strength to tensile strength (Sayles and Haines, 1974; Haynes and Karalius, 1977; Haynes, 1978). An immediate and a creep defect comprise the total deformation of a frozen soil under loading (Andersland, and Ladanyi, 2004). Frozen soils are practically incompressible, hence deformations associated with change in volume 
are often ignored in comparison with the time-dependent deformations. In this study, the complex deformation and shear strength behaviour of frozen soil are neglected to simplify the problem.

Taber in the late 1920's, through series of experiments presented heaving in saturated soils with benzene, while benzene contracted due to freezing. Therefore, the expansion of water when it froze would not contribute largely to the frost heave. It is the ice lens formation that would lead to the frost heave (Taber, 1929).

The water/ice phase change that results in ice lens growth in the porous media increases the moisture suction at the freezing plane (Penner, 1968). This enforces a moisture suction gradient in the unfrozen soil which could cause the movement of water into the freezing front either from a shallow ground water table or by drawing water from the unfrozen soil below the freezing plane. If the formation of the ice lenses produces large enough heaving pressure to force soil particles upward, heaving at the ground surface could be seen. This process is illustrated in Figure 2-10. Ice lenses are shaped normal to the direction of heat flow and when freezing temperature penetrates from the ground surface, the ice lenses form parallel to the surface.

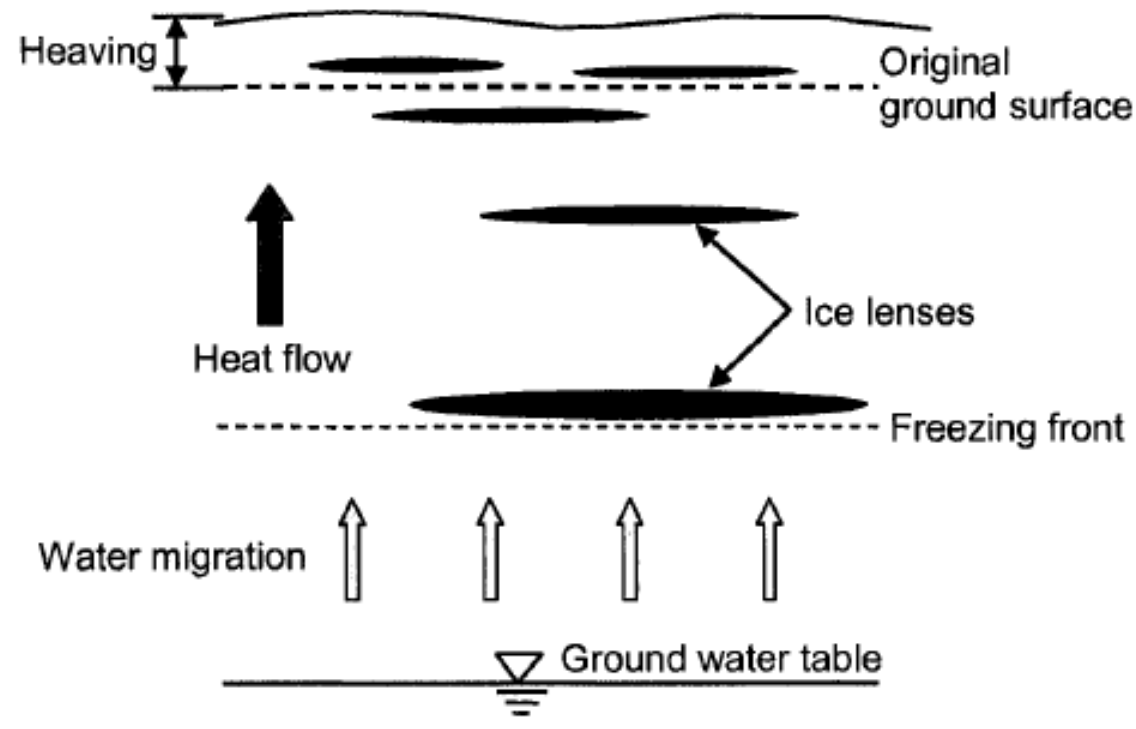

Figure 2-10 Frost heave process (Mitchell, 1976)

A soil volume in freezing condition could be separated into three zones: frozen soil, frozen fringe, and unfrozen soil as shown in Figure 2-11. 
The frozen fringe is a zone between frozen soil and unfrozen soil. It falls between the base of the recent ice lens and the freezing front, and it contributes largely in the ice lensing process. It is realized that not all water freezes at the freezing point of water (typically $0^{\circ} \mathrm{C}$ ). Water in tiny voids of soil or in the adsorbed layers of encompassed solid particles could be present in liquid form at below freezing temperatures, which is called "supercooled water". As a result of the temperature gradient in the frozen fringe, the supercooled water migrates towards the lower temperature zone, which is at the base of the recent ice lens, and where the water has a lower chemical potential (Dash, 1989; Wilen and Dash, 1995). The force that causes the water migration in to the frozen fringe is termed the cryogenic suction. Once the supercooled water reaches the ice lens, it supplies the growth of ice lens.

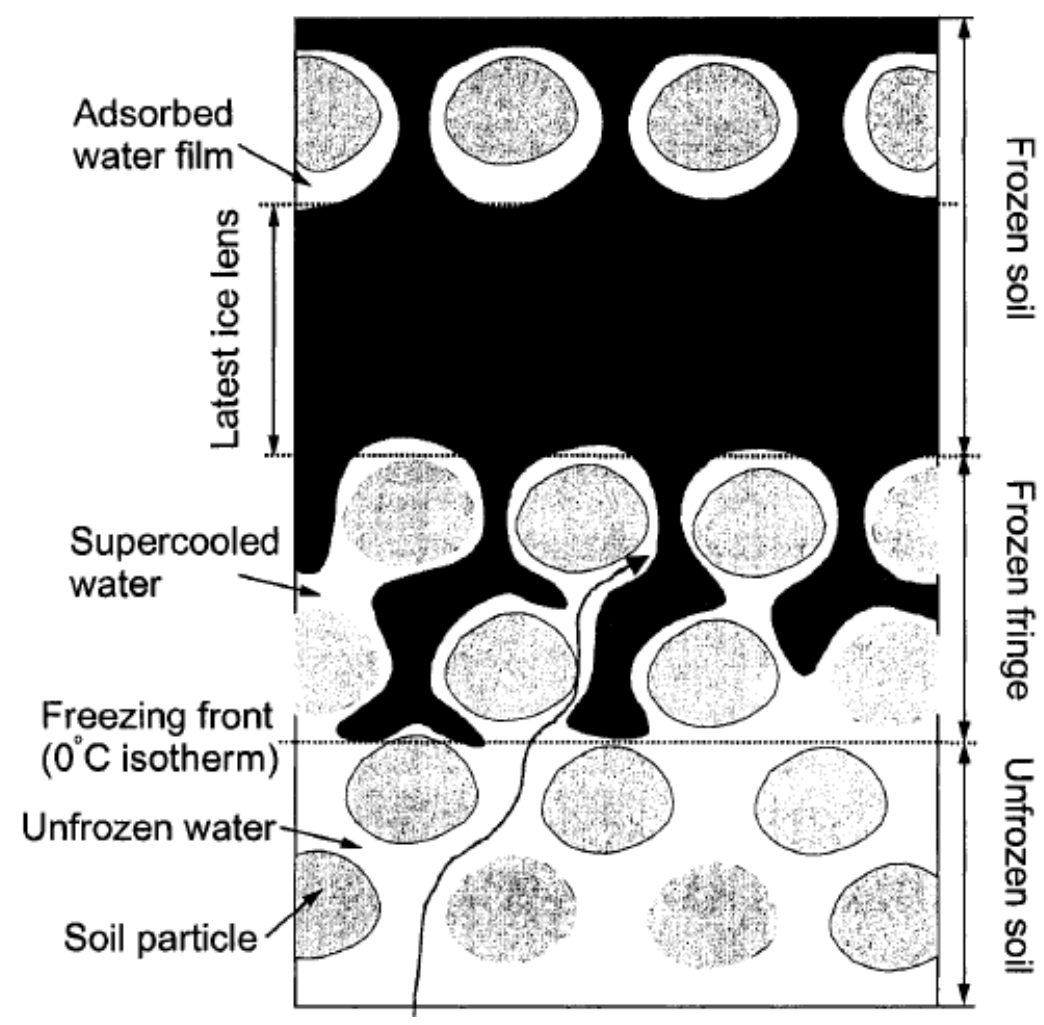

Figure 2-11 Freezing soil zones (Zhu, 2006)

Soil frost susceptibility could be classified either based on soil type, shown in Table 2-1 or laboratory tests, shown in Table 2-2. 
Table 2-1 U.S. Corps of Engineers frost susceptibility criteria based on soil type (Freitag and McFadden, 1997)

\begin{tabular}{|l|l|c|}
\hline \multicolumn{1}{|c|}{$\begin{array}{c}\text { Frost group } \\
\text { (increasing susceptibility) }\end{array}$} & $\begin{array}{c}\text { Sorcentage finer than } 0.02 \\
\text { mm by weight }\end{array}$ \\
\hline Non-frost-susceptible & $\begin{array}{l}\text { (a) Gravel, crushed stone, crushed rock } \\
\text { (b) Sand }\end{array}$ & 0 to 1.5 \\
0 to 3 \\
\hline F1 & Gravelly soils & 3 to 10 \\
\hline F2 & (a) Gravelly soils & 10 to 20 \\
& (b) Sands & 3 to 15 \\
\hline F3 & (a) Gravelly soils & $>20$ \\
& (b) Sands, except very fine silty sands & $>15$ \\
\hline F4 & (c) Clays, PI > 12 & -- \\
& (a) All silts & -- \\
& (b) Very fine silty sands & --- \\
\hline & (c) Clays, PI < 12 \\
& (d) Varved clays and other fine-grained, & -- \\
\hline
\end{tabular}

Table 2-2 Classification of frost susceptibility based on laboratory test (Freitag and McFadden, 1997)

\begin{tabular}{|c|c|}
\hline Average rate of heave (mm/day) & Frost susceptibility classification \\
\hline $0.0-0.5$ & Negligible \\
\hline $0.5-1.0$ & Very low \\
\hline $1.0-2.0$ & Low \\
\hline $2.0-4.0$ & Medium \\
\hline $4.0-8.0$ & High \\
\hline$>8.0$ & Very high \\
\hline
\end{tabular}

Nearly all heave is due to freezing of water that migrates to the frozen fringe. Frost heave is affected by both the duration and the intensity of freezing temperature. If the temperature drops considerably quick (very high rate of cooling), then the soil freezes before water could move to supply an ice lens formation. This phenomenon called in-situ freezing, which would lead only to the growth of pore ice, and no ice lens could form. However, a slow rate of cooling provides adequate time for water to migrate to the freezing fringe. For a non-frost susceptible soil, such as 
sand or gravel, no ice segregation is occurred during freezing, though pore ice would be created as a result of the water phase change in the pores. This expansion would cause macroscopic deformation in saturated soils if the pores in unsaturated soils could not accommodate the ice segregation.

\subsubsection{Thaw Consolidation and Thaw Settlement in Soil}

Upon thawing, the ice lenses which are created in the freezing process gradually would melt. The excess water melted from ice lenses would outlet under its own weight and/or external loading; hence, the thaw consolidation would take place. The rate of the thaw consolidation depends upon both the melting rate of the ice, and the permeability of the soil.

Thawing in frost prone soils is followed by thaw settlement. The major part of the settlement is due to the drainage of melted water during thaw consolidation. The total settlement depends mainly on the amount of ice formation. The rate of settlement is influenced by the type of soil, the drainage condition, and the thawing rate (Phukan, 1985; Simonsen and Isacsson, 1999).

The change of void ratio versus pressure during thawing process is illustrated in Figure 2-12. A conventional consolidometer is used for testing the frozen soil sample. When first loaded to a pressure equal to the field load $\left(\sigma_{0}\right)$, a small decrease in void ratio would occur, from Point a to Point $b$. When the sample is thawed in a top down manner, a large change in void ratio takes place as a result of the phase change of water and drainage of the excess melted water (Point b to c). When additional loading is placed after completion of thawing, consolidation under the initial load is roughly completed. Further drainage occurs by the advancement of a normal consolidation

process (Point $\mathrm{c}$ to $\mathrm{d}$ ). In Figure 2-12, $e_{f}$ and $\mathrm{e}_{\mathrm{th}}$ indicate the void ratio before thawing starts and the void ratio after thawing finishes, respectively. 


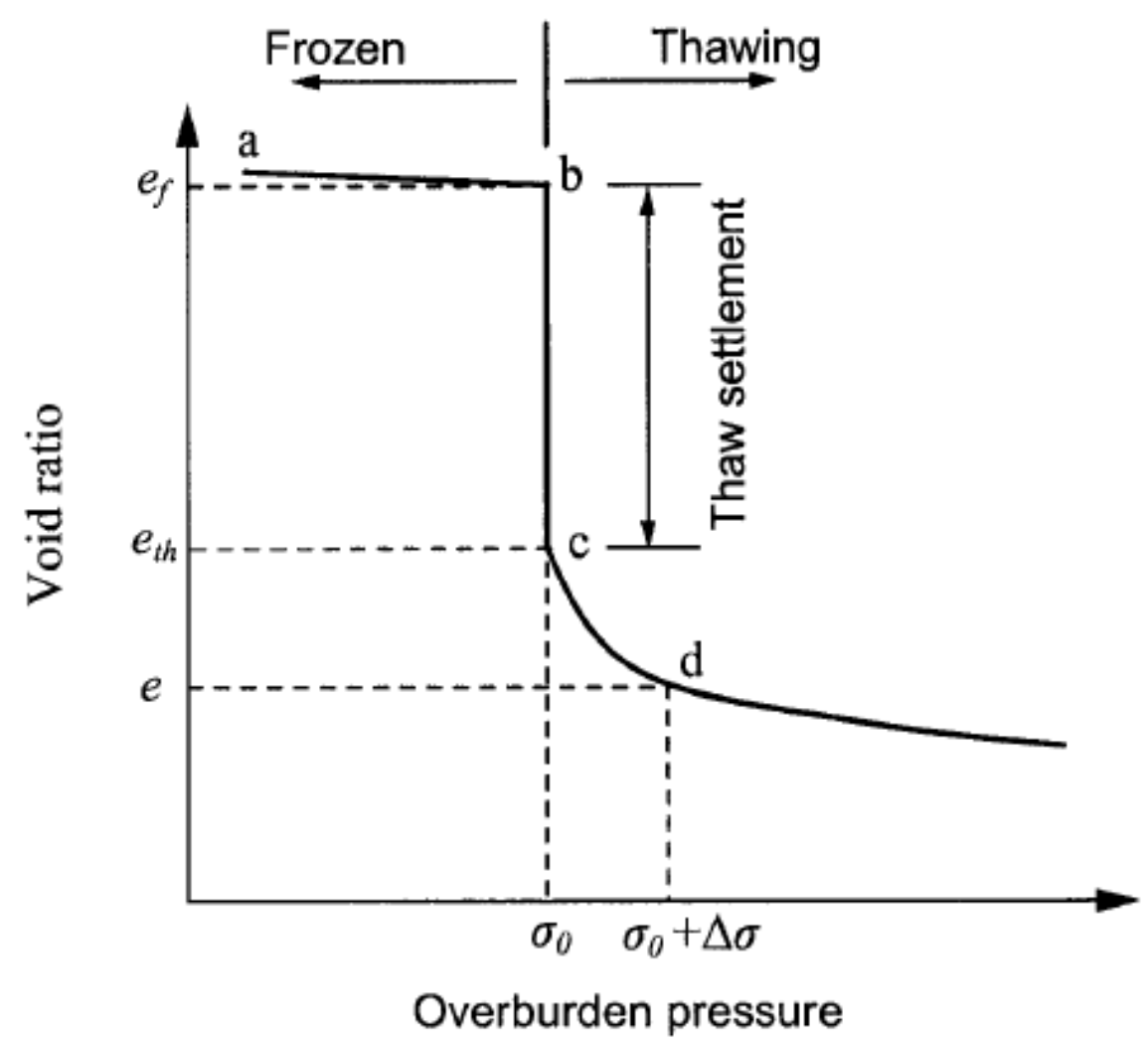

Figure 2-12 Thaw consolidation test result (Tsytovich, 1960)

\subsubsection{Previous Investigation on Freezing and Thawing Behavior of Soil}

There are a few published literatures related to experimental study on freezing and thawing properties of soils.

Viklander (1998) carried out a series of freeze-thaw tests on fine-grained non-plastic till which each sample experienced eighteen cycles of freeze-thaw. The hydraulic conductivity of the soil after the cycles of temperature variations is obtained to have increased for initially dense specimens, however decreased for initially loose samples. The void ratios declined for samples with initially high void ratios, while increased for samples with initially low void ratios.

Qi et al. (2007) performed a set of tests on a silty soil with one freeze-thaw cycle to determine the changes in its engineering properties. A critical dry density is obtained through the experiments which beyond that density, the cohesion and the pre-consolidation pressure would decrease after 
a cycle of freezing and thawing, while if the critical dry density is not obtained, all the three parameters would show increase in their values.

Zou and Boley (2009) conducted open-system freezing-thawing followed by compression tests on fine-grained soils utilizing an oedometer. The test results denoted that the slope of the normal consolidation curve of a soil with a freeze-thaw cycle is different than that of soils without freezethaw cycles. He concluded that this event occurred as a result of ice lens formation which caused heterogeneity in soil samples.

Liu and Peng (2009) carried out unconfined compressive tests on a thawing soil using a temperature controlled triaxial apparatus. The tests are conducted on soil samples with varius moisture contents and under temperature fluctuations. The influences of temperature and moisture content on soil strength are studied and an empirical model to describe the stress-strain relationship is recommended.

In contrast, there are sparse studies on the thaw weakening of frozen soils and associated thaw settlement. Foriero et al. (1995) used FEM to simulate a large-strain thaw-consolidation model. The model is adapted from Gibson et al. (1981) theory, which is considered the variation of permeability and compressibility during thaw consolidation event. In order to predict thawconsolidation settlements a non-dimensional design charts are developed. A warm oil pipeline in a cold region is modeled and verified with the test data.

Ming et al. (2012) numerically simulated the thaw settlement of saturated frozen soil, by using Gibson's theory and a moving boundary condition, and obtained reasonable results.

Based on the study on the physical phenomena associated with heat transfer in soils, and freezing and thawing in soils, it would be almost impossible to capture all the changes during this process. In this study, the problem is simplified by ignoring the change of soil after freezing and focusing more on the frost penetration depth and the deformation change in SNWs due to soil volume change from freezing and thawing. 


\subsection{Numerical Modelling of Heat Transfer in Soil}

This section provides some theoretical background of heat transfer in ground and modelling of freezing and thawing influence on SNWs.

\subsubsection{Theoretical Background of Heat Transfer in Soil Nail Walls}

Fourier's Law, based on Newton's basic theory of heat transfer, is the fundamental building block for thermal soil mechanics. Fourier's Law of one dimensional heat transfer through conduction, for a homogeneous and isotropic material, is written by the following equation

$\mathrm{Q}=-\mathrm{k} \frac{\partial \mathrm{T}}{\partial \mathrm{l}}$

where $\mathrm{Q}$ is the heat flux $\left(\mathrm{W} / \mathrm{m}^{2}\right)$,

$\mathrm{k}=$ thermal conductivity of the material $\left(\mathrm{W} / \mathrm{m} .{ }^{\circ} \mathrm{C}\right)$

$\frac{\partial \mathrm{T}}{\partial \mathrm{l}}=$ temperature gradient.

At steady state, the heat flux is the same at each cross section. Therefore, larger heat conductivity results in a smaller temperature gradient. The thermal conductivity of frozen soil is larger than unfrozen soil because ice has a higher thermal conductivity than liquid water, leading to a smaller temperature gradient.

The thermal conductivity of steel is usually 10 to 25 times higher than soil, while for concrete and grout, thermal conductivity are slightly greater than most soils (Ingersoll et al., 1954). As heat transfer is related directly to thermal conductivity based on Fourier's Law, it would conduct more quickly along the nail than into subsoil between the nails. Freezing temperature transferred along the nails may also cause frost creation in the native soil around the nails, at depths which would typically be considered beyond the frost regions. 
Lunardini (1980) introduced various approximate models for frost penetration depth around a cylinder, considered various assumptions and boundary conditions to solve phase change problems.

\subsubsection{Transient Heat Transfer Model in Freezing and Thawing Soil}

The transient heat transfer model used in this study is based on the following assumptions

$>$ the heat transfer takes place by conduction only

$>$ the soil is fully saturated

$>$ the thermal conductivity of soil is isotropic

$>$ the volume change of water upon freezing or thawing is negligible

$>$ no soil deformation and water migration is associated with the freezing or thawing process.

The governing differential equation for transient heat transfer could be expressed in the following form

$\mathrm{C} \frac{\partial \mathrm{T}}{\partial \mathrm{t}}-\mathrm{L} \rho_{\mathrm{i}} \frac{\partial \theta_{\mathrm{i}}}{\partial \mathrm{t}}-\nabla(\mathrm{k} \nabla \mathrm{T})=0$

where, $\mathrm{T}$ is the temperature $\left({ }^{\circ} \mathrm{C}\right), \mathrm{t}$ is the time $(\mathrm{s}), \mathrm{C}$ is the heat capacity of the soil mixture $(\mathrm{J} / \mathrm{m}$ $\left.{ }^{3} \cdot{ }^{\circ} \mathrm{C}\right), \rho_{\mathrm{i}}$ is the density of ice $\left(\mathrm{kg} / \mathrm{m}^{3}\right), \theta_{\mathrm{i}}$ is the volumetric fraction of ice $\left(\mathrm{m}^{3} / \mathrm{m}^{3}\right)$, and $L$ is the latent heat of fusion per unit mass of water, $\nabla \equiv \frac{\partial}{\partial x}+\frac{\partial}{\partial y}+\frac{\partial}{\partial z}$ is the gradient operator, and $\mathrm{k}$ is the thermal conductivity of the soil mixture $\left(\mathrm{W} / \mathrm{m} .{ }^{\circ} \mathrm{C}\right)$. The first term in Equation 2.2 represents the change in energy storage in regards to time. The second term presents the rate of the latent heat of fusion when changing between solid or liquid state. The third term shows the net thermal energy by conduction. 


\subsubsection{Frost Penetration Prediction Models}

There are many approaches to obtain the rate of frost penetration in soils. Generally, these methods could be classified as following: empirical method from exploration drill holes, and from field tests, and analytical modeling (Jumikis, 1977). Charts and maps are used to represent empirical data. While, analytical models estimate frost penetration depth by taking into account the freezing index, soil and ambient temperature variations. They also considere the proximity of water sources (Jumikis, 1977). The key differences between these analytical models are their assumptions and boundary conditions. More commonly used models are provided below.

Neumann (1860) introduced the first analytical model for frost penetration depth. It is originally designed to investigate the formation of ice buildup on a still lake. Berggren (1943) developed the model by incorporating soil thermal properties into the theory and predicting the frost penetration depth in soils (Jumikis, 1977; Lunardini, 1981).

In the Neumann equation higher accuracy of the frost depth prediction requires higher quality of data on the thermal properties of the frozen and unfrozen soil (Jumikis, 1977). A special case of the Neumann solution which is originally developed to estimate ice sheet formation in the Polar Regions, resulted in Stefan's solution (Jumikis, 1977). However, it could easily be incorporated to predict the frost penetration depth in soils. As Neumann's method, Stefan's solution does not account for the volumetric heat capacity of the both frozen, and unfrozen soil, and therefore appears to overestimate frost penetration depth. However, the difference limits to $10 \%$ for soils with high water content and freezing climate (Aldrich, 1956).

The modified Berggren equation is simply the Stefan's solution which takes into account volumetric heat capacity. It uses a correction coefficient, with reference to the local freezing index and thermal properties of the soil (Aldrich and Paynter, 1953). For a layered soil a correction coefficient is developed, accounting for the latent heat of fusion of water and weighted volumetric heat capacity for each layer (Jumikis, 1977). 
Similar to Stefan's solution, portnov's solution (1962) considers the initial temperature state of soil equal to $0^{\circ} \mathrm{C}$, without the volumetric heat capacity of soil. Portnove's solution allows surface temperatures fluctuations with time within a range below or equal to $0^{\circ} \mathrm{C}$; although, it overestimates the frost penetration depth (Unterreiner, 1994). Lefur et al. (1964) developed Portnov's solution to consider an initial soil temperature greater than or equal to $0^{\circ} \mathrm{C}$.

\subsubsection{Frost Penetration Modeling for Walls}

Most of modeling for frost penetration is one-dimensional to present the advancement of a vertical freezing front through horizontally layered soil. These models have only limited application for a retaining wall, since frost penetration and heaving occur two-dimensionally with a complex interplay between thermal, mechanical, and hydraulic processes (Duchesne, 2003).

$\mathrm{Li}$ et al. (1989) modeled a two-dimensional frost heave in a retaining wall. He utilized a FE program developed by Blanchard and Fremond (1985). The program consideres Fourier's Law to simulate heat transfer throughout the soil. Water migration to the freezing fringe is a strong temperature-dependent process and is controlled by Darcy's Law. It decreases sharply when the temperature falls below freezing point of water. The concentration of unfrozen water is deduced to be $100 \%$ above $0{ }^{\circ} \mathrm{C}$, discontinuous at $0^{\circ} \mathrm{C}$, and declines swiftly to zero at a temperature ranging between $-3^{\circ}$ to $-4^{\circ} \mathrm{C}$, although in reality some unfrozen water may exist in clays and silts at temperatures as low as $-30^{\circ} \mathrm{C}$ (Jumikis, 1977; Tsytovich, 1960).

The program GEL 2D (Fremond and Willianls, 1979) is used for this purpose to predict the deformations in a SNW designed at La Plagne, France, for the 1992 Winter Olympics in Albertville (Vengeon, 1989).

\subsection{Mitigation Measures for Preventing Frost Damage on Retaining Structures}

The behavior of soils in cold regions is strongly influenced by temperature, and thus, the analysis of ground thermal regimes is of importance in many problems of scientific interest. Additionally, 
the thermal interaction between engineering structures and frozen ground must be realized to allow for their suitable design. While cold is commonly considered as the single feature of high latitudes, it is often the difficulties resulting from thawing that are important in engineering design. The thaw settlement is not only a thermal event, but also depended on the meltwater dissipation rate which is controlled by the drainage capacity of the soil (Nixon and Ladanyi, 1978).

Freezing and thawing effects could result in facing failure between the nails or nail head pullout. This is owing to the weakening of the soil between the nails, although no specific reports on the failure are captured (Duchesne, 2003). It could be concluded that the designed spacings are sufficient to retain the soil between the nails against frost action. However, more data on the performance of a SNW in frost prone regions would be required to confirm this inference.

Frost heave occurs when three requirements are met simultaneously: (1) frost susceptible soil, (2) source of water, and (3) freezing temperatures. If any of these factors are avoided or mitigated, resulting damage from frost heave could be eliminated. If a project contaminated with frost prone soil has to be advanced, the most efficient way to limit frost action is to remove all the soil above the frost penetration depth with non-frost susceptible soil. However, this method is practical only when a non-frost susceptible soil is available at a reasonable cost.

Preventing the source of water could work as an alternative measure if replacing susceptible soil to frost is not possible due to economical reason. An appropriate drainage system could not only remove the rainfall or water from melted snow swiftly, but it could also degrade the ground water table. The ice lens creation would impede, if water has to flow a long distance before it contributes to the formation of ice lenses. Another method is to block the water movement by using an obstacle between the water source and frost front. This barrier could be an impervious board layer made of an asphalt-impregnated canvas or commercial bentonite (Sowers and Sowers, 1970).

Recently, geosynthetics such as geotextiles and geocomposites is utilized as capillary barriers to reduce frost heave (Henry, 1998). The large pores of these geosynthetics could efficiently disconnect the capillary water immigration from the ground water table. 
The third option to mitigate the potential frost damage is to install thermal insulation layer on the ground surface. An insulating layer, with low heat conductivity, delays the penetration of frost into the frost prone soil; hence, the amount of heaving and its associated damages could be declined.

Once frost heave is mitigated, the damage resulting from thaw weakening would be diminished too. However, a proper design of a drainage system is always necessary to avoid structures, such as retaining walls and pavements, from thaw weakening due to infiltrated rainfall or melting snow in the spring.

In addition to the use of air entrained concrete for the wall construction, frost induced effects could be neglected or considerably mitigated by increasing the wall thickness to the approximate frost penetration depth. This could be achieved by using porous backfill or insulating material between the initial and final facing or outside the permanent facing (FHWA, 2015). Figure 2-13 illustrates two examples of proposed frost protection details using Styrofoam insulation. Because a $25 \mathrm{~mm}$ thick Styrofoam insulation board is typically equal to a $300 \mathrm{~mm}$ thick layer of gravel, proper protection against frost action could be obtained with a relatively thin layer of Styrofoam. 


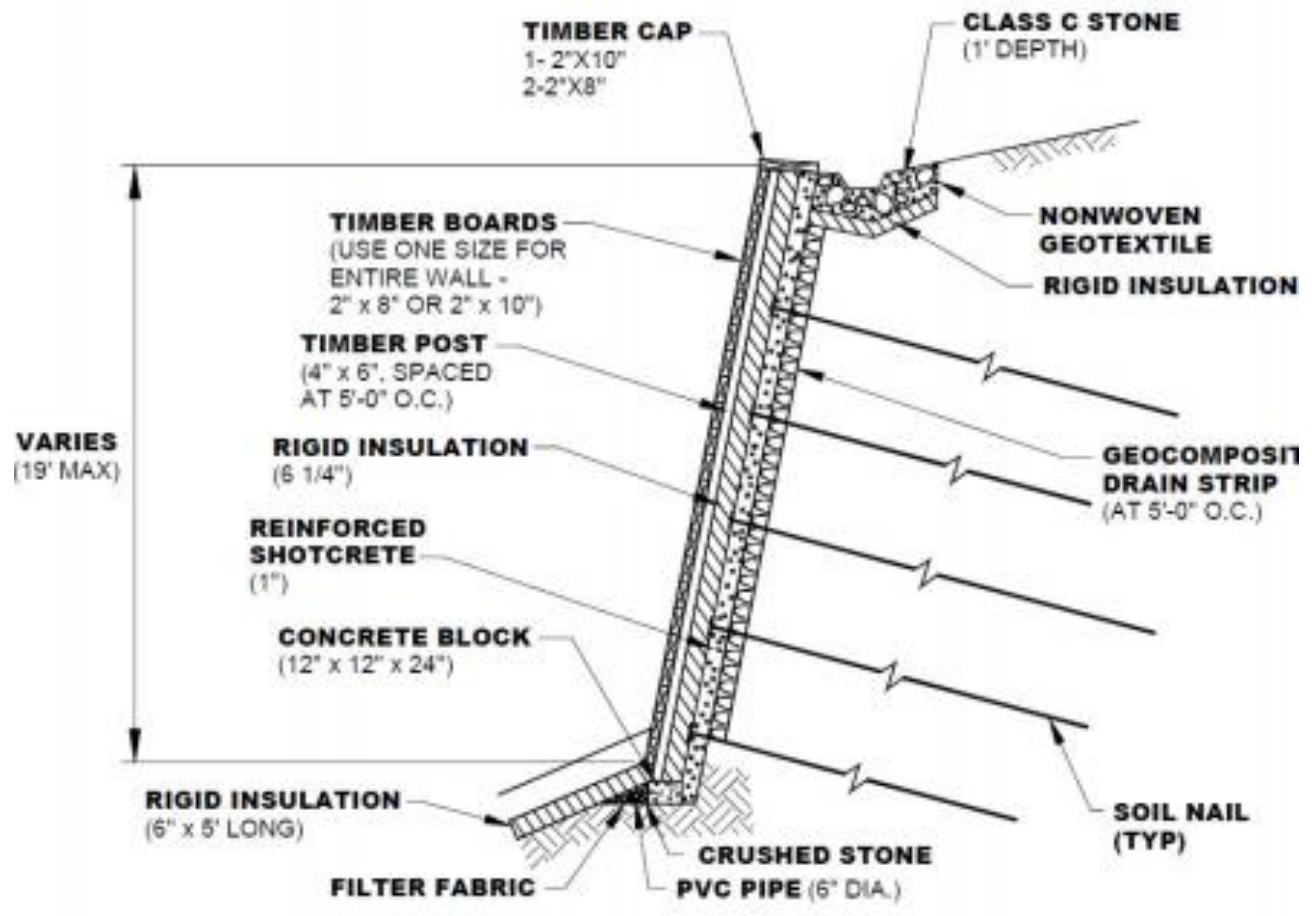

a) Example of Soil Nail Wall with Frost Protection

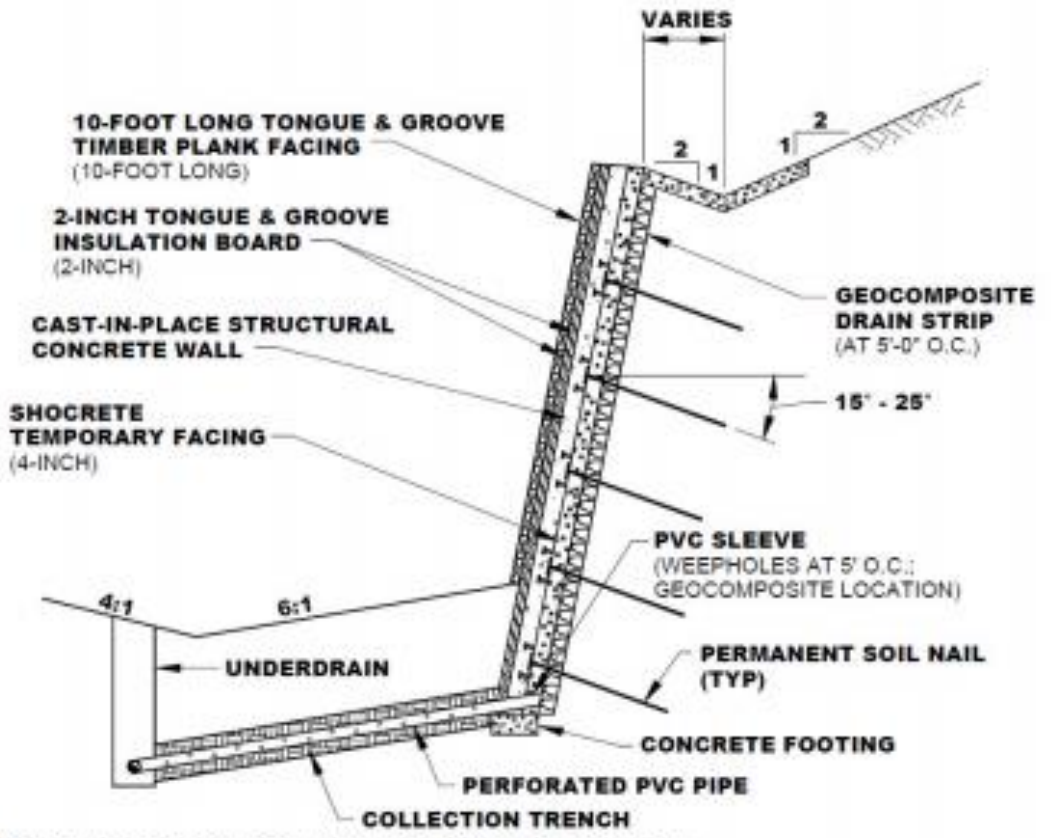

b) Example of soil nail wall with Frost Protection

Figure 2-13 Typical details for a weep hole in a steep soil nail slope (FHWA, 2015) 


\subsection{Constitutive Models for Freezing and Thawing Soil}

Multi-physical modeling deals with events in relation to more than two of the different physical fields. Such physical fields include: mechanical fields (load and deformation), thermal field (temperature), hydraulic field (fluid pressure and mass flow), bio/chemical field (reactions), and electric/magnetic field (charges, currents, and magnetic circuits).

There are three main algorithms for multi-physical modeling: one-way coupling; loose coupling; and full coupling (Minkoff et al., 2003). The algorithm for one-way coupling is the earliest approach for multi-physical modeling, that equations are solved separately for different fields in each step, and the result from one field is read as input to the other (without information passed back) to solve for the next step. This approach is straightforward, and cheap computation-wise. Therefore, it's suitable when one field is dominating the process compared to the others.

The most realistic outputs for such problems could be obtained through full coupling algorithm, in which all the field variables in one set of equations would be solved simultaneously. However, this method could be extremely costly computation-wise due to huge matrix forming the coupling equations. The sequential coupling approach lays between one-way and full coupling algorithms. In the sequential coupling approach, the equations for different fields are solved one by one, but information is then read sequentially between various fields. The results from this approach may not be as accurate as the full coupling method, however it is much faster and the outputs are reasonable.

Thermal-hydro-mechanical (THM) modeling is affected by multi-physical coupling where temperature, hydraulic pressure, and mechanical deformation are simultaneously considered. The procedure involved in a coupled THM system is illustrated in Figure 2-14.

THM is a widely used technique for modeling geotechnical engineering problems, such as porous media in which heat and mass transfer are often referred to as thermal consolidation. Such thermally induced consolidation events could be pertained to the released energy in the form of 
heat from the disposal of a high-level radioactive iste, or from biological radioactive istes in the landfills (Zhu, 2006).

Some researchers have attempted to incorporate the THM approach in order to tackle the freezing and thawing problems in porous medium e.g. rocks, concrete, and soils. Researchers at early times who utilized THM process in addressing the heat and mass movement in freezing soils include: Harlan (1973), Guymon and Luthin (1974), Taylor and Luthin (1978), and Jame and Norum (1980). In order to solve the partial differential equations, constitutional equations are developed, and numerical frameworks are determined. As a result of limitation in computation tools, the application of these methods are sparse until late 1990's when computer technology improved, and the THM process became popular in both research and practice (Zhu, 2006).

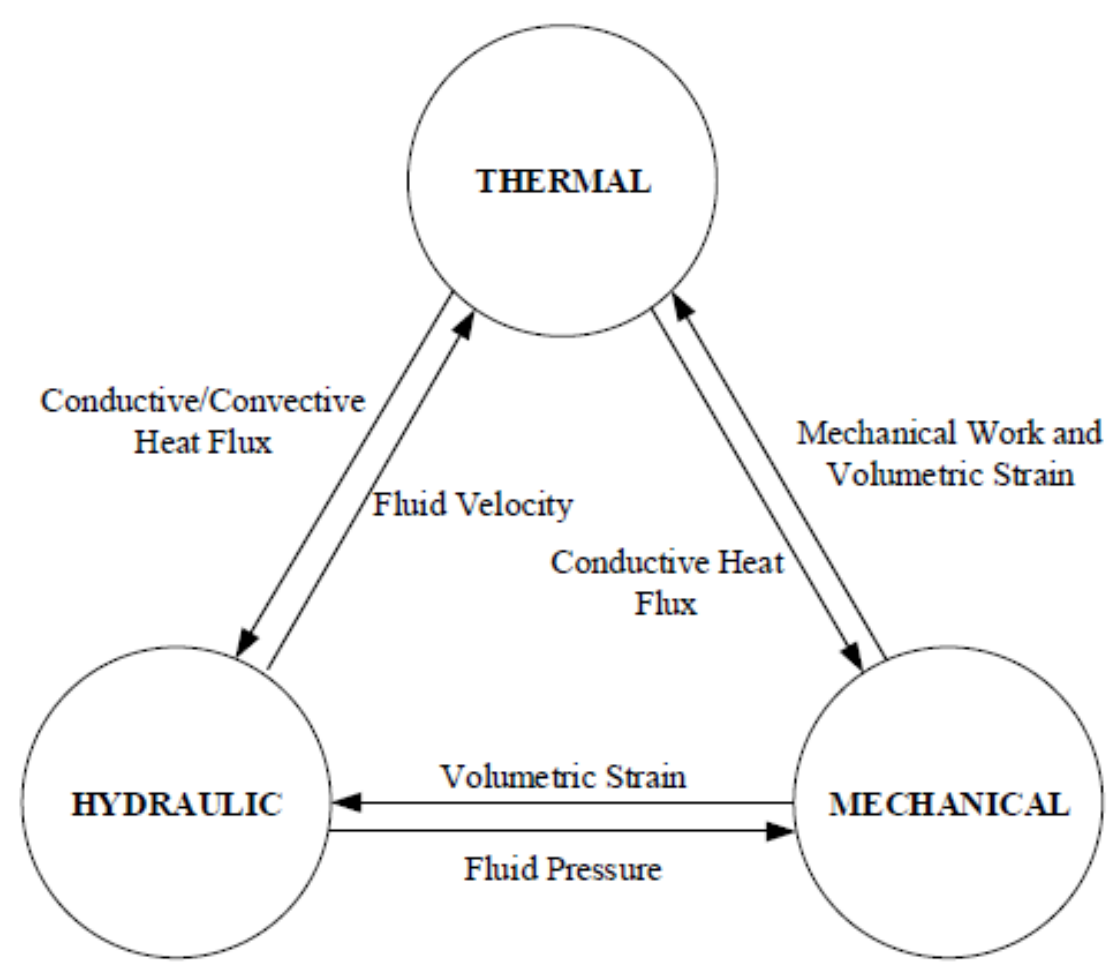

Figure 2-14 The interaction mechanisms in a coupled thermal-mechanical-fluid flow system (Neaupane et al., 1999)

Corapcioglu and Panday (1995) proposed a THM model to describe unsaturated soil thawing. The soil air in the model is assumed at the atmospheric pressure, whereas other components in the 
THM model are considered incompressible including solid particles, water, and ice. Latent heat of water is considered, while factors such as the evaporation and sublimation of water are omitted.

Neaupane et al. (1999) improved a coupled THM model to predict the freezing and thawing behavior of rocks. A linear stress-strain constitutive law for thermo-poro-elasticity is used. In this model, Darcy's equation for the fluid flow and the Fourier's law for the heat flux are introduced to the conservation equations. Later Neaupane and Yamabe (2001) developed the model by incorporating the thermo-poro-elasto-plasticity constitutive law and the Mohr-Coulomb yield criteria. An experiment is conducted to measure the rock mass deformation upon freezing. Then the model is validated with the test data and yielded a good agreement.

Exadaktylos (2006) constructed a coupled model for saturated porous medium subjected to freezing and thawing. The model is developed based on the theory of thermodynamics of reversible process and did not take into consideration the frost action influences as a result of thaw consolidation, due to its application for rocks and concrete.

Michalowski and Zhu (2006) constructed a model to simulate frost action processes based on a porosity rate function which is an indicative of ice growth. The model utilized two primary material parameters including the maximum rate, and the temperature which occurs at the peak rate. The model could be simply generalized, to deal with the boundary value problems and simulate inconsistent three-dimensional processes, using the standard numerical techniques owing to a continuum mechanics formulation utilized in the model.

Qin et al. (2010) constructed a coupled THM phenomena formulated based on the mixture theory for unsaturated soils. The model considered the thermal expansion of the solid particles, the fusion flux caused by thermal gradient, the latent heat of fusion, and the impacts of porosity, and moisture content on heat conduction as well as temperature, and stress dependent degree of saturation.

Kang et al. (2013) proposed a THM model for freezing and thawing in rock. The model is implemented into the finite difference program FLAC-3D to study the behavior of the underground low temperature gas storage. 
Michalowski and Zhang (2014) proposed an elasto-plastic constitutive model based on critical state framework, considering the modified Cam clay yield criteria. The model simulated the stressstrain behavior of the soil subjected to mechanical loading as well as temperature variations. The model is calibrated and implemented in the FE software (ABAQUS) to deal with various boundary conditions. A retaining wall subjected to freezing and thawing temperature is simulated using the model.

This chapter presents the phenomena associated with freezing and thawing in soils, and literature reviews on modelling these phenomena in geotechnical applications, mainly in earth retention systems. 


\section{Chapter 3 : Numerical Modeling and Model Verification}

\subsection{Finite Element Code}

The FEM is a numerical tool which allowed researchers to bypass the complexity of mathematical equations associated with the analytical analyses of structures, to investigate the behaviour of structures, and to optimize the engineering design. In the numerical solution, the whole body is discretized into elements. Hence, instead of formulating mathematic equations for the entire body (analytical solutions) which could be a costly computation; the equations are formulated for each element and combined to determine the solution for the whole body.

In other word, FEM is a computational technique which could be utilized to determine the approximate solutions of boundary value problems in engineering. Boundary value problems are also called field problems. The field is the domain of interest and most often represents a physical structure. The field variables are the dependent variables of interest governed by the differential equation. The boundary conditions are the specified values of the field variables on the boundaries of the field.

This method is introduced as a useful tool in geotechnical engineering in the late 1960s. The FE software suites are widely employed by researches to tackle geotechnical problems. In a study done by Ozawa and Duncan (1973), a FE program, ISBILD, is developed for analysis of stress and movements in dams. This program took into account the staged construction trough incremental analysis procedures. The same program is used by Allen and Meade (1984) to obtain loads and displacements of concrete culverts. The analysis results appears to be more accurate compared to other analytical methods available at that time.

Yang, et al. (1997) used ABAQUS to simulate the behaviour of a double-cell concrete box culvert. The Drucker-Prager elasto-plastic model is used to model the soil behavior, and contact pair to model soil- structure interface, which allowed sliding and loss of contact during loading. 


\subsection{Details of Finite Element Model for Freezing and Thawing Study}

In this study a non-linear FE model is established to investigate the effect of freezing and thawing on the performance of SNW. The FE program, ABAQUS, is employed in this research. The model is discretized with two-dimensional solid elements. In this model a reinforced soil slope inclined at 85 degrees, and with vertical height of $5 \mathrm{~m}$ is considered. The problem is defined as a twodimensional plane strain analysis.

The nail system is modeled as a steel-grout system using equivalent parameters. To simulate the soil-nail interface, the reinforcing bars are modeled as an embedded element. Facing wall and nails are modeled as linear elastic materials, whereas the Mohr-Coulomb yield criterion is used for plastic behavior of soil to model the soil subjected to freezing and thawing event.

All outer surface of model (except the exposed surface to ambient temperature) is restrained from moving in perpendicular direction of the surface.

The FE model is first validated by an instrumented SNW in Brunswick, Maine, in the U.S. (Duchesne, 2003). Then the model is extended to consider temperature conditions in Ontario to investigate the influence from freezing and thawing on SNW in Ontario.

This chapter presents the components of the FE model development including material properties, mesh, element types and thermo-mechanical boundary conditions. It also describes the assumptions and solution method used in the modeling of SNW, followed by the results of a series of thermo-mechanical analyses and discussion. These analyses are performed in order to understand the frost penetration depth and its associated stresses on the performance of a SNW in cold regions.

\subsubsection{Material Modeling}

The following section describes the detailed constituent properties, model components, and the methodology used to simulate the SNW behaviour subjected to freezing and thawing cycle. 
The first step of a FE analysis is to discretize the geometry of a structure using a collection of discrete portions called "FEs". Elements are linked at specific points called nodes, with no gaps along linked boundaries. The group of the nodes and FEs are called the FE mesh. Since the number and the type of the elements would have a significant impact on the FE results, the meshing of the model is taken into special consideration to effectively estimate the variables over the selected region of interest. In order to analyze the behavior of a solid media, the governing equations for each finite element would be solved (Cook et al., 2003), considering the external loads and boundary conditions.

The governing equation could be expressed as

$$
[\mathrm{K}]\{\mathrm{r}\}=\{\mathrm{R}\}
$$

where,

$[\mathrm{K}]=$ global stiffness matrix

$\{r\}=$ global displacement vector

$\{\mathrm{R}\}=$ global load vector

Due to the fact that the Mohr-Coulomb criteria with non-associative plastic flow are used for soil (Griffiths and Lane, 1999), the resulting [K] matrix is non-symmetric. The equations are solved by using a non-symmetric solver (ABAQUS, 2010).

\subsubsection{Selection of Soil Properties for simulation}

Several soil constitutive models are available in ABAQUS. The Mohr-Coulomb model is chosen for simulations in this study. The Mohr-Coulomb model uses the classic Mohr-Coulomb yield criteria. Failure occurs when the shear stress on any plane in the material reached a value that depends linearly on the normal stress on the same plane. 
In this study, the soil is modeled as a two-dimensional, plane strain medium. It is assumed that the soil properties are temperature-dependent. In the description of the material properties of soil, nonassociated Mohr-Coulomb plasticity model is used. The ABAQUS Mohr-Coulomb model requires the following input soil parameters:

$\gamma:$ Unit weight $\left(\mathrm{kg} / \mathrm{m}^{3}\right)$

$v$ : Poisson's ratio (-)

$E$ : Young's modulus $(\mathrm{Pa})$

$C$ : Cohesion intercept $(\mathrm{Pa})$

$\phi$ : Friction angle (degrees)

$\psi$ : Dilation angle (degrees)

As illustrated in Figure 3-1, the Mohr circles of stress at failure are obtained by plotting the results of the laboratory tests in term of effective stresses. The tangent line to the failure circles from several tests, performed with different initial effective stresses, is called the Coulomb failure criterion (Equations. 3.2-3.3).

$\tau_{f=C^{\prime}+\sigma_{n f}^{\prime}} \tan \emptyset^{\prime}$

Where:

$\tau_{f}:$ Shear stress on the failure plane

$\sigma_{n f}^{\prime}:$ Normal effective stress on the failure plane

$c^{\prime}:$ Cohesion

$\emptyset^{\prime}$ : Angle of shearing resistance 


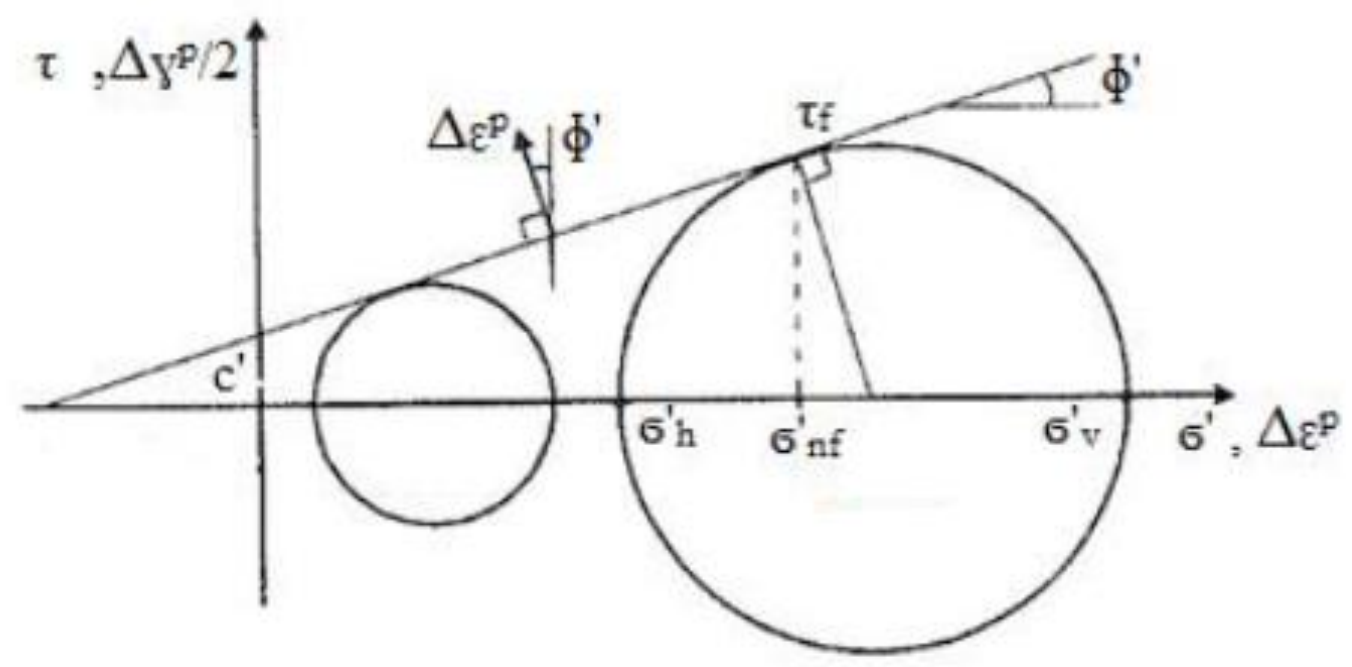

Figure 3-1 Mohr's circles of effective stress (Ports and Zdravkovic, 2001)

The Mohr-Coulomb failure criterion is described as

$\dot{\sigma}_{1}-\dot{\sigma}_{3}=2 c^{\prime} \cos \theta^{\prime}+\left(\dot{\sigma}_{1}+\dot{\sigma}_{3}\right) \sin \theta^{\prime}$

$\sigma_{1}^{\prime}=\sigma_{v}^{\prime}$, and $\sigma_{3}^{\prime}=\sigma_{h}^{\prime}$

Hence, the yield function is given below

$F\left(\left\{\sigma_{1}^{\prime}\right\},\{k\}\right)=\dot{\sigma}_{1}-\dot{\sigma}_{3}-2 c^{\prime} \cos \theta^{\prime}-\left(\dot{\sigma}_{1}+\dot{\sigma}_{3}\right) \sin \theta^{\prime}$

This equation could be expressed more conveniently in terms of stress invariants $p^{\prime}, J$, and $\theta$ (Equations. 3.5-3.6).

$F\left(\left\{\sigma_{1}^{\prime}\right\},\{k\}\right)=J-\left[\left(\frac{C^{\prime}}{\tan \theta}\right)+p^{\prime}\right] g(\theta)=0$

$g(\theta)=\frac{\sin \theta^{\prime}}{\cos \theta+\left(\frac{\sin \theta \sin \theta^{\prime}}{\sqrt{3}}\right)}$ 


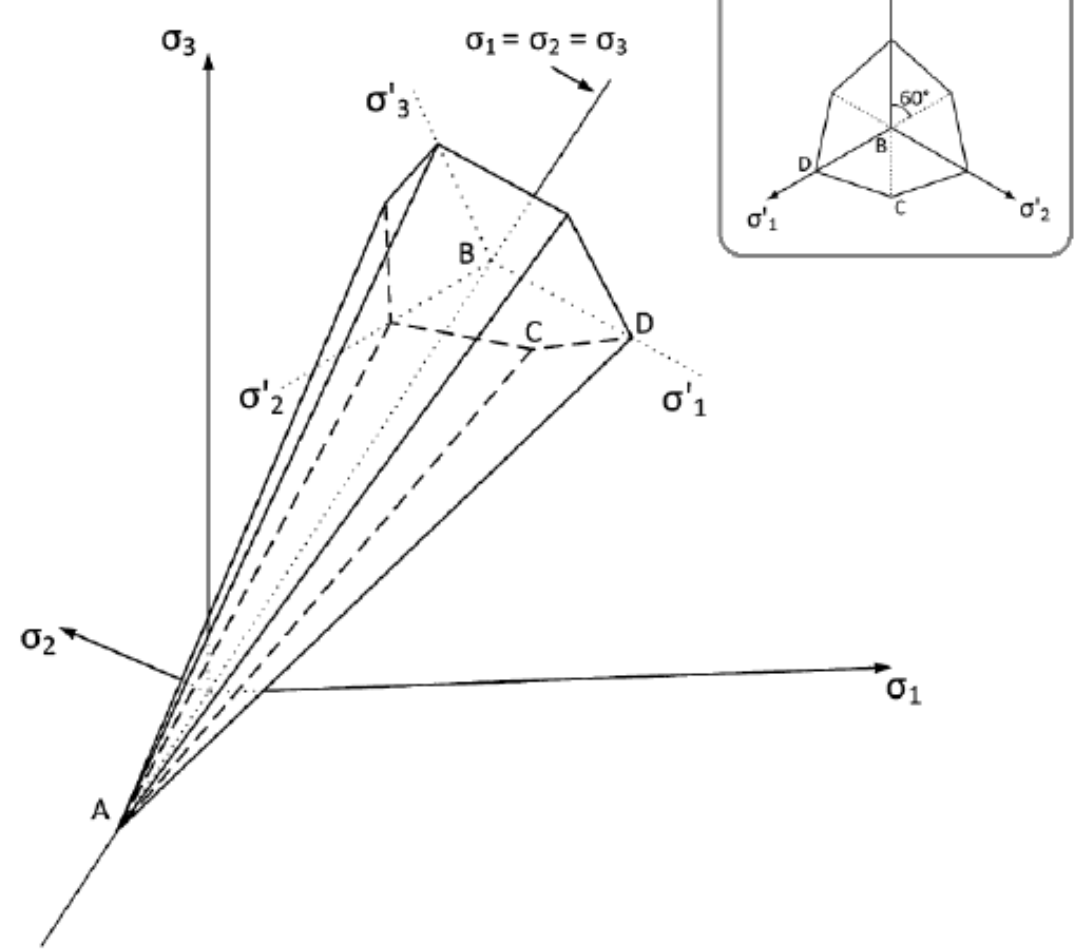

Figure 3-2 Mohr-Coulomb failure criterion: pyramidal surface in principal stress space and, in a detail, the cross-section in the equipressure plane (Labuz and Zang, 2012)

As depicted in Figure 3-2, an irregular hexagonal cone is plotted by the yield function in principal effective stress space.

\subsubsection{Steel Nail Model}

Reinforcements in the form of pre-stressed nails are included in the model to evaluate their effects on the stress-strain distribution within the soil mass. The nails have a density of $7800 \mathrm{~kg} / \mathrm{m}^{3}$, and an elastic modulus of $200 \mathrm{GPa}$, based on published data (ABAQUS, 2010). As presented in Figure 3-3, the behavior of steel nails in tension and compression are idealized as linear elastic ranging up to yielding strength and constant in plastic range after yielding strain. 
The nails are considered as embedded elements, which meant they are fully bonded to the surrounding soil. The nails have length of $8.5 \mathrm{~m}$ and are placed with an inclination of 15 degrees from the horizontal.

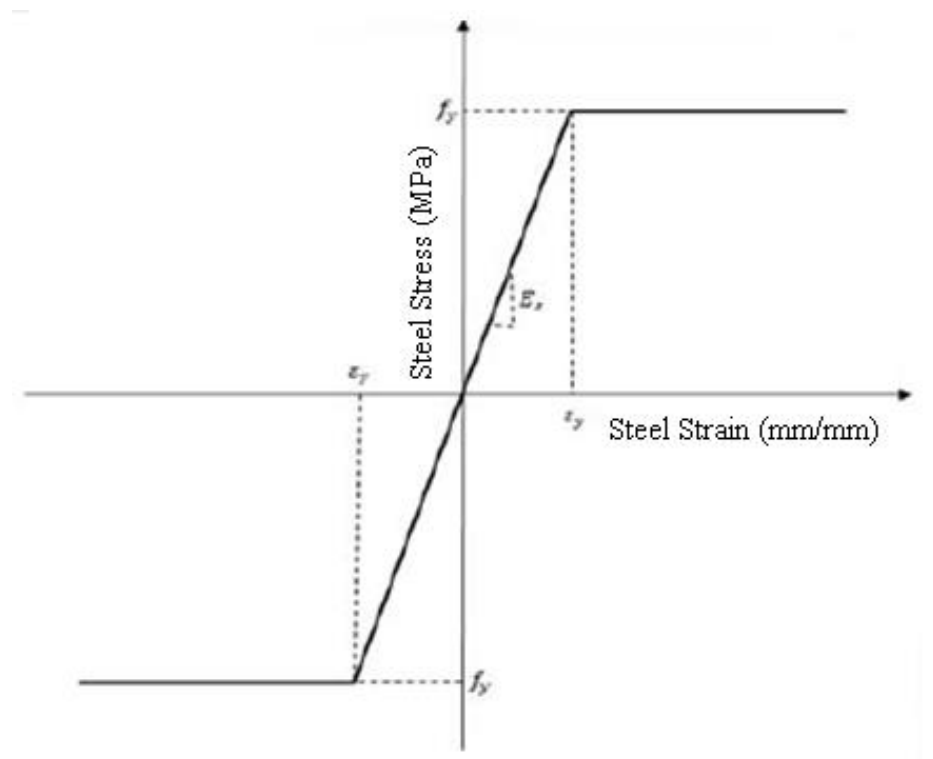

Figure 3-3 The tensile and compressive stress-strain curve of steel (Wulff, 1965)

\subsubsection{Concrete Wall}

The concrete wall is modeled as an elastic material using a linear isotropic elastic model. The elastic characteristics of concrete is defined using modulus of elasticity $(E)$ and Poisson's ratio $(v)$.

\subsubsection{Solid Elements}

The solid (continuum) elements are the standard volume elements of ABAQUS which could be used for linear (first-order) analysis and for complex nonlinear analyses involving contact, plasticity, and large deformations. They are available for stress, heat transfer, coupled thermalstress, coupled pore fluid-stress, and coupled thermal-electrical analyses. In first-order plane strain, 
the strain operator provides constant volumetric strain throughout the element. This constant strain prevents mesh "locking”.

In the modeling of the SNW a two-dimensional four-node general-purpose solid element with two active degree of freedom at each node is used as shown in Figure 3-4.
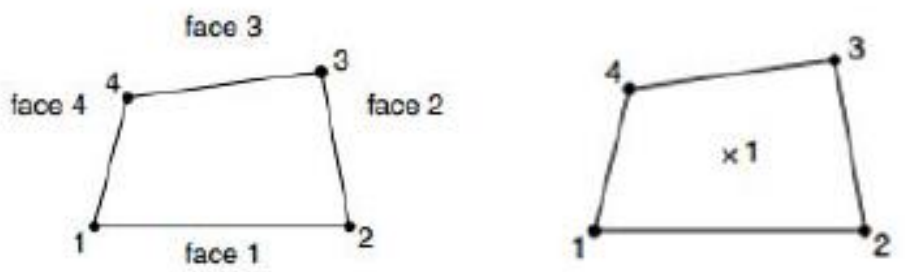

Figure 3-4 Node ordering, face numbering, and element numbering of integration points for 4-node reduced integration element (ABAQUS, 2010)

\subsubsection{Selection of Element Type and Mesh}

A thermo-mechanical analysis of a SNW has to incorporate different element types for the thermal and mechanical procedure. The thermal process is carried out by using a 4-node linear heat transfer quadrilateral element (element type DC2D4 in ABAQUS) elements. The first-order (linear) heat transfer elements use a numerical integration rule for the heat capacitance terms and for the calculations of the distributed surface fluxes with the integration stations located at the corners of the element. Linear elements are preferred in cases involving latent heat effects, since they use such a special integration technique to provide accurate solutions with large latent heats.

A 4-node bilinear, plane strain, reduced integration with hourglass control (CPE4R) elements is used in the mechanical analysis to investigate the effects of freezing and thawing event on the performance of a SNW. Reduced integration technique would reduce running time, due to use of a lower-order integration to form the element stiffness. 


\subsubsection{Loading and Boundary Conditions}

Boundary conditions is used to prescribe temperatures (degree of freedom 11) at nodes in a heat transfer analysis. Boundary conditions also specify as functions of time by referring to amplitude curves. For purely heat transfer elements a boundary without any defined boundary conditions (natural boundary condition) which corresponds to an insulated surface (adiabatic surface) is considered for the lateral boundaries. As mentioned before, the SNW is subjected to a surcharge load acting at top surface of the embankment as shown in Figure 3-5.

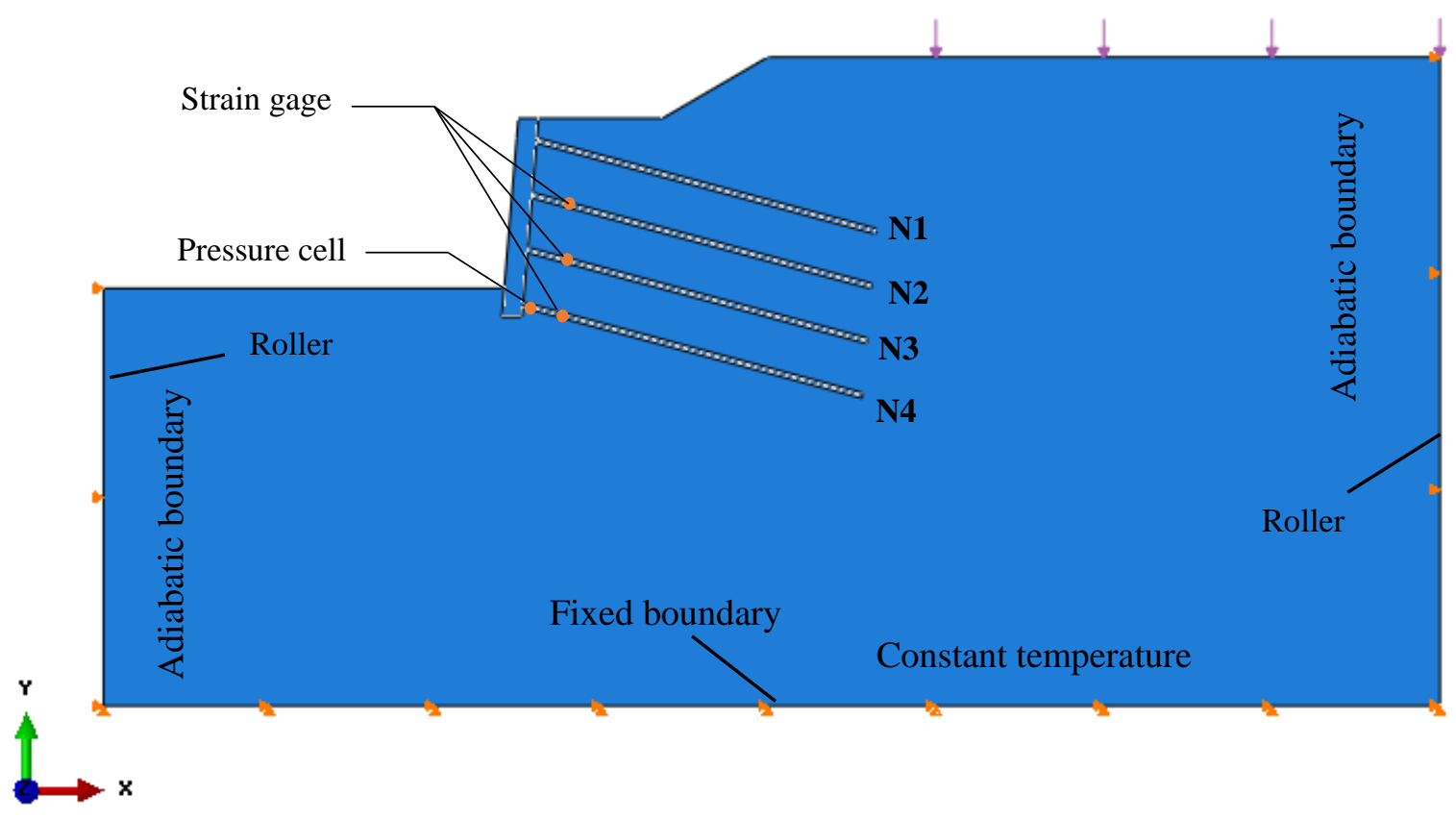

Figure 3-5 Soil nail wall with surcharge load at the top of embankment

The SNW model is prevented to move in horizontal and vertical direction. Thus, the bottom surface of model is made fixed; however the sides are allowed to move vertically.

\subsubsection{Connection of Soil Nails to the Wall}

In practice, the connection of soil nail to the wall is rigid. Bearing plate and nut could be used to connect the wall to the temporary facing. The nail is also rigidly connected with permanent facing 
using headed-stud connection system, reinforcing fully continuous with the concrete facing (FHWA, 2003; Joshi, 2003). In ABAQUS, connection between soil nails and wall facing is modeled as a rigid connection. Nails are considered as embedded element; that are, fully bonded to the surrounding soil.

The embedded element technique in ABAQUS provides a means to model the soil-nail interaction, while also capturing the structural response. Multiple nail layers could be embedded into a single layer of solid elements (ABAQUS, 2010).

The position of the embedded node (nail) is adjusted; so that the node would lie precisely on the edge of the host element (soil mass). This adjustment is performed at the start of the analysis, and would not create any strain in the model.

The tied contact capability is used in heat transfer simulation of the SNW model, where the nodal degrees of freedom include temperature. ABAQUS uses exactly the same formulation for tied contact in non-mechanical simulations as it employs for mechanical simulations.

In the mechanical analysis, in order to simulate the soil-wall interaction; the wall (slave nodes) are constrained to the soil (master surface) precisely at the start of the analysis.

In mechanical simulations an unconstrained slave node could freely penetrate the master surface. In a thermal simulation an unconstrained slave node would not exchange thermal energy with the master surface. To avoid such unconstrained nodes in tied contact pairs, the capability for adjusting the surfaces of a contact pair is utilized. This capability moves slave nodes onto the master surface before ABAQUS has verified for the initial contact state.

If you would not have ABAQUS adjusting the position of the slave surface, slave nodes that are overclosed in the initial configuration would remain overclosed at the start of the simulation, which may cause convergence problems. 


\subsection{Equivalent Nail-Grout Parameters}

Soil nail structure is modeled as a plane strain problem in ABAQUS two-dimensional. Since, the nails are circular in cross-section and placed at designed horizontal spacing, it is necessary to determine equivalent stiffness for the correct simulation of circular soil nails as quadrilateral elements.

For the grouted nails, equivalent modulus of elasticity $\mathrm{E}_{\mathrm{eq}}$ should be determined accounting for the contribution of elastic stiffnesses of both grout cover as well as reinforcement bar. From the fundamentals of strength of materials, $E_{\text {eq }}$ could be determines as

$E_{e q}=E_{n}\left(\frac{A_{n}}{A}\right)+E_{g}\left(\frac{A_{g}}{A}\right)$

where

$E_{g}$ is the modulus of elasticity of grout material

$E_{n}$ is the modulus of elasticity of nail

$E_{e q}$ is the equivalent modulus of elasticity of grouted soil nail

$A=0.25 \pi D_{D H}^{2}$ is the total cross-sectional area of grouted soil nail

$\mathrm{A}_{\mathrm{g}}=\mathrm{A}-\mathrm{A}_{\mathrm{n}}$ is the cross-sectional area of grout cover; and

$A_{n}=0.25 \pi d^{2}$ is the cross-sectional area of reinforcement bar, and $D_{D H}$ is the diameter of drilled hole.

Two-dimensional plain strain assumptions are taken into account. The calculated value of equivalent modulus of elasticity for the grouted soil nail is divided by the horizontal spacing of soil nails.

The same procedure is followed for calculation of Keq (Equivalent Heat Conductivity)

$K_{e q}=K_{n}\left(\frac{A_{n}}{A}\right)+K_{g}\left(\frac{A_{g}}{A}\right)$ 
Given values of equivalent parameters for nails are listed in Table 3-2 for the thermo-mechanical analysis.

\subsection{Thermal Analysis}

In ABAQUS, for the heat transfer by conduction, through two in-contact bodies, an interface thermal conductance value must be defined. Establishing a proper contact between granular materials such as soil, and concrete which would have a rough surface, is infeasible. Thermal resistance would develop at the interface due to air content in the voids between the two surfaces. Interface thermal conductance is described as the ratio between the temperature drop and the average thermal flow through the interface (Holman, 1997). An interface thermal conductance value of $25 \mathrm{~W} / \mathrm{m}^{2}$ is adapted in this study, which is taken from the research conducted by Rees \& Thomas (2009) on ground slab heat loss.

The ABAQUS capability for heat transfer analysis is intended to model solid body heat conduction with general, temperature-dependent conductivity; latent heat effects; and quite general convection and radiation boundary conditions. Latent heat effect could have significant influence on the thermal regime and must be included in many heat transfer problems involved phase change. When latent heat is given, it is assumed to be in addition to the specific heat effect.

Heat transfer problems could be nonlinear because the material properties are temperature dependent or because the boundary conditions are nonlinear. Usually the nonlinearity associated with temperature-dependent material properties is mild because the properties would not change rapidly with temperature. However, when latent heat effects are included, the analysis may be severely nonlinear.

The thermal analysis runs in two steps: a steady-state heat transfer step where the initial temperature of all elements is applied. Steady state conduction is a form of conduction that would occur when the temperature difference driving the conduction is constant, so that after an equilibration time, the spatial distribution of temperatures in the conducting object would not 
change any further. In steady state conduction, the amount of heat entering a section is equal to amount of heat coming out. Next step, transient heat transfer of exposed surface would occur. Transient conduction is considered in the analysis since the ambient temperature changed as a function of time.

In a heat transfer analysis the thermal conductivity of the materials must be defined. Additionally, the specific heat, and density of the materials must also be considered for transient heat transfer problems. As changes in internal energy due to phase changes are important in this simulation, latent heat of fusion is defined for heat transfer elements.

\subsection{Sequentially Coupled Approach}

In this research, the analysis of the SNW is carried out utilizing the sequentially coupled approach. This approach would be used, when the stress and deformation profile in a model depends on the temperature history, whereas temperature distribution could be determined without the availability of stress field in the model. The thermo-mechanical problem would be solved by first using the thermal analysis to obtain the temperature distribution in an uncoupled heat transfer analysis. Then for the mechanical part of the analysis, the temperature history would be read from the output file (called ODB file in ABAQUS) of the thermal analysis, and then would update the analysis as a nodal temperature field in ABAQUS by using predefined fields (ABAQUS, 2010). The steps for sequentially coupled thermo-mechanical analysis are illustrated in Figure 3-6. 


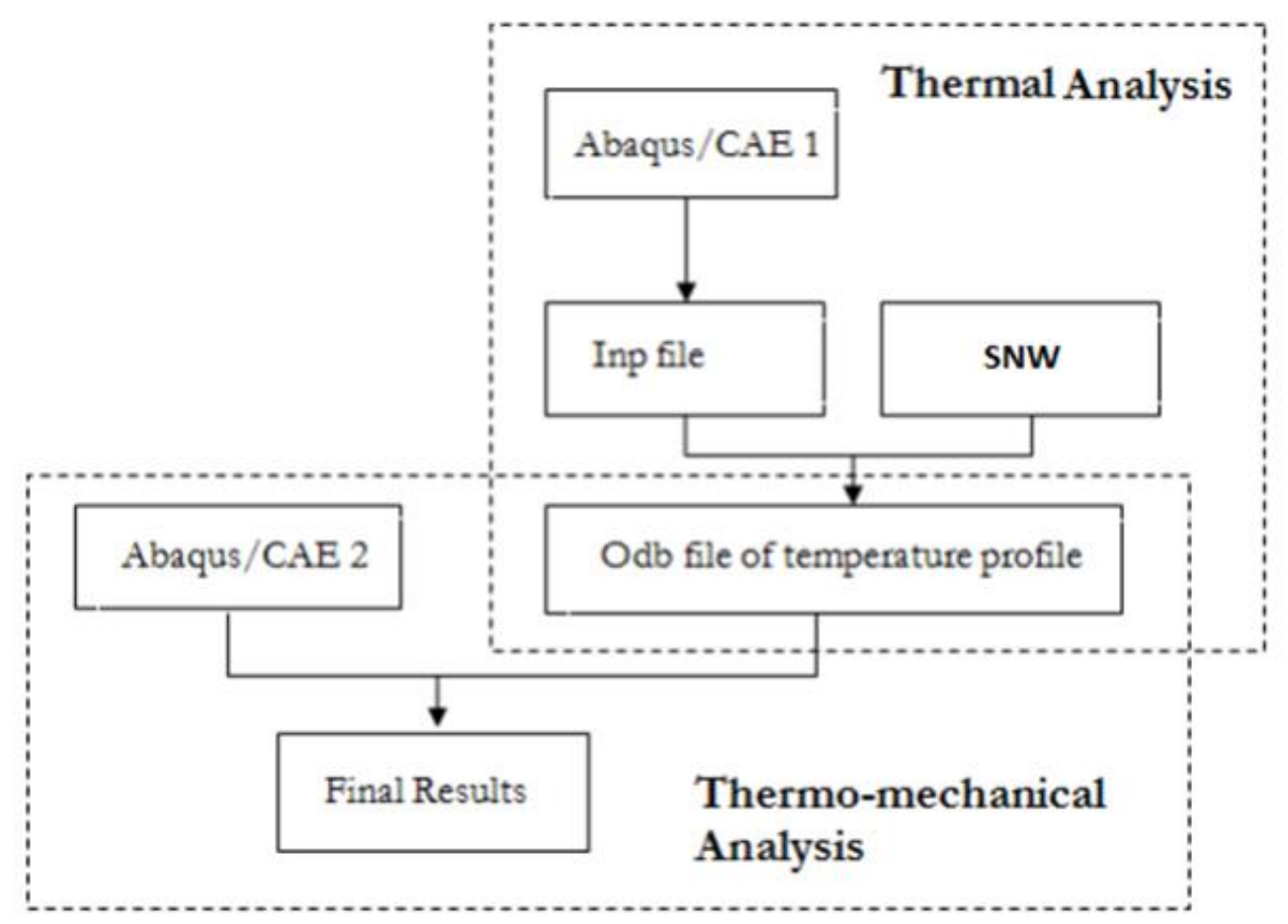

Figure 3-6 Steps for sequentially coupled approach (Aziz and Tao, 2012)

\subsubsection{Transferring the Heat Transfer Results to the Mechanical Analysis}

The time-dependent temperature would be read into the stress analysis as a predefined field. It is predefined, because it is not changed by the stress analysis solution. Such predefined fields would be always passed into ABAQUS at the nodes. They are then interpolated to the calculation points within elements as needed. The temperature interpolation in the stress elements is usually approximate, and one order lower than the displacement interpolation in order to obtain a compatible variation of thermal and mechanical strain.

In order to determine the temperature contours at different times in the stress analysis, the nodal temperatures would be read as a function of time in the thermal analysis results or output file. ABAQUS would assume that node numbers are the same for corresponding nodes in the stress analysis mesh, and in the heat transfer analysis mesh. 


\subsubsection{Thermal Strain}

Thermal strains arise as a consequence of volume changes caused by both temperature gradients, and phase transformations. The change in dimensions due to the temperature variation is called thermal strain, $\varepsilon^{\text {th }}$ which is a function of ( $\left.\mathrm{T}-\mathrm{T}_{0}\right)$, where $\mathrm{T}_{0}$ is the initial temperature, and $\mathrm{T}$ is the applied temperature. With exception of some materials, typically the material expands, when it is heated and shrinks upon cooling.

Thermal strain is a linear function of temperature change, which could be expressed as

$\varepsilon_{k l}^{t h}=\alpha(T)\left(T-T_{0}\right) \delta_{k l}$

Where $\alpha$ is thermal expansion coefficient and is temperature dependent property, and $\delta_{k l}$ is kronecker's delta. The above equation is true, when the initial temperature is equal to the reference

temperature $T_{r e f}$. If we have different reference temperatures then Equation 3.9 could be written as

$\varepsilon_{k l}^{t h}=\alpha(T)\left(T-T_{r e f}\right)-\alpha\left(T_{0}\right)\left(T_{0}-T_{r e f}\right) \delta_{k l}$

where $\alpha\left(T_{0}\right)$ is the thermal expansion coefficient at initial temperature. If the material is free to move, internal stresses as a result of thermal strains are not generated, opposed to mechanical strains which are related to internal stresses by the material constitutive law (Bauchau and Craig, 2009). To include the thermal strain in the linear elastic equation, the Cauchy stress should be incorporated.

\subsection{Solution Procedures}

The coupled thermo-mechanical analysis is run in three steps to calculate the stresses caused by temperature variation: the initial condition based on transient heat transfer analysis, the geostatic state, and the loading step. A step-by-step iterative procedure which consists of smaller increments 
and a number of iterations at each increment is employed to obtain an equilibrium solution. All increment sizes and number of iteration are specified automatically by ABAQUS. The NewtonRaphson technique is used to find equilibrium solutions for each iteration.

The three steps are performed in sequences, where the results of one step would become the initial conditions of the following one. After the analysis is complete, not only the results of the final step would be available, but also the results of previous ones. Each of these three steps have the following purpose:

1) Initial Step: In this step, the temperature history which is calculated in an uncoupled transient thermal analysis would be introduced as a predefined field. The initial vertical stress for soil is considered to vary linearly with depth, and the horizontal stress is calculated by multiplying the vertical effective stress by the coefficient of lateral earth pressure at rest $\left(\mathrm{k}_{\mathrm{o}}\right)$.

2) Geostatic Step: This step would be the first step for most geotechnical studies performed in ABAQUS. In this step, the initial stresses corresponding to the weight of the SNW are applied to the model. The initial effective vertical stress is considered to vary linearly with depth and the horizontal stress is calculated by multiplying vertical stress by the coefficient of earth pressure at rest $\left(\mathrm{k}_{0}=0.5\right)$. Subsequently, ABAQUS verified if the introduced stresses are in an equilibrium condition, whether all elements remained at an elastic state or not. It may require several iterations to achieve this equilibrium state. After finding the correct initial stresses with proper boundary conditions, the loading step could proceed further.

3) Static Step: In this step the surcharge load equal to $14(\mathrm{kPa})$ is applied to the $\mathrm{SNW}$ as a uniform pressure at the top of the embankment. 


\subsection{Verification Process}

The validation of the FEM model is performed through a comparison study between numerical simulations with the field measurement from an instrumented SNW in Brunswick, Maine, U.S. (2003). The thermo-mechanical boundary conditions used for the simulation are adopted from Maine data.

\subsubsection{Model Geometry}

The geometry of the model for the SNW in Maine, U.S., boundary conditions and initial temperature distribution are shown in Figure 3-7 and 3-8. The vertical boundaries are adiabatic. The initial temperature of the bottom boundary is $3{ }^{\circ} \mathrm{C}$ and the temperature along the exposed boundaries is $6^{\circ} \mathrm{C}$. The steady-state distribution of the temperature before the process initialized at $\mathrm{t}=0$ is shown in Figure 3-8. The simulations is performed for the ambient temperature that is consistent with Brunswick climate at Maine, U.S.The thermal boundary conditions are as follows: at time $t=0$, the temperature along the external boundary suddenly drops from $12^{\circ} \mathrm{C}$ to $-7^{\circ} \mathrm{C}$, over the course of four months while the temperature at the bottom of the model is kept steady at $3^{\circ} \mathrm{C}$. For the mechanical analysis, the bottom of the embankment is fixed and for the lateral boundaries, rollers are used. 


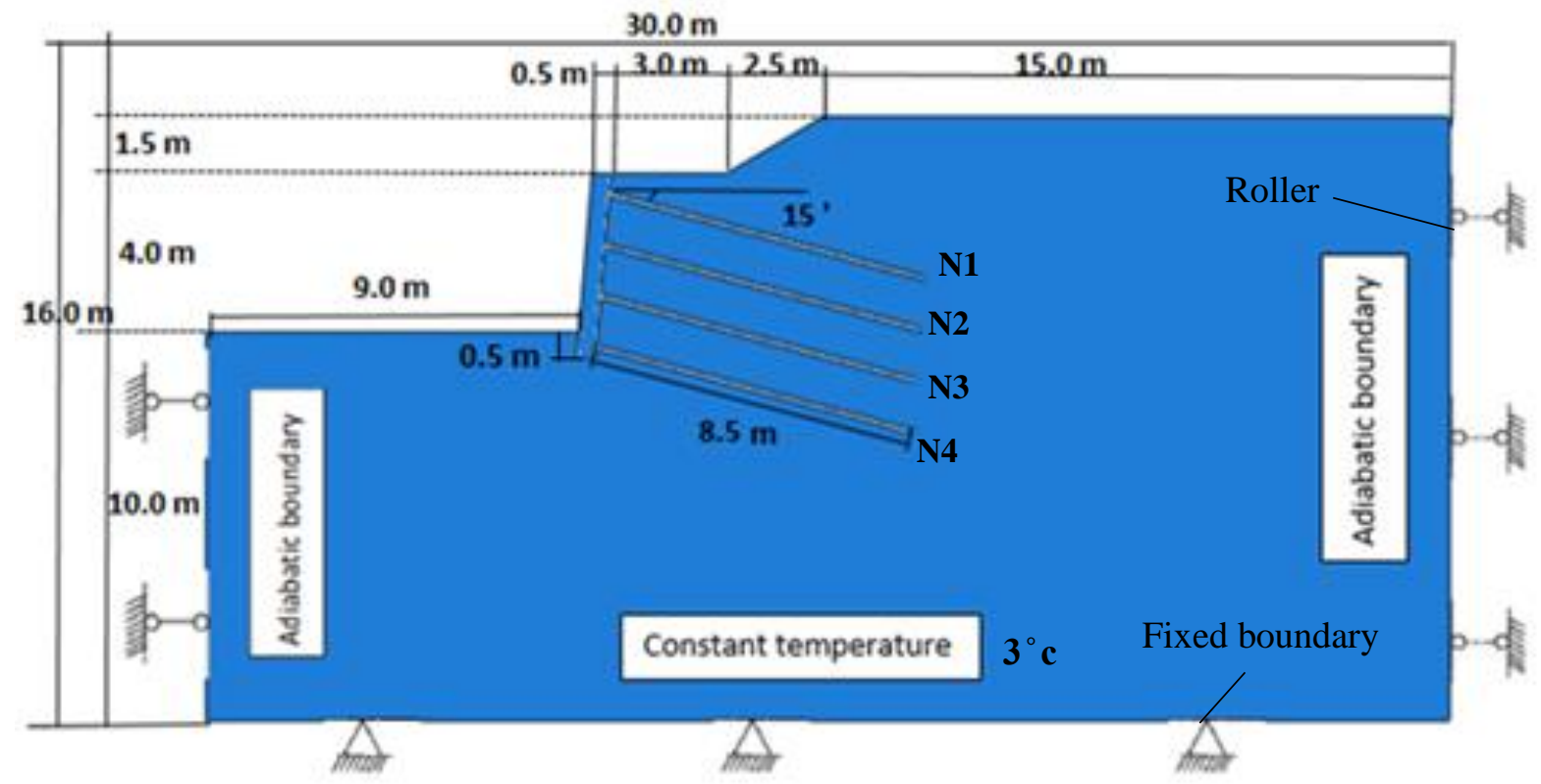

Figure 3-7 Geometry and boundary conditions

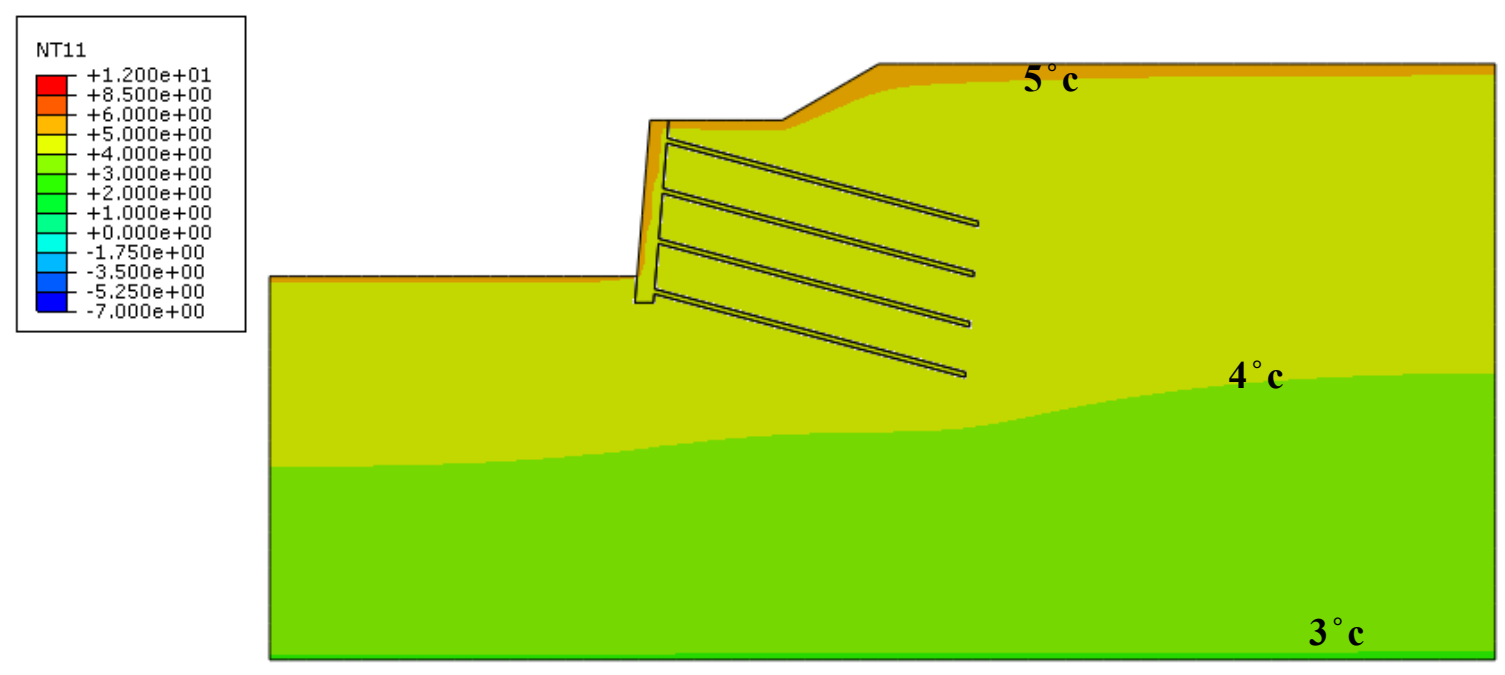

Figure 3-8 Initial temperature distribution

\subsubsection{Mesh Design}

Since the size of the elements would have a significant impact on FE results, the meshing of the SNW is taken into special consideration. The SNW model is divided into elements, each having 
quadrilateral shapes. The transient heat transfer part of the sequential approach uses the 4-node linear heat transfer quadrilateral element (element type DC2D4 in ABAQUS), whereas in the mechanical part, the model is discretized using 4-node bilinear plane strain quadrilateral, reduced integration elements (element type CPE4R in ABAQUS).The FE mesh is shown in Figure 3-9.

\subsubsection{Instrumentation}

In order to monitor the SNW behavior, there are numbers of instruments and gages mounted on the SNW in Maine; strain gages along the nails and pressure cell on the bottom of wall. These instruments intend to measure the strain change along the nails and the total earth pressure on the wall during freezing and thawing seasons.

The largest magnitudes of stress along the nail are observed in the gage located $1.5 \mathrm{~m}$ from the exposed nail head. For the above mentioned reason the FE results for the thermally induced stresses along nails are validated for that monitoring point, $1.5 \mathrm{~m}$ behind the concrete facing wall, for the nails N2, N3 and N4 (no data is available for the nails on the first row) as shown in Figure 3-9.

At the end of this chapter, the comparison of the numerical model results and available field test data are presented at the instrumented locations shown in Figure 3-9. The comparisons include the thermally induced stress along instrumented nails, wall movements and heaving pressure on the wall versus time over the course of freezing season which presented in Figures 3-11 through 3-14. 


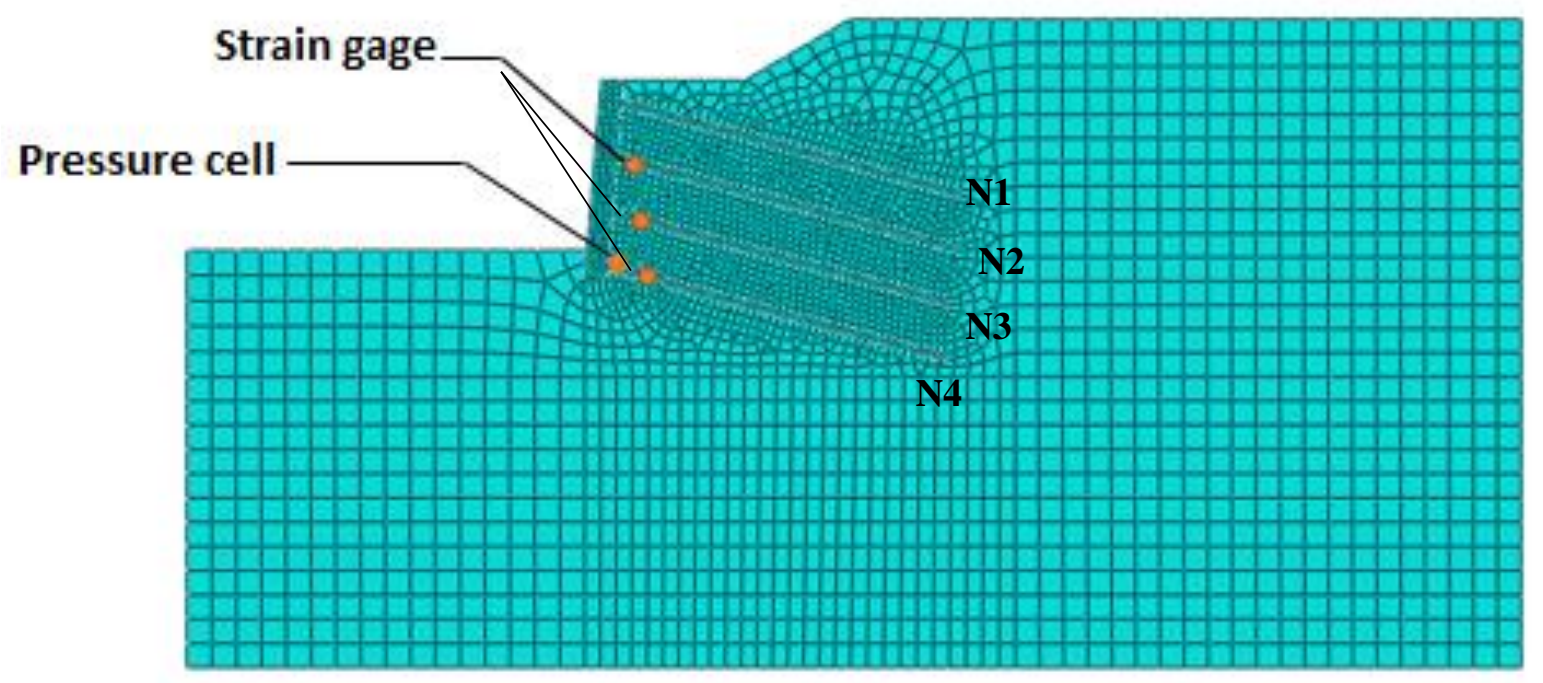

Figure 3-9 Finite element mesh and the locations of the strain gages and pressure cell

\subsubsection{Effects of Freezing and Thawing on Material Properties}

Soil temperature gradually drops down as winter approaches, and the moist ground freezes. The freezing process involves phase change of water in the soil pores into ice. Ice lensing may increase the volume of soil about 9\% (Andersland and Ladanyi, 2004). Meantime, in spring time the ice lenses would melt and the soil layer becomes wet and soft. This loss of soil strength may produce thaw settlement in soil layers. Obviously, temperature fluctuations in soil layers have a notable impact on the soil properties.

In addition to mechanical properties, thermal conductivity $(\mathrm{k})$ and specific heat $(\mathrm{c})$ are required for the modeling of freezing and thawing process. Density $(\rho)$ of soil, nail and concrete wall are; $1842.13 \mathrm{~kg} / \mathrm{m}^{3}, 7800 \mathrm{~kg} / \mathrm{m}^{3}$ and $2240 \mathrm{~kg} / \mathrm{m}^{3}$, respectively. The model takes into account the latent heat of fusion of water (approximately $334,000 \mathrm{~J} / \mathrm{kg}$ ) and variation of the soil thermal properties. Release or absorption of the latent heat has a significant influence on the temperature profile and it retards the frost or thaw front propagation. 
Equivalent heat conductivity (k) and modulus of elasticity (E) are used for the nail-gout system. The material properties of the soil, nail and concrete wall are listed in Table 3-1 and 3-2. These data are based on published literature by Xu et al. (2001) for frost susceptible silty sand.

Table 3-1 Soil properties for thermo-mechanical analysis

\begin{tabular}{cccccccc}
\hline Temperature $\left({ }^{\circ} \mathrm{c}\right)$ & $\mathrm{k}\left(\mathrm{W} / \mathrm{m} .{ }^{\circ} \mathrm{c}\right)$ & $\mathrm{c}\left(\mathrm{J} /\left(\mathrm{Kg} .{ }^{\circ} \mathrm{c}\right)\right)$ & $\mathrm{E}(\mathrm{Pa})$ & $v$ & $\emptyset\left(^{\circ}\right)$ & $\psi\left({ }^{\circ}\right)$ & $\alpha\left(1 /{ }^{\circ} \mathrm{c}\right)$ \\
\hline 20 & 1.004 & 1126.364 & $2.75 \mathrm{E}+07$ & 0.3 & 30 & 0.1 & 0 \\
0 & 1.004 & 1126.364 & $2.75 \mathrm{E}+07$ & 0.3 & 30 & 0.1 & 0 \\
-1 & 1.085 & 1050.764 & $5.39 \mathrm{E}+07$ & 0.3 & 31 & 0.1 & 0.00476 \\
-3 & 1.12 & 1018.823 & $7.85 \mathrm{E}+07$ & 0.3 & 32 & 0.1 & 0.00267 \\
-5 & 1.132 & 1007.294 & $9.71 \mathrm{E}+07$ & 0.3 & 33 & 0.1 & 0.00168 \\
-10 & 1.146 & 994.0636 & $1.32 \mathrm{E}+08$ & 0.3 & 35 & 0.1 & 0.00084 \\
-15 & 1.153 & 987.6376 & $2.05 \mathrm{E}+08$ & 0.3 & 38 & 0.1 & 0.00056 \\
-25 & 1.167 & 974.7856 & $2.75 \mathrm{E}+08$ & 0.3 & 44 & 0.1 & 0.00032 \\
\hline
\end{tabular}

Table 3-2 Nail and wall properties for thermo-mechanical analysis

\begin{tabular}{cccccc}
\hline & $\mathrm{k}\left(\mathrm{W} / \mathrm{m} .{ }^{\circ} \mathrm{c}\right)$ & $\mathrm{c}\left(\mathrm{J} /\left(\mathrm{Kg} .{ }^{\circ} \mathrm{c}\right)\right)$ & $\mathrm{E}(\mathrm{Pa})$ & $v$ & $\alpha\left(1 /{ }^{\circ} \mathrm{c}\right)$ \\
\hline Nail & $2.6^{1}$ & 434 & $4.609 \mathrm{E}+09^{2}$ & 0.25 & $1.30 \mathrm{E}-07$ \\
Wall (Concrete) & 1.2 & 970 & $4.90 \mathrm{E}+09$ & 0.25 & $8.00 \mathrm{E}-06$ \\
\hline
\end{tabular}

$1(W / m . ~ c / m)$

${ }^{2}\left(\mathrm{Kg} / \mathrm{m}^{2} / \mathrm{m}\right)$

As the freezing temperature propagates into the soil, the soil starts heaving vertically along surface of embankment, and horizontally against wall facing. This type of ground movement would occur in the direction of heat flow that is penetrating from top surface and facing of the wall. The SNW, now would have a tendency to tilt since the horizontal displacement in its upper part is not restricted, whereas at the bottom is confined by the pavement.

The temperature profiles for the SNW are shown in Figure 3-10 for warm season as well as cold season, when the temperature drops below zero. When the ambient temperature is about $-7^{\circ} \mathrm{C}$; the ground is frozen. The freezing front below the top surface in the open ground is about $1.5 \mathrm{~m}$ which is in a good alignment with $1.7 \mathrm{~m}$ frost depth predicted from freezing index in the area based on FHWA publication (HRT-08-057). Frost penetrates behind the wall to a maximum depth of $2.4 \mathrm{~m}$ 
behind the facing along the top row of the nails, which is influenced by a two-way frost front progressing from both the top and the front of the wall. This frost depth decreases to only $0.2 \mathrm{~m}$ along the lower nails. The contours of temperature distribution for the SNW are illustrated in Figure 3-10 over the course of freezing and thawing seasons.

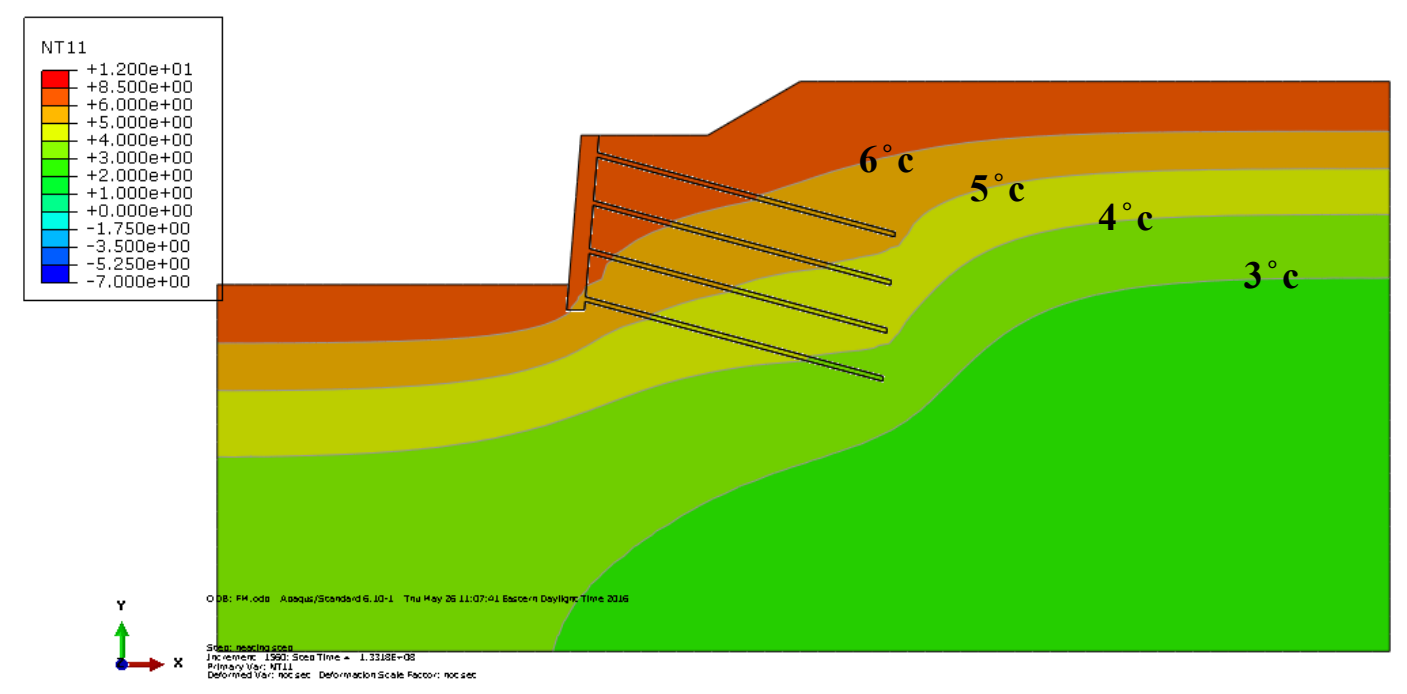

(a) Temperature distribution for warm season

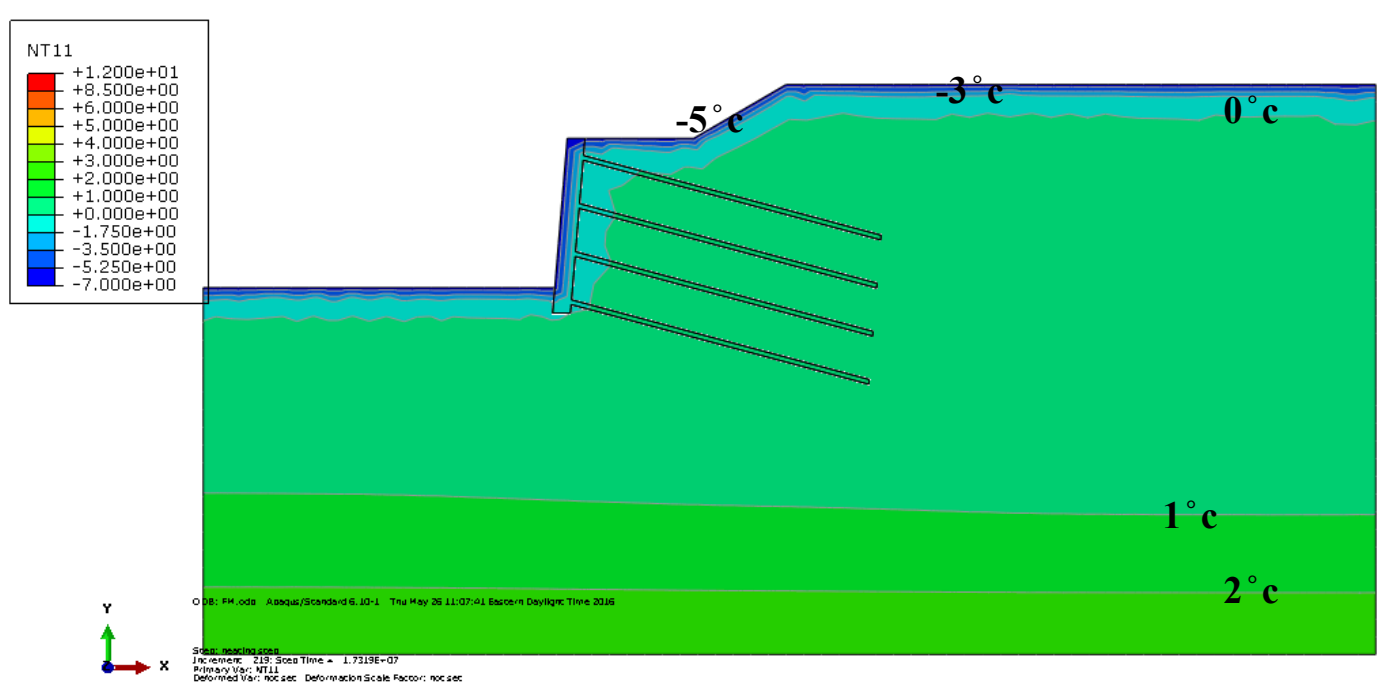

(b) Temperature distribution for cold season

Figure 3-10 Temperature distribution for both warm and cold seasons

The upper rows of nails which are exposed to bi-directional heat transfers from ground surface and wall side typically carry higher stresses induced by the temperature variation. For this reason it is 
important to investigate the behaviour of the top-most nails which fall within the bi-directional frost fronts. In the current study, the thermally induced stress along nails are calibrated based on available data for instrumented nails in Maine, U.S. (no data are provided for the nails at the first row; N1).

Figures 3-11 presents the thermally induced stresses versus time along nails for both the FE analysis and field measurements. During the cold season, the maximum thermally induced stress on the instrumented nail is observed around $14 \mathrm{MPa}$ and it occurs during the period of deepest frost penetration time. The peak stress occurs in the instrumented nail located closest to the center of the wall; N3 as shown in Figure 3-11b, slightly higher than nail in the second row (N2) and much lower stress occurs in the nail close to the bottom of the wall (N4).

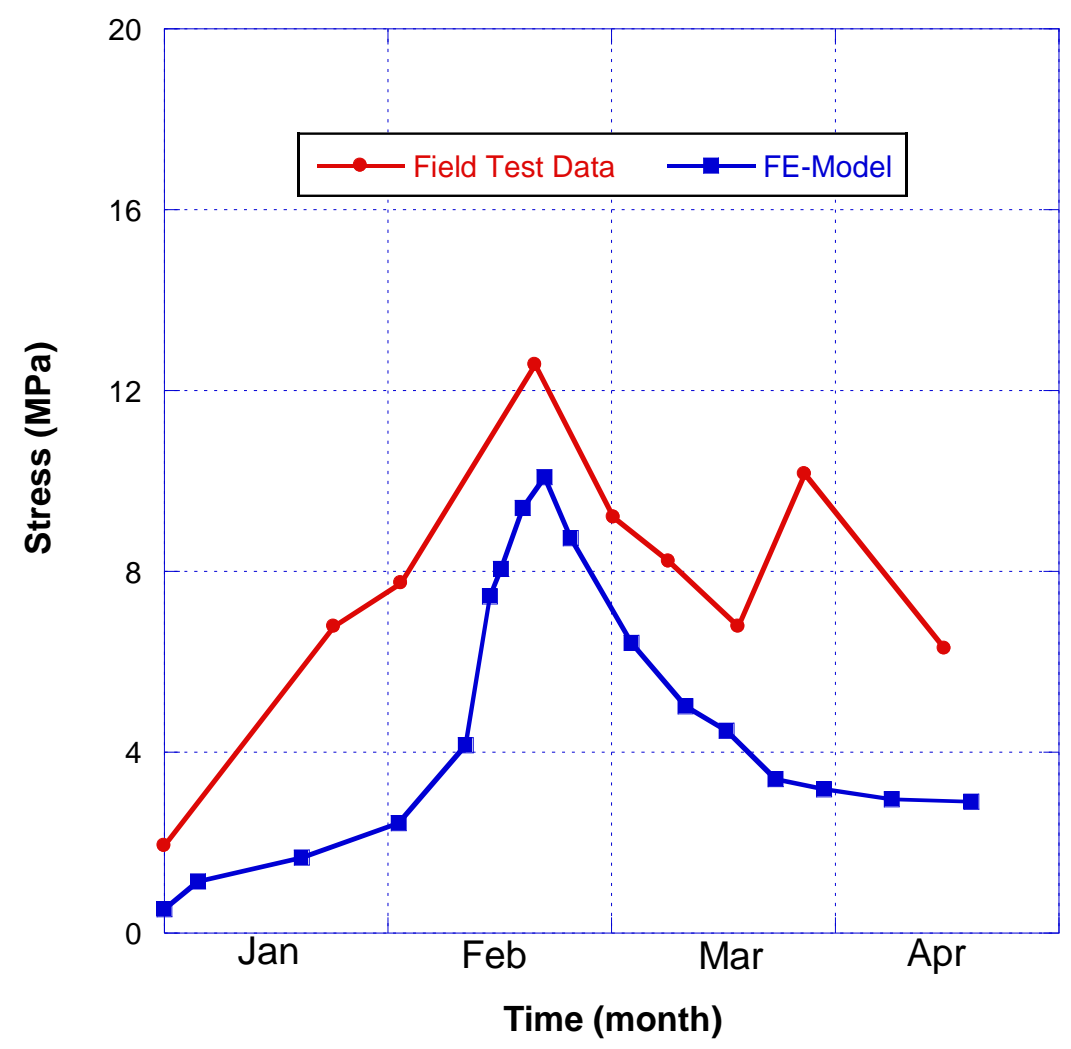

(a) $\mathrm{N} 2$ 


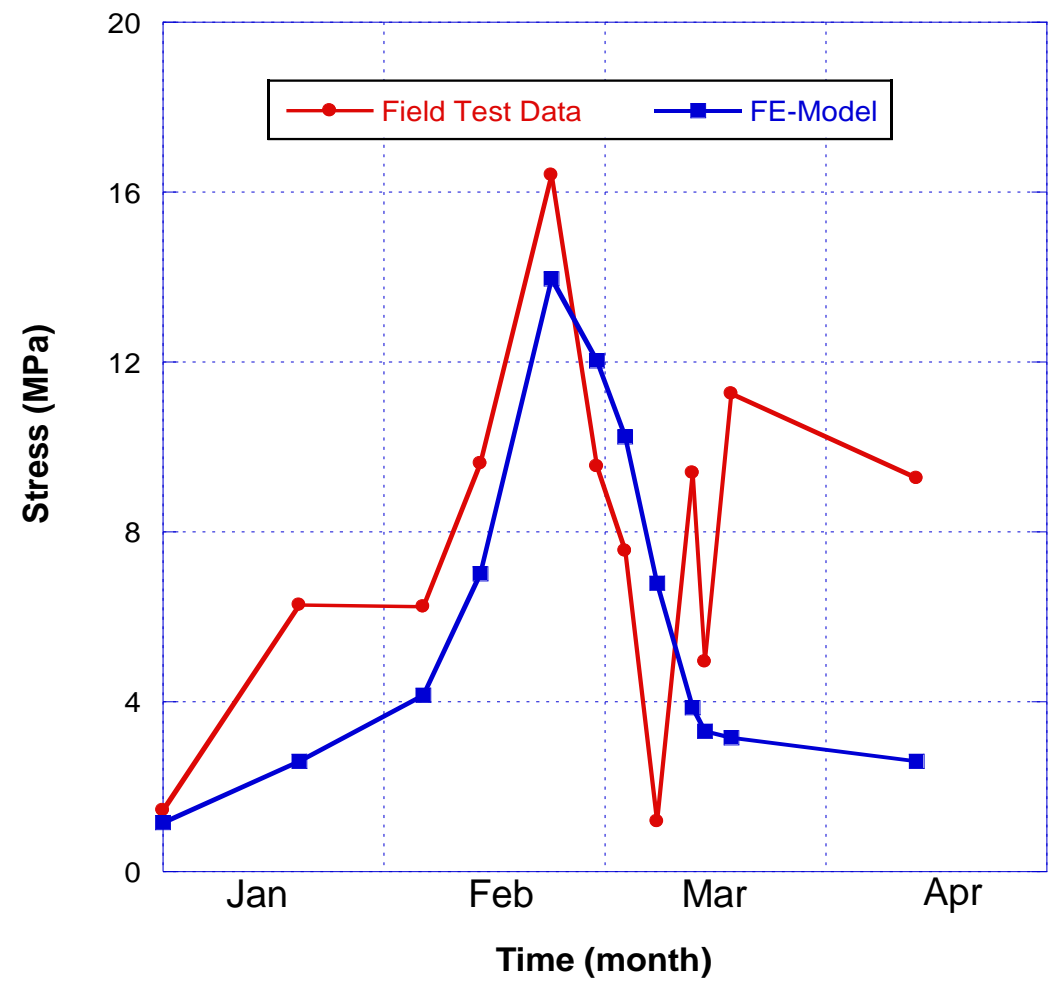

(b) N3

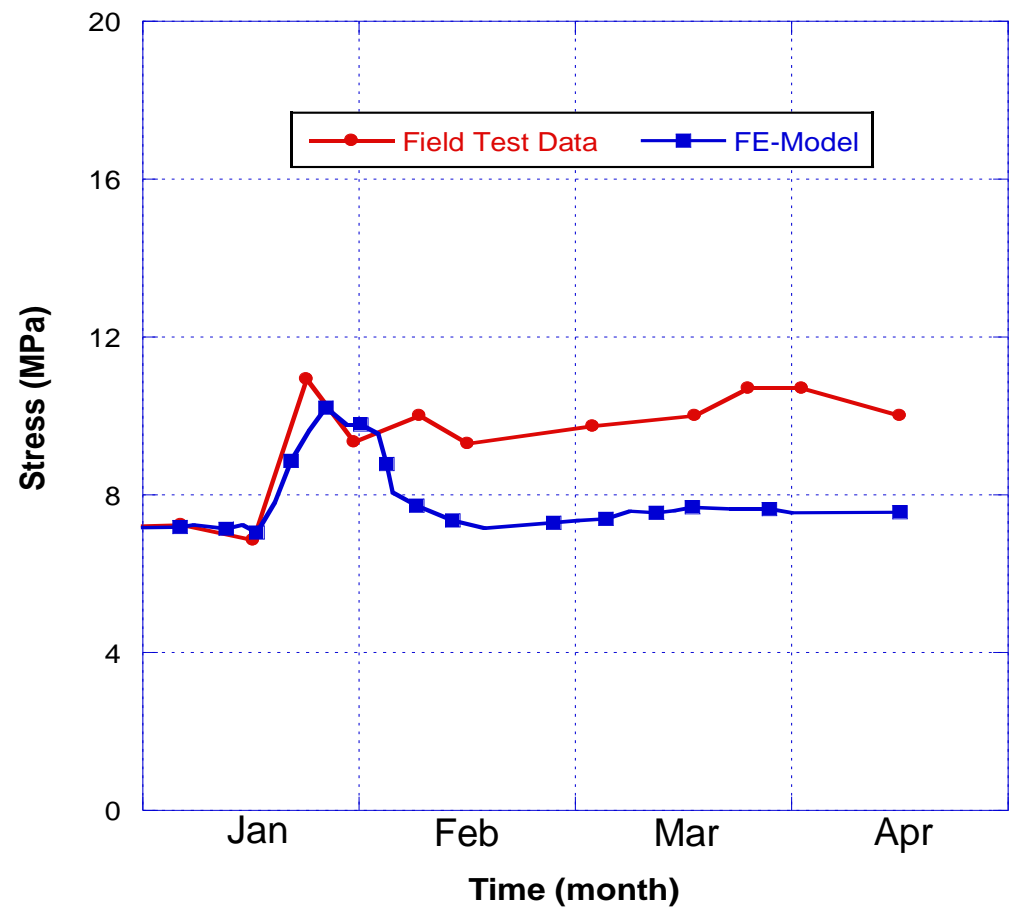

(C) $\mathrm{N} 4$

Figure 3-11 Comparison of thermally induced stresses with time on nails between finite element model and field measurement 
The earth pressure on the wall versus time due to heaving is presented in Figure 3-12 for both the FE analysis and field test data. During the cold season, the maximum heaving pressure on the nailed soil wall is observed around $0.005 \mathrm{MPa}$ and it occurs during the period of deepest frost penetration time.

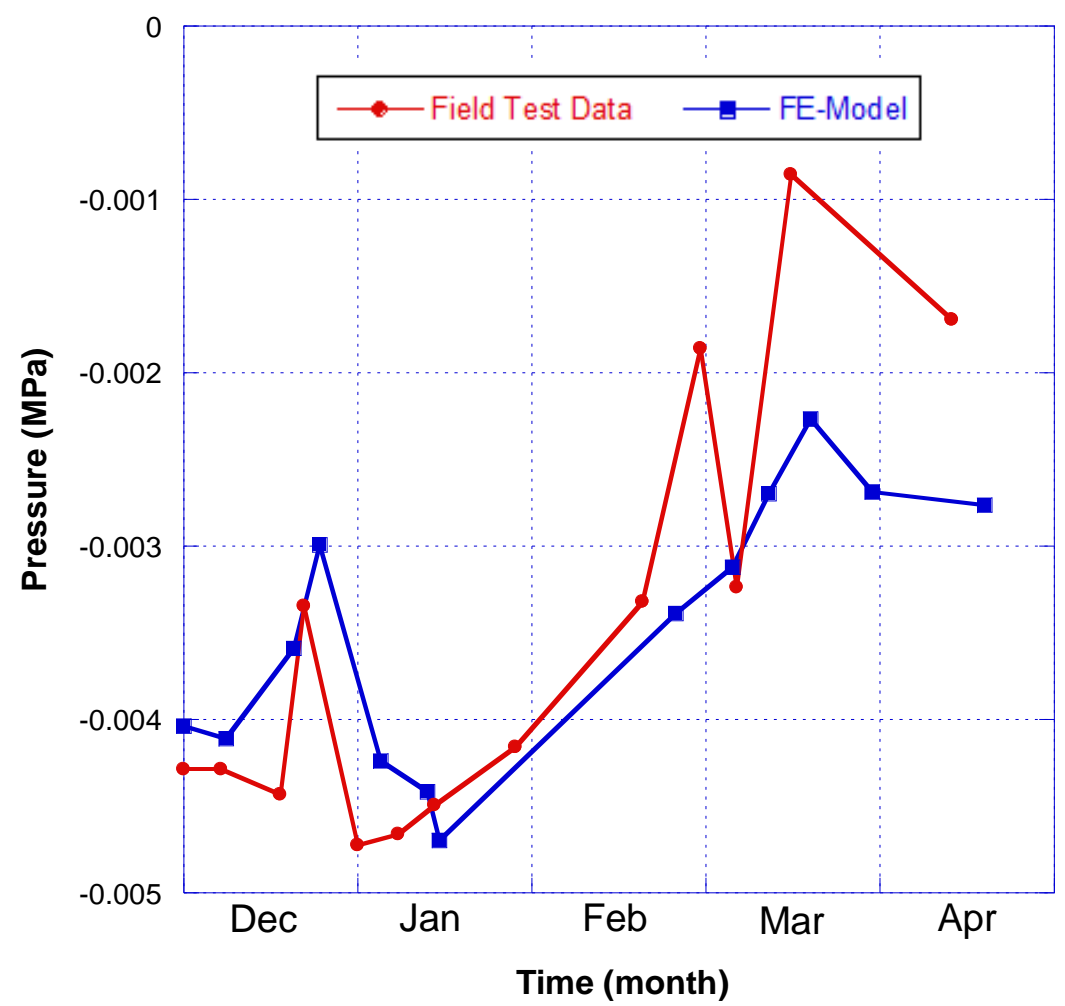

Figure 3-12 Comparison of the heaving pressure on wall versus time

Figure 3-13 shows the horizontal displacement profile of the wall, when ambient temperature reaches its lowest value and freezing front propagates to about $1.5 \mathrm{~m}$ into the ground. It is apparent that the wall movement closely corresponds to the seasonal temperature change. The maximum wall movement is around $0.02 \mathrm{~m}$, which is enough to mobilize the nail tension. Frost pressure at the top of the wall results in a negative displacement to the left, which consequently leads to the compression of the soil and a positive movements to the right at the lower portion of the wall. 

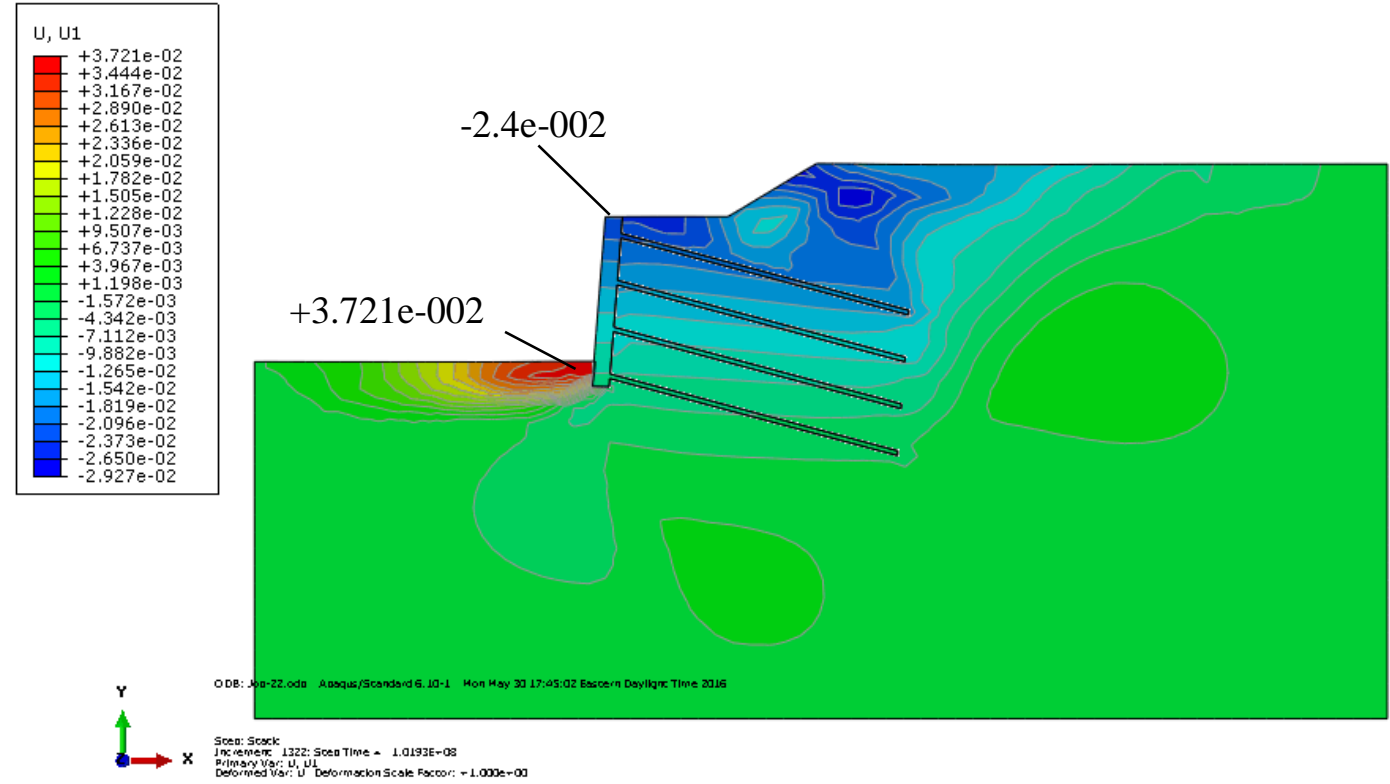

Figure 3-13 Horizontal displacement profile of the soil nail wall in Maine, U.S.

Vertical displacement profile of the SNW caused by the frost heave of the surrounding frost susceptible soil is shown in Figure 3-14, when temperature reaches to its lowest value. The heaving on the top of embankment away from the nailed wall is about $0.015 \mathrm{~m}$, though it is smaller than the vertical displacement of the wall due to applied surcharge load on the top of embankment. The frost heave force pushes the wall down by about $0.02 \mathrm{~m}$, and as a consequence the soil beneath the toe of the wall is compressed.

Due to the fact that there are no instrumentations installed for wall movement in Maine, no comparison could be made for the wall movement due to thermal loading. 


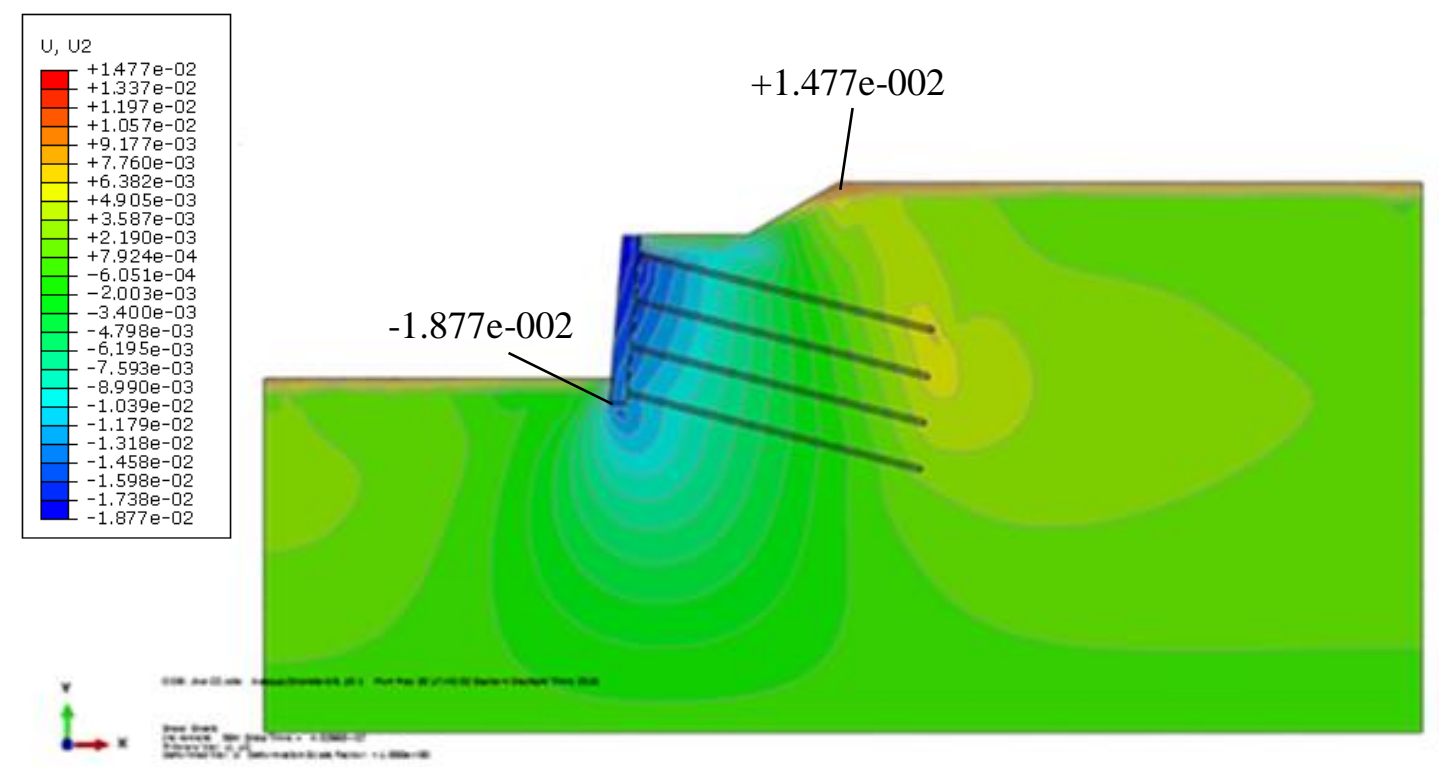

Figure 3-14 Vertical displacement profile of the soil nail wall in Maine, U.S.

The FE simulation yielded reasonable results and correlates well with the field measurements of thermal stresses along the nails as well as heaving pressure on the wall. 


\section{Chapter 4 : Mitigation Measures-Parametric Study}

\subsection{Introduction}

Earth structures, such as embankments and slopes, and earth retaining walls, is commonly used in cold regions for transportation and other applications. In addition to typical design considerations for earth structures at normal temperature, a design must also consider the unique problems associated with freezing temperature, such as frost heave, thaw settlement, lateral expansion, and degradation of material properties. SNWs are always susceptible to frost effects because of the exposed facing. Therefore, construction of SNWs in cold regions with frost susceptible soils would require extra attention and frost protection measures due to detrimental frost effects.

In order to address the frost damage, and the beneficial effect of the insulation during cold seasons, a model is developed using FE software, ABAQUS. ABAQUS provides user the ability to analyze two-dimensional transient heat flow problems with time-dependent boundary conditions, and temperature-dependent boundary conditions. Additionally, the software is capable of simulating the material thermal conductivity as a function of temperature. It also takes into consideration the latent heat of fusion, and changes in heat capacity and thermal conductivity associated with state of water.

After verification of the FE model based on the measured field test results in Maine, the modeling technique proved to be effective in predicting the performance of SNW subjected to freezing and thawing cycle. Therefore, the validated model is utilized to investigate the effect of mitigation measures on the behavior of SNW in cold weather climates and frost susceptible soils.

The application of following measures are studied on mitigating frost damage to SNWs: application of facial insulation, and lightweight foam concrete (LFC) as a facing material. For each method, the results are developed from SNW in terms of frost penetration, thermally induced stress on the nails, heaving pressure on the wall, and wall displacement. The investigation results in a series of conclusions with respect to the effects of frost action on the behavior of SNW. These 
simulations are conducted on the SNW with the same geometry, material properties, and assumptions used in the previous chapter.

\subsection{Effects of Thermal Insulation}

Many SNWs is successfully implemented in non-frost susceptible soils and warm regions, however, their advantages may be utilized in cold regions as well. The challenge with the application of SNWs in cold regions would be the effect of freezing temperature on the behavior of the soil behind the wall. The soil, susceptible to freezing temperature may pose a damaging effect on the SNW behavior during cold seasons.

In addition to simulating a hypothetical uninsulated SNW subjected to freezing and thawing process, the influence of various insulation techniques on the SNW performance is also simulated and studied.

In one case, a $0.01 \mathrm{~m}$ thick layer of thermal insulation is simulated between the facing elements as illustrated in the Figure 4-1, whereas no insulation is placed at the top of the wall.

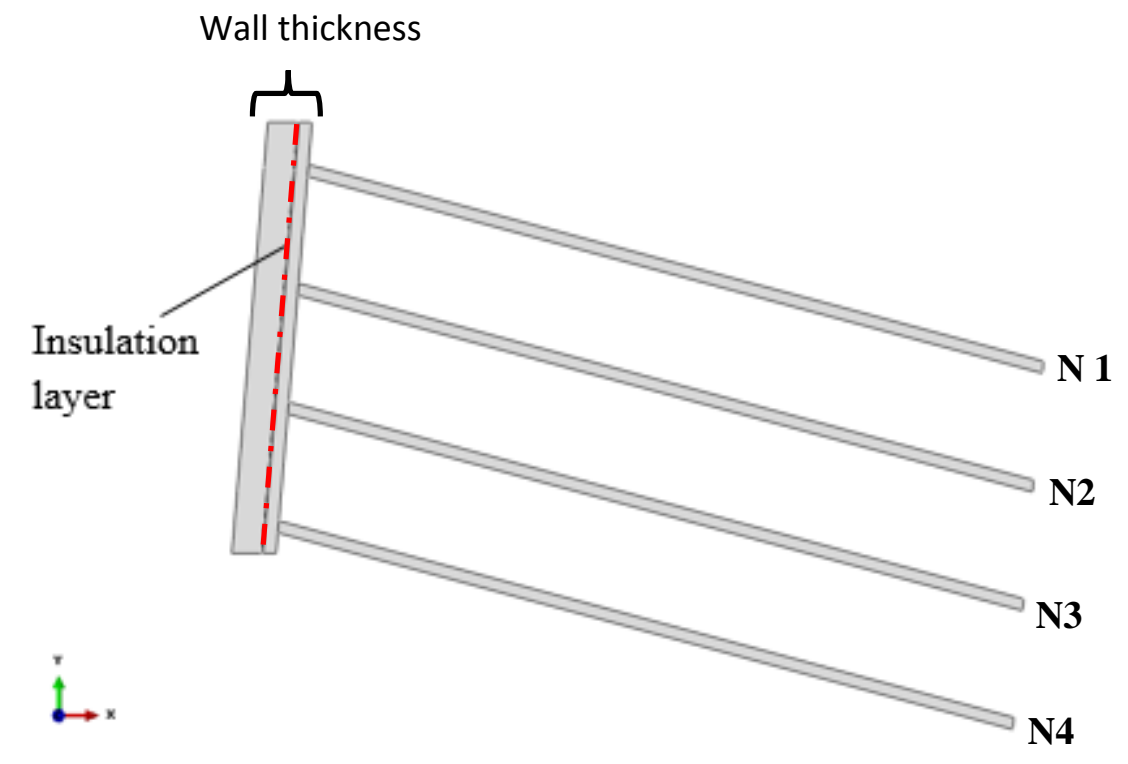

Figure 4-1 Insulation layer placement for the soil nail wall model 
LFC is a highly air entrained sand cement slurry or cement only slurry with greater than $20 \%$ air by volume. It is a lightweight, free-flowing, self-compacting, and highly insulating material. Application of LFC in the wall construction illustrates reasonable resistance to freezing-thawing exposure, and bearing capacity (Mydin, 2010).

The material properties of the thermal insulation layer (Zhang, 2014), and LFC are shown in Table 4-1.

Table 4-1 Material properties of insulation layer and LFC

\begin{tabular}{llllll}
\hline & Density & Heat & Thermal & Modulus of & Poisson \\
& $\boldsymbol{\rho}$ & $\begin{array}{l}\text { capacity c } \\
\text { conductivity } \mathbf{k} \\
\left(\mathrm{Kg} / \mathrm{m}^{3}\right)\end{array}$ & $\mathrm{J} /\left(\mathrm{Kg} .{ }^{\circ} \mathrm{C}\right)$ & $\begin{array}{l}\text { elasticity } \\
\left(\mathrm{W} / \mathrm{m} .{ }^{\circ} \mathrm{C}\right)\end{array}$ & $\begin{array}{l}\text { ratio } \\
(\mathrm{Pa})\end{array}$ \\
\hline $\begin{array}{l}\text { Insulation } \\
\text { layer }\end{array}$ & 50 & 2000 & 0.02 & $1.00 \mathrm{e}+7$ & $\mathbf{v}$ \\
LFC & 800 & 800 & 0.16 & $1.70 \mathrm{e}+9$ & 0.3 \\
\hline
\end{tabular}

\subsection{Performance of a Hypothetical Soil Nail Wall in Timmins, Ontario}

The FE model, which is validated in the previous chapter, is employed to examine the performance of a hypothetical SNW under the intensive temperature fluctuations in Northern Ontario, and to investigate the effectiveness of the different insulation techniques.

\subsubsection{Problem description}

The same model for the geometry and mesh, along with similar mechanical and thermal boundary conditions are adopted from previous chapter (shown in Figure 3-7 and 3-9). The total width of the model is $30.0 \mathrm{~m}$, and the total height is $16.0 \mathrm{~m}$. The FE model is created large enough to prohibit the influence of the boundary conditions on the displacements, and the heat transfer in the 
vicinity of SNW. Therefore, horizontal displacements are not allowed along lateral sides, and the bottom is considered fixed both horizontally, and vertically. In terms of thermal boundary conditions, thermal energy is not allowed to flow across the two vertical sides.

The only difference is the temperature taken for Timmins, Ontario. The monthly mean temperature is obtained from Canada weather database (Figure 4-2), which is used as the external thermal boundary conditions, whereas the temperature at the bottom is kept constant at $3{ }^{\circ} \mathrm{C}$.

Two different insulation measures are taken into consideration: a $0.01 \mathrm{~m}$ thick thermal insulation layer and LFC for the facial insulation. The material properties of the insulations are varied to simulate different situations ranging from thermally non-insulated to highly effective insulated SNW.

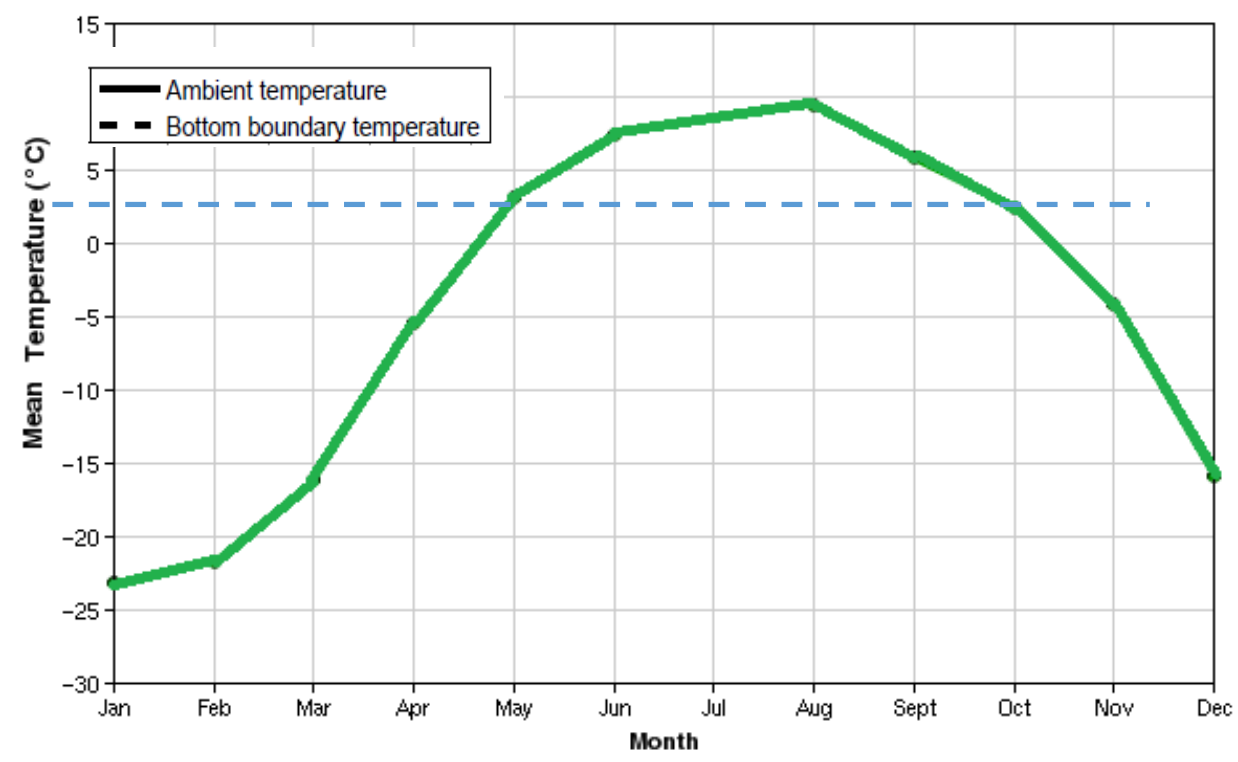

Figure 4-2 Thermal boundary conditions

\subsubsection{Results and Discussion}

The temperature profiles for the SNW with and without insulation are compared in Figure 4-3 and Figure 4-4 for cold and warm seasons over the course of one year. 
The freezing front propagates to about $2.0 \mathrm{~m}$ below the surface in the open ground. During the cold season, when the air temperature drops to its lowest value, the freezing front progresses further to about $2.2 \mathrm{~m}$ below the exposed surface of the embankment. The frost penetration in the open ground is almost similar for all developed SNW models irrespective of the present or absent of facial insulations. Although using facial insulation changes the thermal profile behind the wall, its influence on the freezing front, particularly for the open ground surface is observed to be negligible.

The freezing front also penetrates from the wall side into the soil. The soil nails exhibite slightly more temperature fluctuation and slightly deeper frost penetration in compare to the native soil between the nails. This is expected due to the higher thermal conductivity of the steel nail.

For the case without insulation system, the freezing front propagates to a maximum depth of roughly $4.0 \mathrm{~m}$ along the nails near the top of the wall (affected by bi-directional freezing from the uninsulated top and the front of the wall). On the other hand, for the walls with insulation systems, the frost front progresses into soil along the topmost nail slightly less in compare to the noninsulated wall. By referring to Figure 4-3 through Figure 4-5, it is concluded that the facial insulations have a negligible effect on the frost propagation along the upper rows of nails due to the uninsulated top of the wall.

For the walls with insulation system, the facial insulation prevents the freezing front penetration from the wall side; however the freezing front still progresses from the uninsulated top of the wall as shown in Figure 4-3 and 4-4. Hence, the insulation systems are effective in reducing the frost propagation by nearly $0.5 \mathrm{~m}$ along the nails at the lower wall area. Moreover, during the warm season, the insulation system plays a role in delaying the increase in temperature profile for the SNW. 


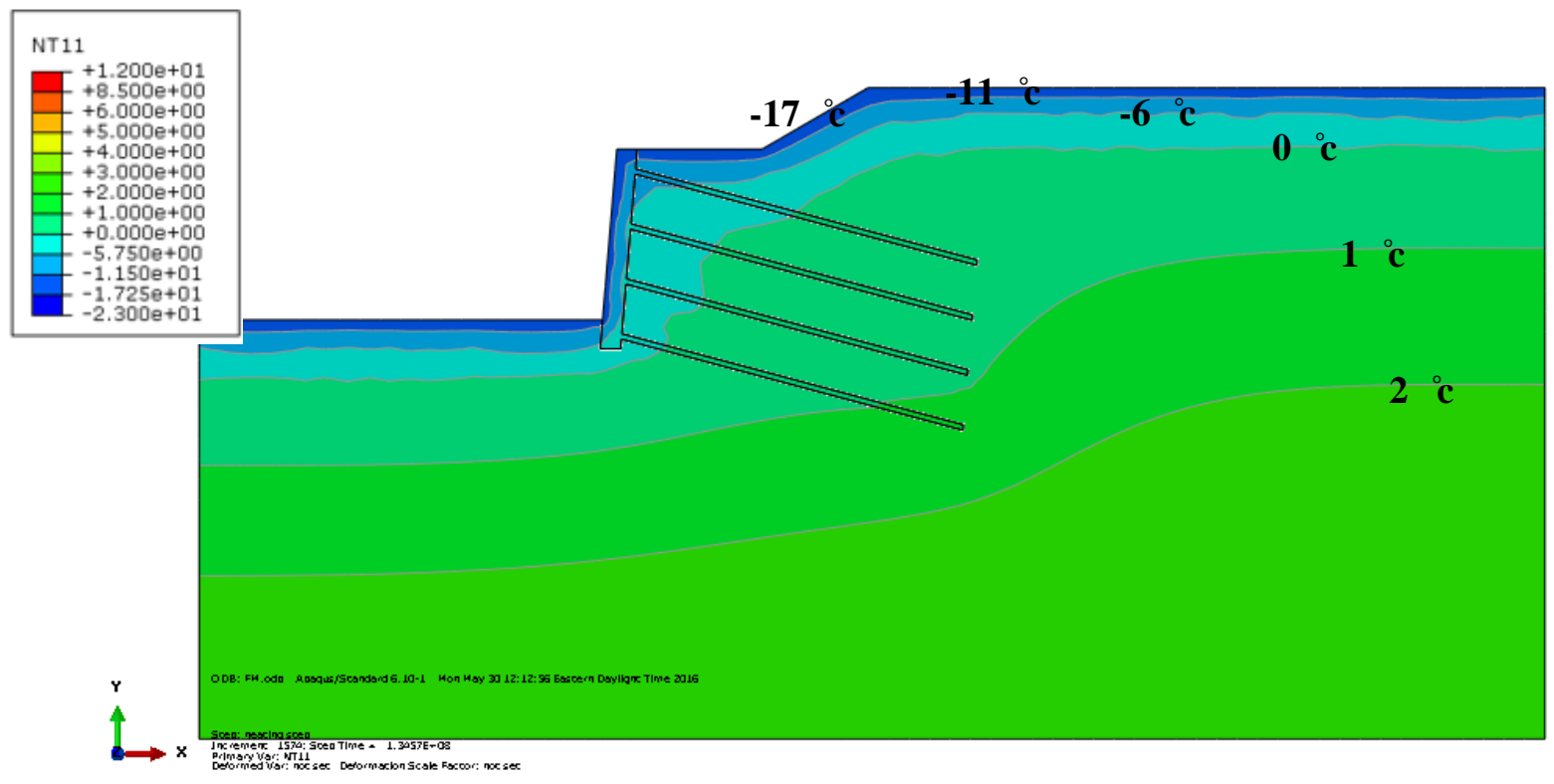

(a) Temperature distribution for cold season, non-insulated soil nail wall

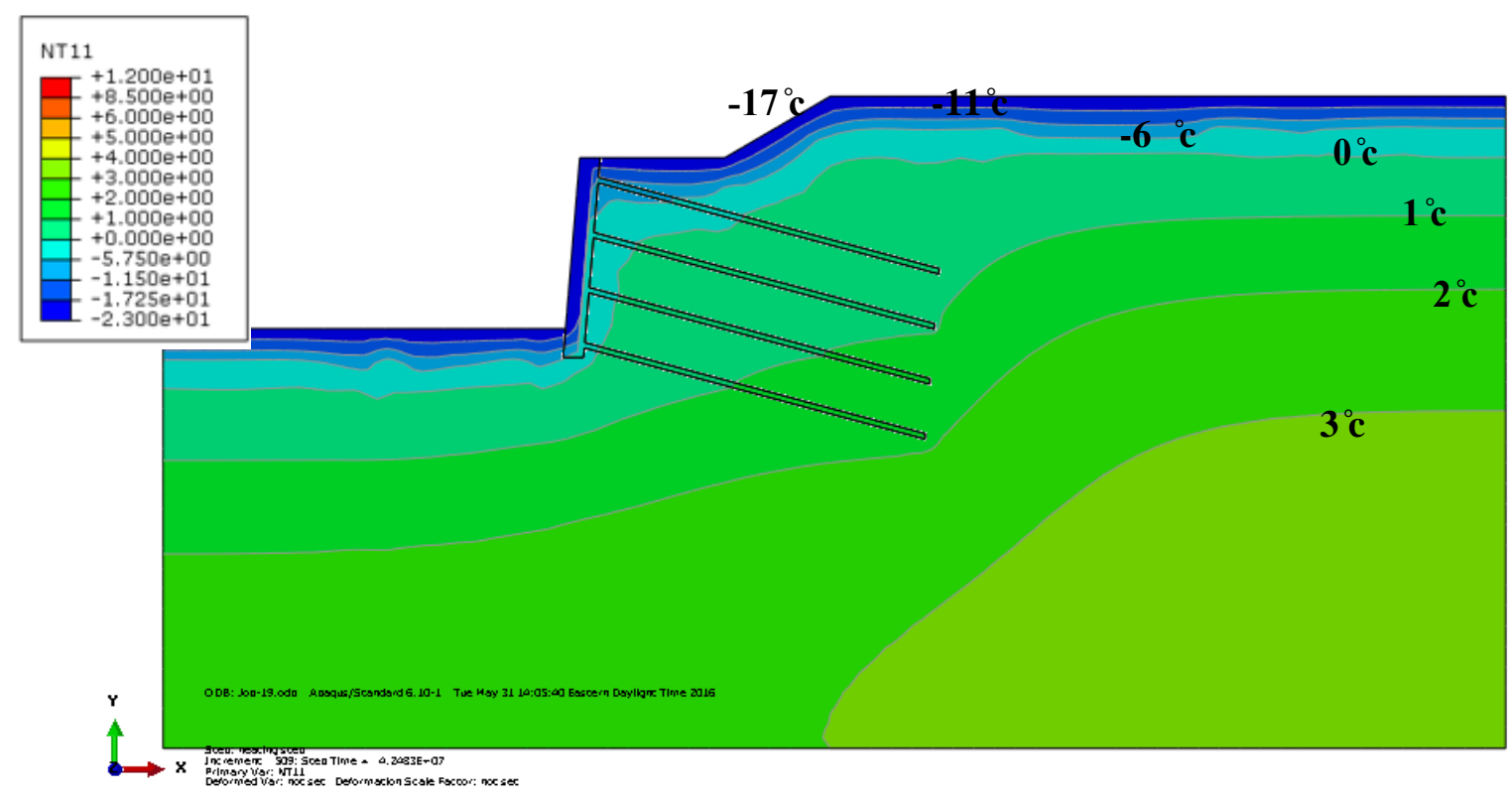

(b) Temperature distribution for cold season, insulated soil nail wall 


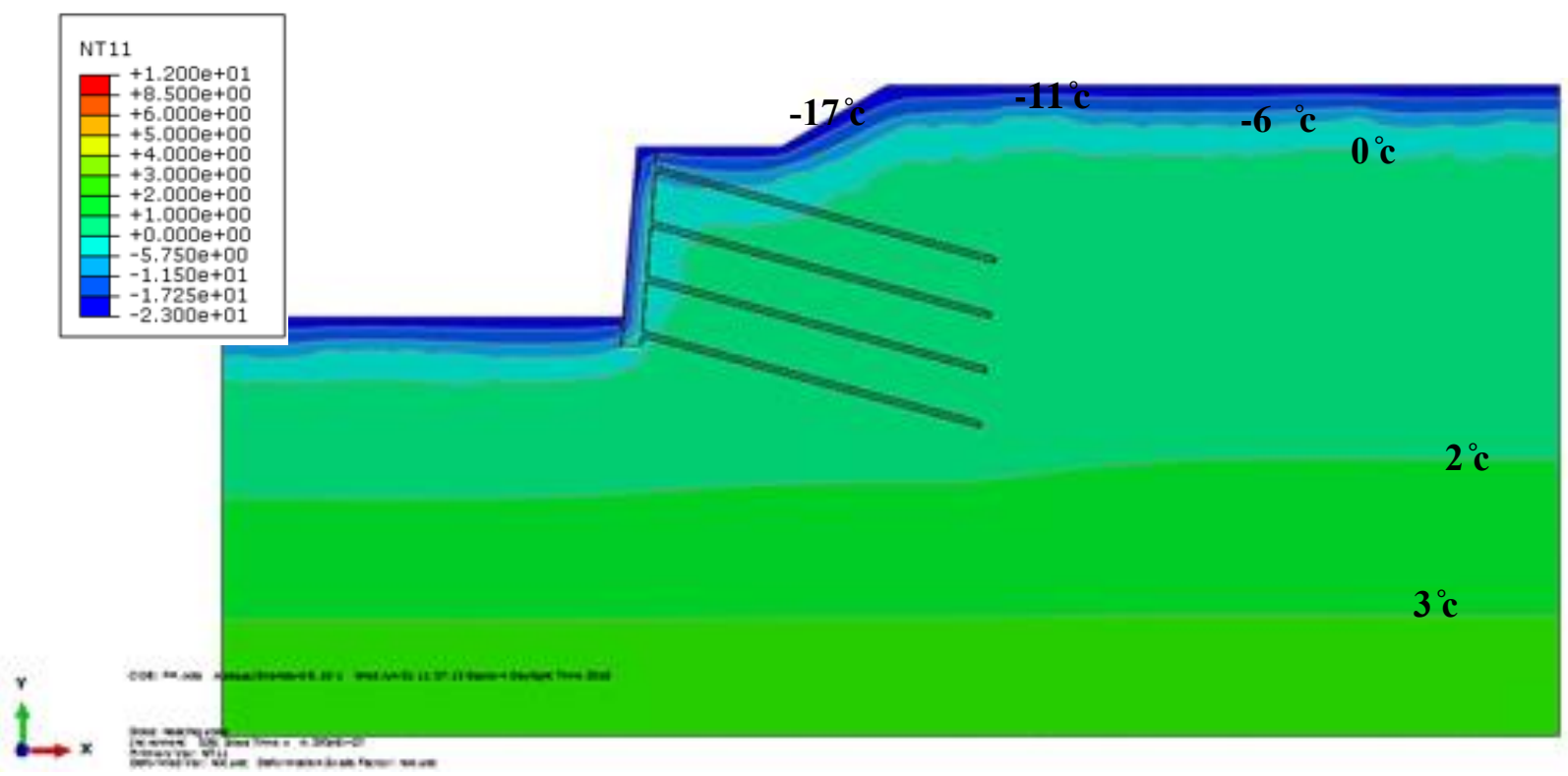

(c) Temperature distribution for cold season, insulated soil nail wall with LFC

Figure 4-3 Temperature distribution for cold season in Timmins, Ontario

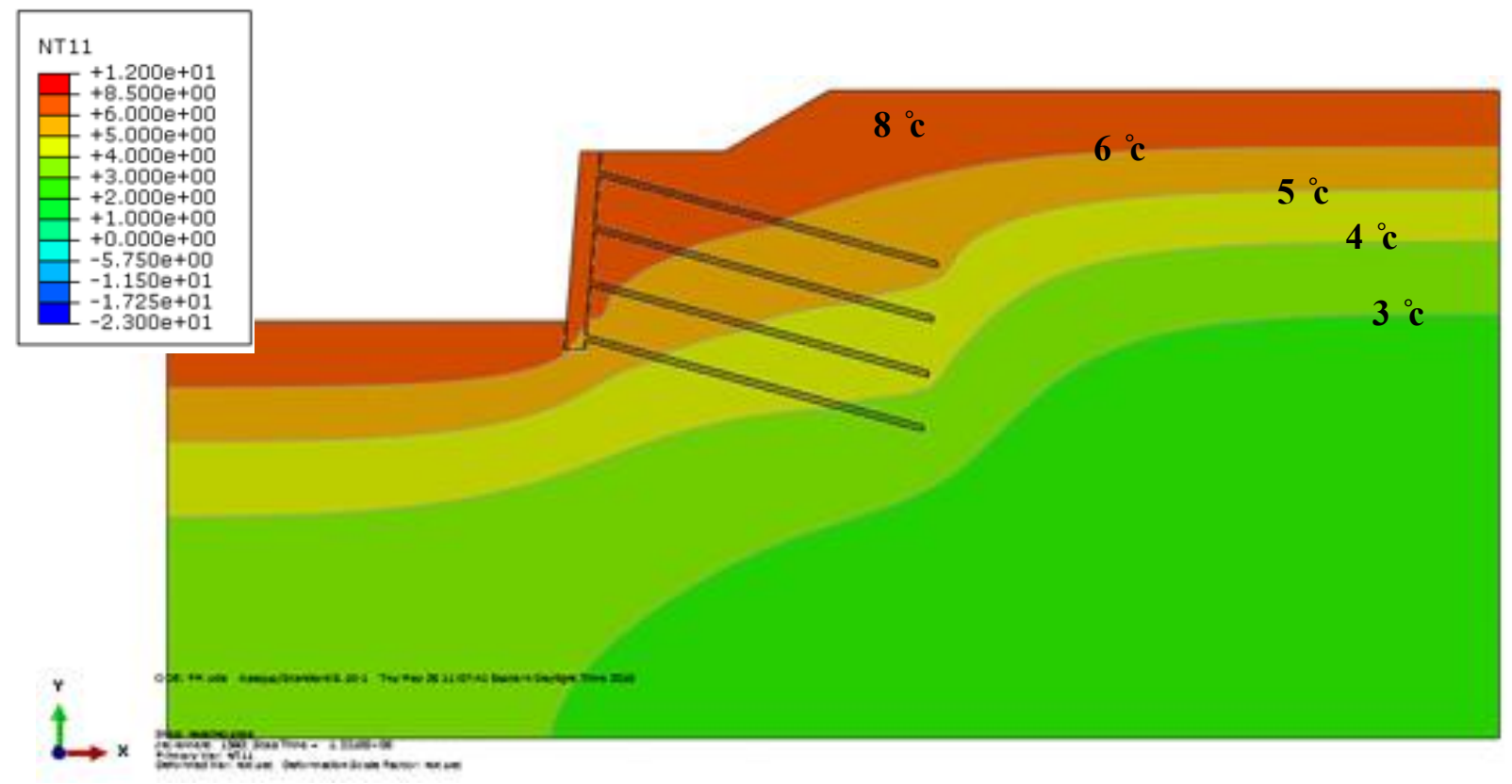

(a) Temperature distribution for warm season, non-insulated soil nail wall 


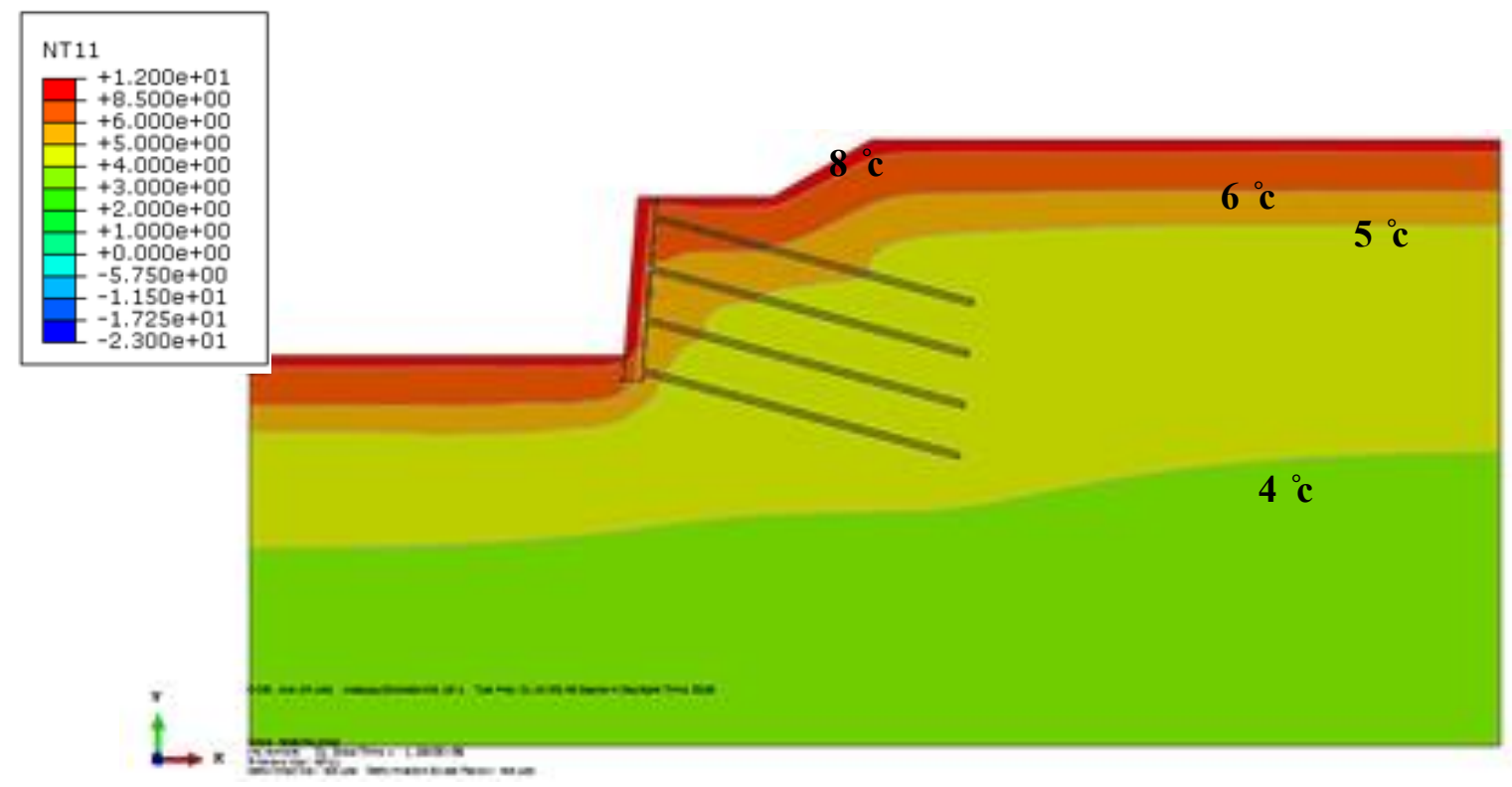

(b) Temperature distribution for warm season, insulated soil nail wall

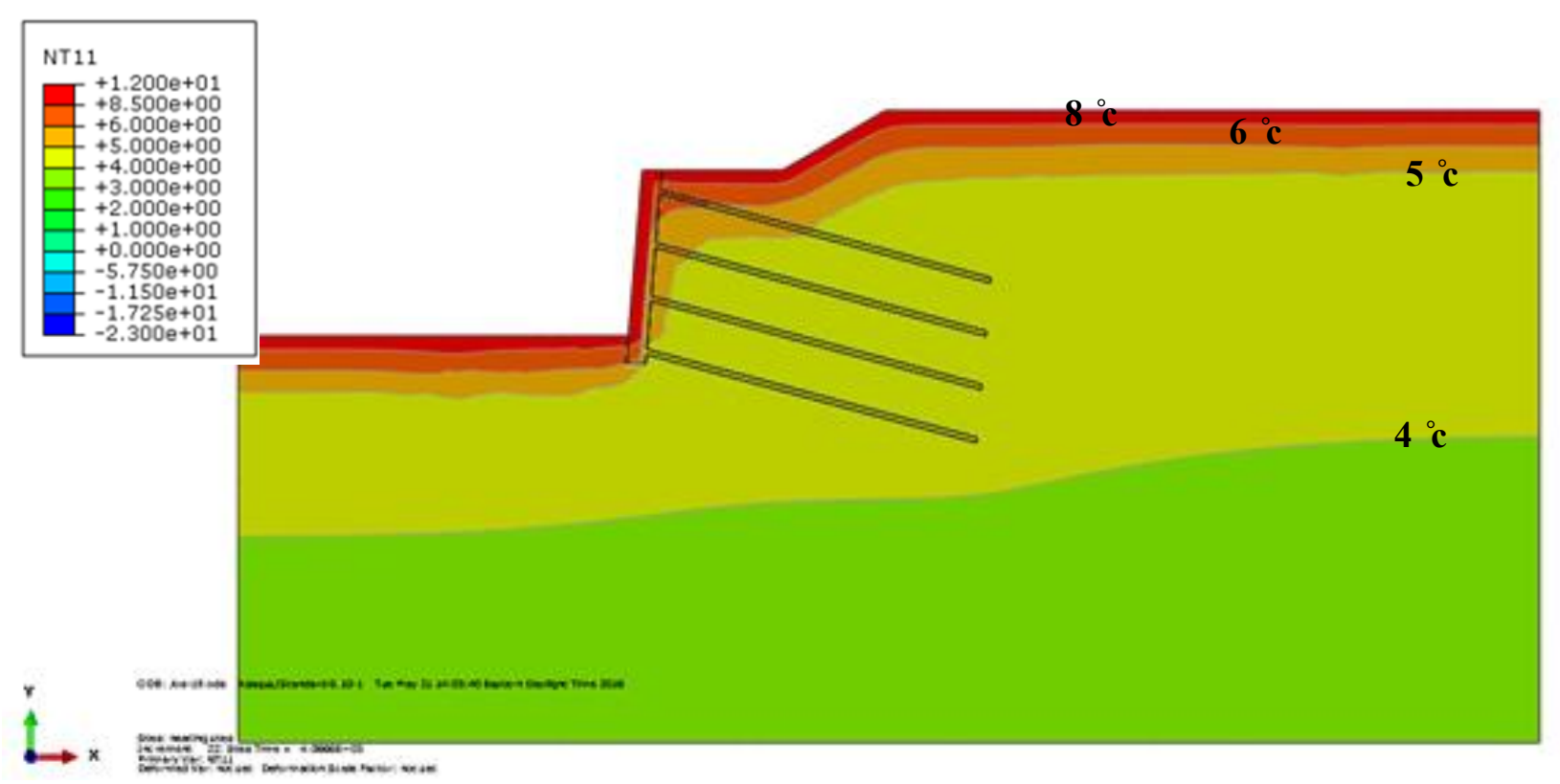

(c) Temperature distribution for warm season, insulated soil nail wall with LFC

Figure 4-4 Temperature distribution for warm season in Timmins, Ontario

The increase in the nail stresses and pressures on the wall are attributed to heaving force. The thermally induced stresses versus time along instrumented nails is presented in Figure 4-5 for the hypothetical insulated and non-insulated SNWs located in Timmins, Toronto. 
During the cold season, the highest thermally induced stress on instrumented nail is approximately $42 \mathrm{MPa}$, which occurs during the moment of the deepest frost penetration. The peak stress occurs in the nail located closest to the middle of the wall (N3). The stress increase in the N3 is slightly higher than the N2. A much lower increase in stress is found in the bottom nail (N4) compared to those in the nails in the middle of the wall.

Figure 4-5 (b) indicates that the insulation layer lowers the thermally induced stresses for nails N2, $\mathrm{N} 3$ and N4 by approximately 18\%, 14\% and 33\%, respectively. However, for the insulated wall with LFC material the thermally induced stresses for nails $\mathrm{N} 2, \mathrm{~N} 3$ and $\mathrm{N} 4$ is diminished by around 40\%, 22\% and 40\%, respectively as shown in Figure 4-5 (c). Therefore, it could be noted from Figures 4-5, that the insulation system reduces the effect of frost action over the nails by preventing frost from penetrating into the backfill.

The facial insulation has lowest influence over the nail stress near the top of the wall, since the facial insulation does nothing to impede frost front from the top surface.

The FE analysis results indicate that, as insulation system contributes to the overall reduction of frost propagation along the wall, colder weather induces deeper frost penetration from the top of the wall, which can considerably raise the stresses in nails within its frost front. However, the facial insulation shows its effectiveness for the nails at the lower part of the wall, as the results reveal that little stress increase occurs in nails during cold season, whereas for the non-insulated wall a large increase occurs in the stress for the topmost nails. 


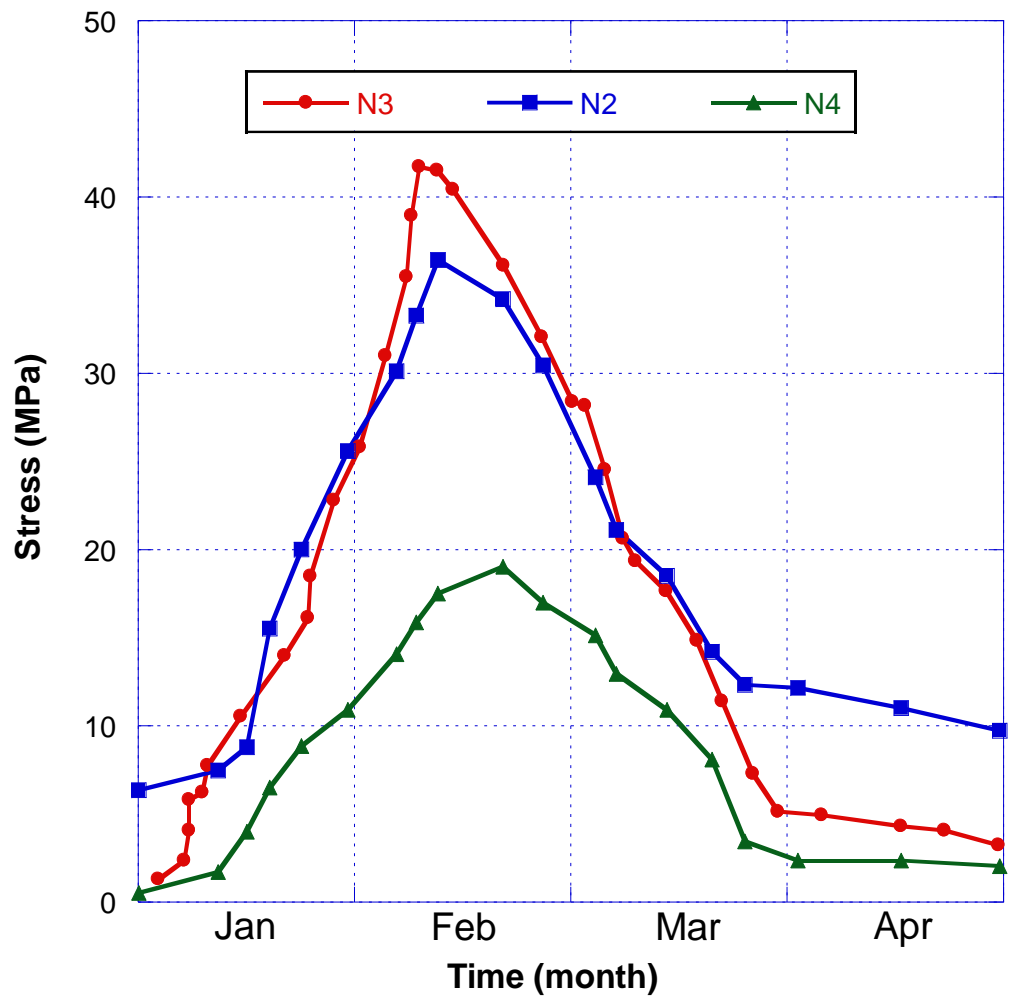

(a) Thermally induced stresses versus time for non-insulated SNW

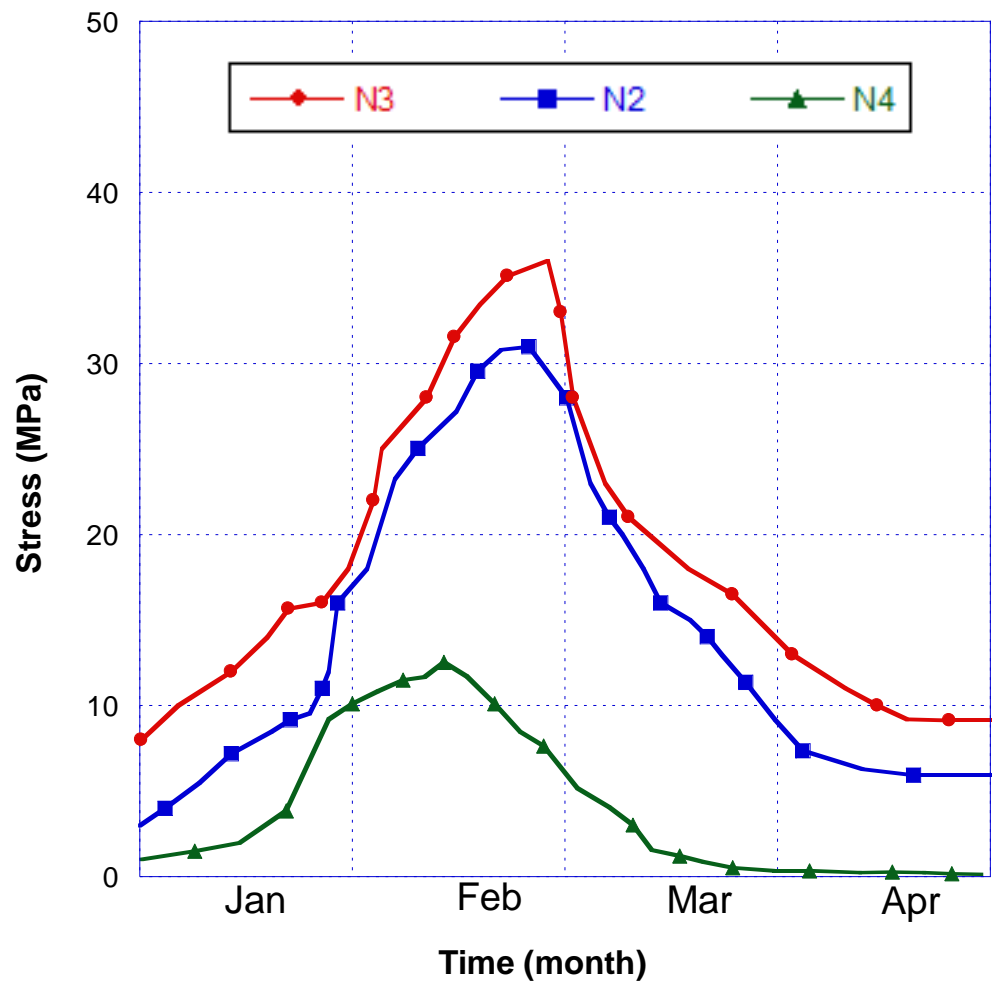

(b) Thermally induced stresses versus time for insulated soil nail wall 


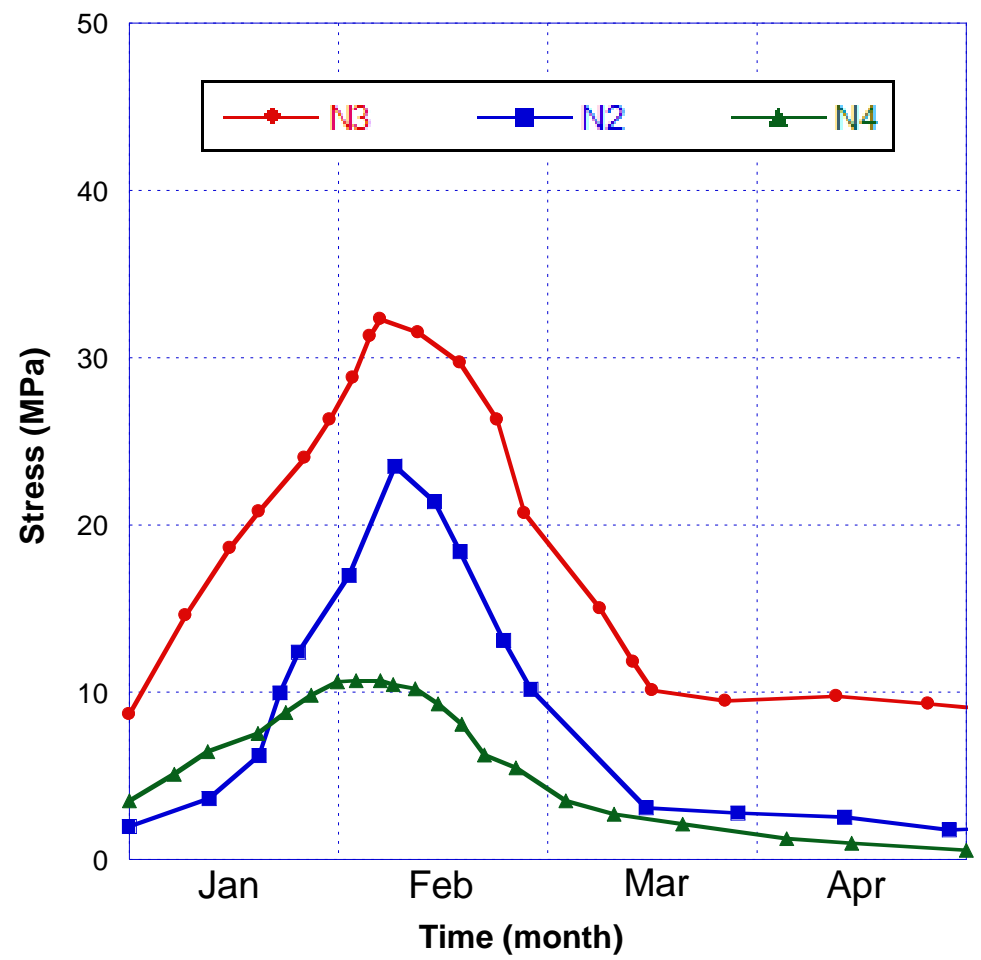

(c) Thermally induced stresses versus time for insulated soil nail wall with LFC

Figure 4-5 Thermally induced stress versus time for instrumented nails

The earth pressure on the wall versus time during heaving for the insulated and non-insulated SNW are compared in Figure 4-6. During the cold season, the maximum earth pressure increase on the wall is about $0.008 \mathrm{MPa}$, which occurs during the time of the deepest frost penetration.

The insulation systems are proved to be very efficient in reducing the earth pressure on the wall (Figure 4-6). With the insulation layer, the peak earth pressure on the wall, during the cold season is reduced by approximately $23 \%$. However, for the insulated SNW with the LFC, a reduction of about $29 \%$ is obtained from FE simulation. Hence, it could be concluded that using LFC material for facial insulation has a considerable effect on the pressure distribution on the wall, and frost heave prevention owing to delay in freezing frost penetration.

By end of April, the frost induced pressure on the wall has levelled off, indicating that the soil is thawing and shows no more reaction to temperature variation. The horizontal movement of the 
SNW caused by the heaving force is an important measure that resonates the intensity of frost action.

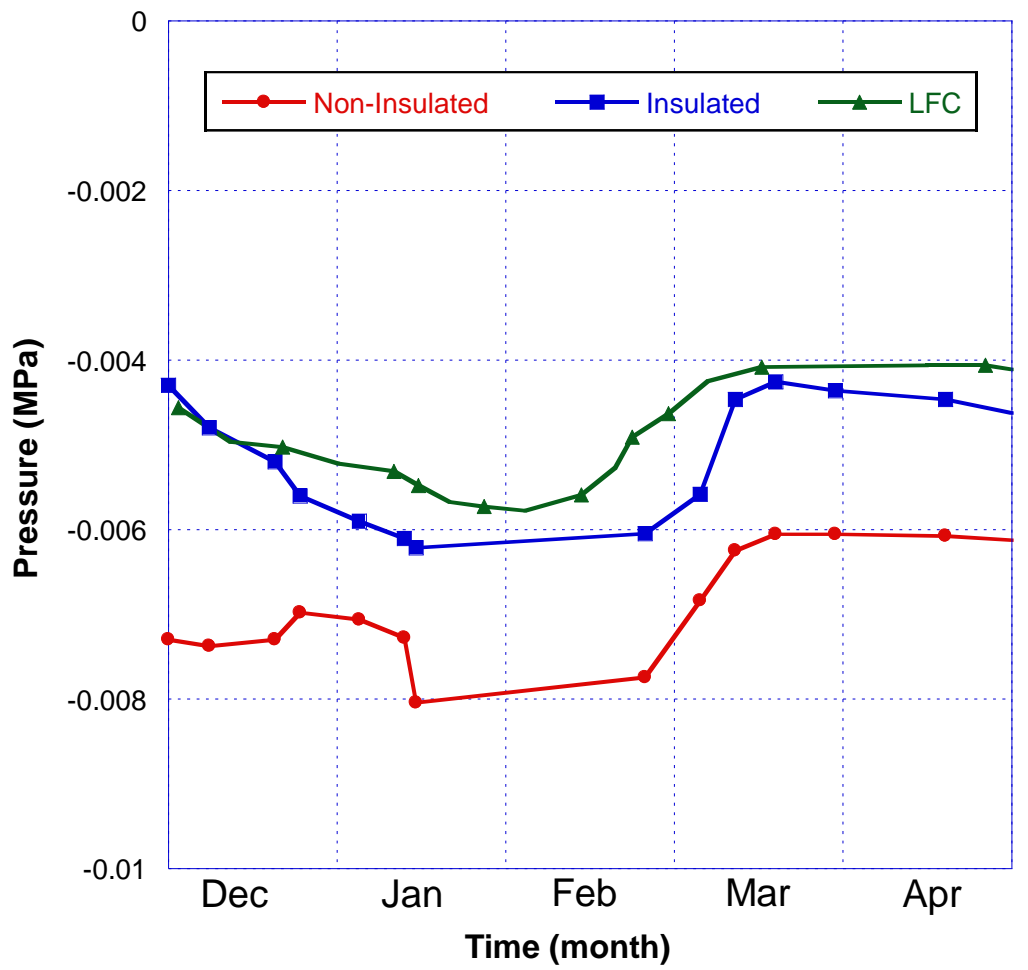

Figure 4-6 Lateral earth pressure increase on the wall versus time due to heaving

Heaving occurs in the direction of the heat flow. Along the facing, temperature profile propagates parallel to the wall, thus the heaving occurs horizontally. The facing element is an obstacle to heaving. Hence, the wall would move horizontally.

To investigate the influence of the insulation systems on the SNW in mitigating the wall movement, two cases are simulated: a $0.01 \mathrm{~m}$ thick facial insulation with thermal conductivity of $\mathrm{k}=0.02 \mathrm{~W} / \mathrm{m} .{ }^{\circ} \mathrm{C}$, and for the other case, $\mathrm{LFC}$ for wall facing with thermal conductivity of $\mathrm{k}=0.16$ $\mathrm{W} / \mathrm{m}$. ${ }^{\circ} \mathrm{C}$. The results of FE simulations are compared with the non-insulated wall as illustrated in Figure 4-7.

For the non-insulated wall, the horizontal displacement at the top of the wall occurs when the ambient temperature reaches its lowest value and the freezing front propagates to around $2.0 \mathrm{~m}$ during the cold season (Figure 4-7). It is apparent that heaving pressures develop during freezing 
weather, and the wall movement closely reflects the seasonal temperature variation. The maximum wall movement due to thermal loading is around $0.045 \mathrm{~m}$; approximately $1 \%$ of the wall height. This value is exceeding the normal range for the wall displacement, 0.2 to $0.3 \%$ of wall height, based on the survey by Juran and Elias (1987) on the performance of soil nailed wall in cold weather areas.

With the first facial insulation $\left(\mathrm{k}=0.02 \mathrm{~W} / \mathrm{m} .{ }^{\circ} \mathrm{C}\right)$, the peak horizontal wall displacements is reduced by nearly $28 \%$. When a more effective insulation ( $\mathrm{LFC}$ material with $\mathrm{k}=0.16 \mathrm{~W} / \mathrm{m}$. ${ }^{\circ} \mathrm{C}$ ) is utilized, the maximum outward movement drops by roughly $44 \%$.

The FE results denoted that the insulation systems are effective at reducing the wall displacement by limiting the frost progress behind the SNW; hence, the installation of insulation systems could significantly reduce the potential damage by frost force.

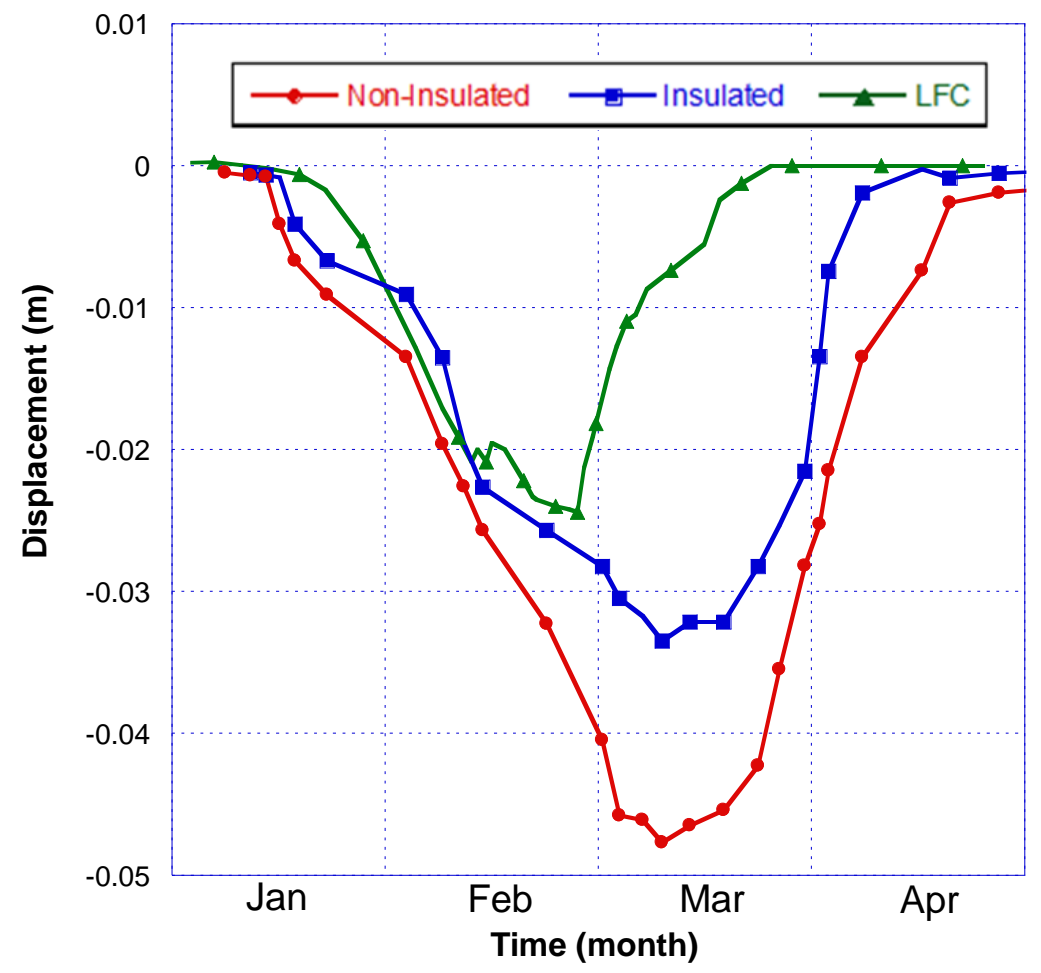

Figure 4-7 Horizontal displacement of a hypothetical soil nail wall in Timmins, Ontario (negative is to the left) 
The maximum horizontal displacements are found at the top of the wall. Vertical displacements of the wall are on the same order of magnitude as the horizontal movements measured at the top of the wall.

The effectiveness of the different insulation systems on the reduction of the vertical wall movement caused by the frost heave of the surrounding frost susceptible soil is studied. Insulation systems included: a facial insulation layer with the thermal conductivity of $\mathrm{k}=0.02 \mathrm{~W} / \mathrm{m} .{ }^{\circ} \mathrm{C}$ and, and the application of LFC for facial insulation with the thermal conductivity of $\mathrm{k}=0.16 \mathrm{~W} / \mathrm{m}$. ${ }^{\circ} \mathrm{C}$. The FE results of the comparison for the insulated, and non-insulated SNW are presented in Figure 4-8.

For the non-insulated wall, the vertical displacement of the wall occurs when the ambient temperature reaches its lowest value and the freezing front propagates to around $2.0 \mathrm{~m}$ during the cold season (Figure 4-8). The growth of ice lenses causes the wall to displace downward by about $0.05 \mathrm{~m}$ and tilt. With the thermal insulation layer, the peak vertical wall displacement is reduced by approximately $27 \%$. However, for the wall constructed with LFC, the maximum vertical movement is reduced by roughly $38 \%$.

The FE results indicated that the insulation systems are effective at decreasing the wall displacement by slowing down the frost progress behind the SNW.

The wall displacement profiles for a non-insulated hypothetical SNW in Timmins and Toronto are illustrated as an example in the annex. 


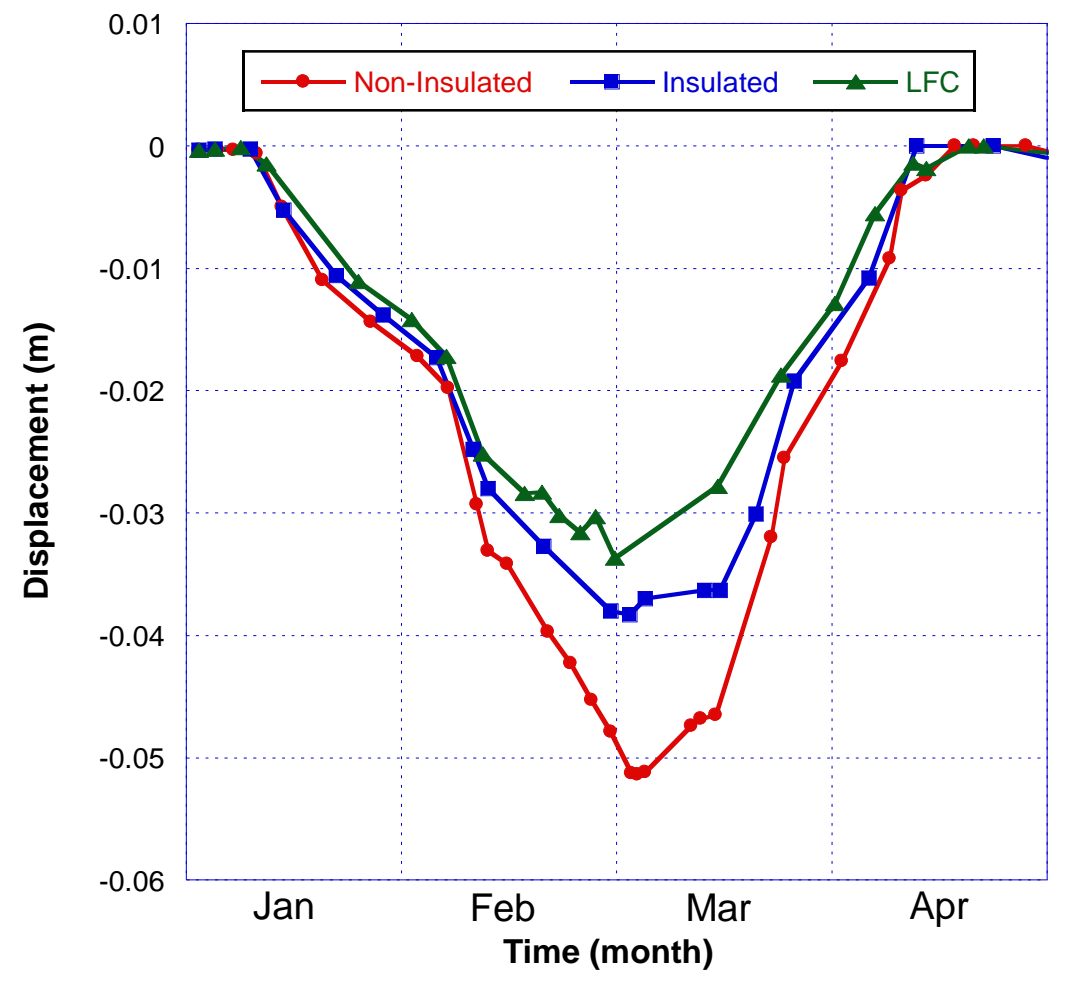

Figure 4-8 Vertical displacement of a hypothetical soil nail wall in Timmins, Ontario

The effects of freezing conditions on the performance of a SNW are successfully simulated using the FE model. The SNW displacements, caused by the frost force are tracked in the analyses. In addition, the effectiveness of the various mitigation measures is investigated. 


\subsection{Performance of a Hypothetical Soil Nail Wall in Toronto, Ontario}

\subsubsection{Problem Description}

In this section, the effects of freezing condition on the performance of a hypothetical SNW are examined for Toronto, Ontario. Similar to the previous example, all the variables are kept constant except the implementation of ambient temperature for Toronto, Ontario. The monthly mean temperature is obtained from Canada Weather Database (Figure 4-9), which is used as the thermal boundary condition, while the temperature at the bottom is kept steady at $3{ }^{\circ} \mathrm{C}$.

Two different insulation measures are taken into consideration: a thermal insulation layer and LFC for the facial insulation. The material properties of the insulations are varied to study different situations ranging from thermally non-insulated to highly effective insulated SNW.

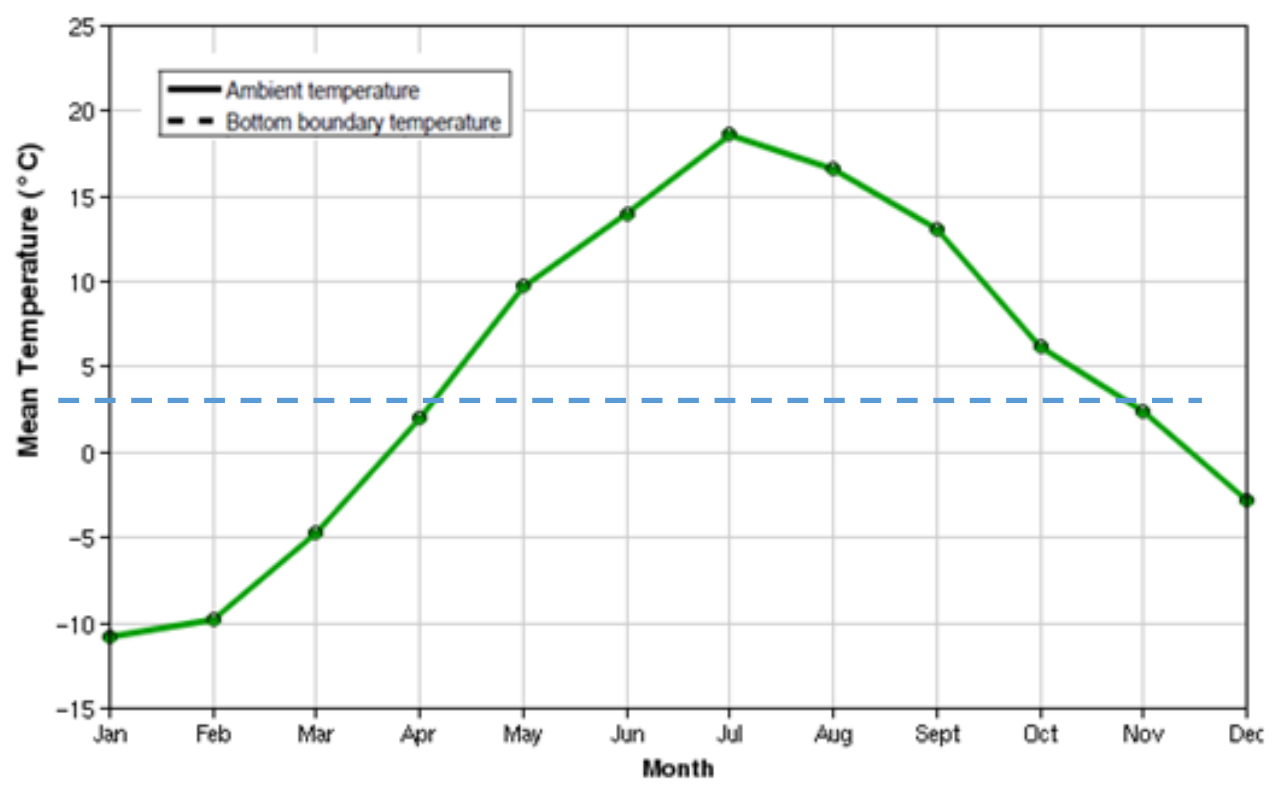

Figure 4-9 Thermal boundary conditions for a soil nail wall in Toronto, ON 


\subsubsection{Results and Discussion}

The temperature contours for the SNW with and without insulation are compared in Figure 4-10 through Figure 4-11 for cold and warm seasons.

The freezing front propagates to about $1.0 \mathrm{~m}$ below the surface far from the non-insulated hypothetical SNW in Toronto, ON. During the cold season, when the air temperature drops to its lowest value, the frost front penetrates further to about $1.2 \mathrm{~m}$ below the exposed surface of the embankment.

The frost penetration in the open ground is about the same for the all developed SNW models, with and without facial insulations, as no insulation is applied for the top surface.

By utilizing the insulation system, the thermal profile behind the wall would change. However, its influence on the freezing front progress, from the open surface is negligible.

For the case without insulation system, the freezing front propagates to a maximum of $2.0 \mathrm{~m}$ along the topmost nails near the top of the wall due to a two-way freezing front from the uninsulated top and the front of the wall, though for the walls with insulation systems, the frost front progresses into soil along the topmost nail slightly less. By referring to Figure 4-10 and 4-11, it can be concluded that the facial insulations have a negligible effect on the frost propagation along the upper rows of nails, because of uninsulated top of the wall.

The effectiveness of the insulation systems could be observed in Figure 4-10. For the case with thermal insulation layer, the frost propagation decreases to nearly $0.5 \mathrm{~m}$ along the nails at the lower wall area, whereas for the insulated wall with LFC, the freezing front propagates just past the facial insulation at the lower wall area.

As the warm season approaches and the air temperature reached its highest value, the ground is completely thawed. However, the facial insulation plays a role in delaying the increase in temperature for the insulated SNW during the warm season. 


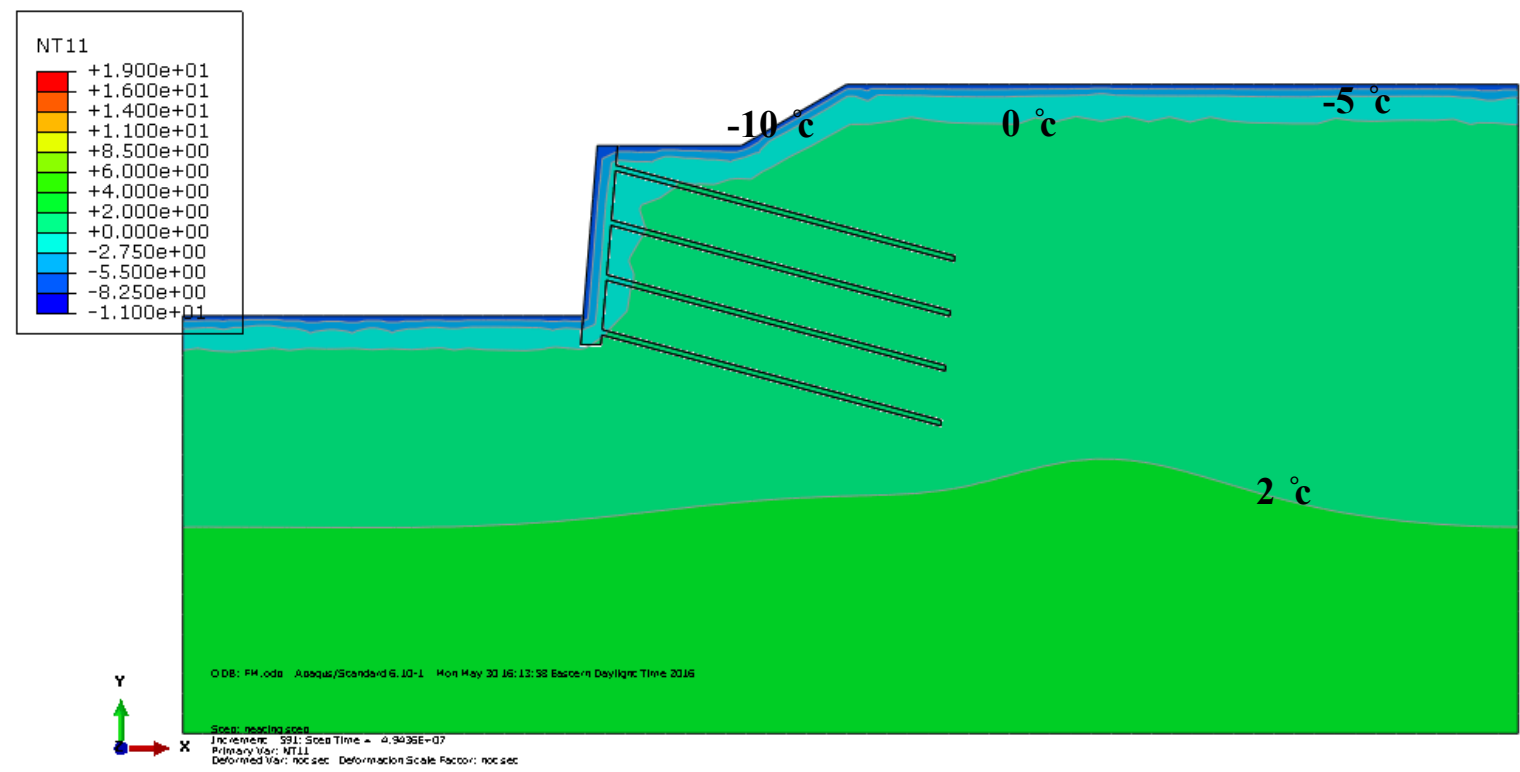

(a) Temperature distribution for cold season, non-insulated soil nail wall

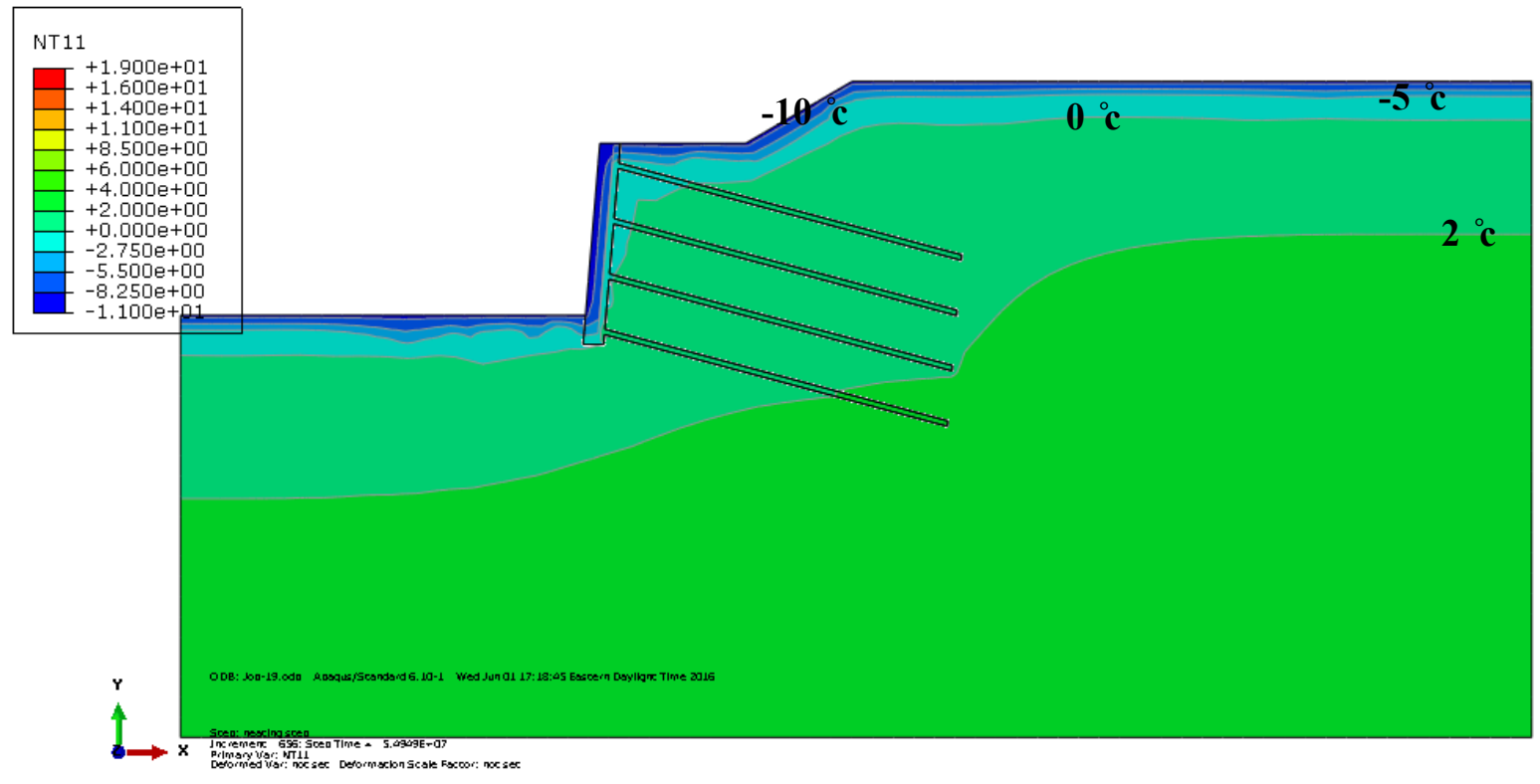

(b) Temperature distribution for cold season, insulated soil nail wall 


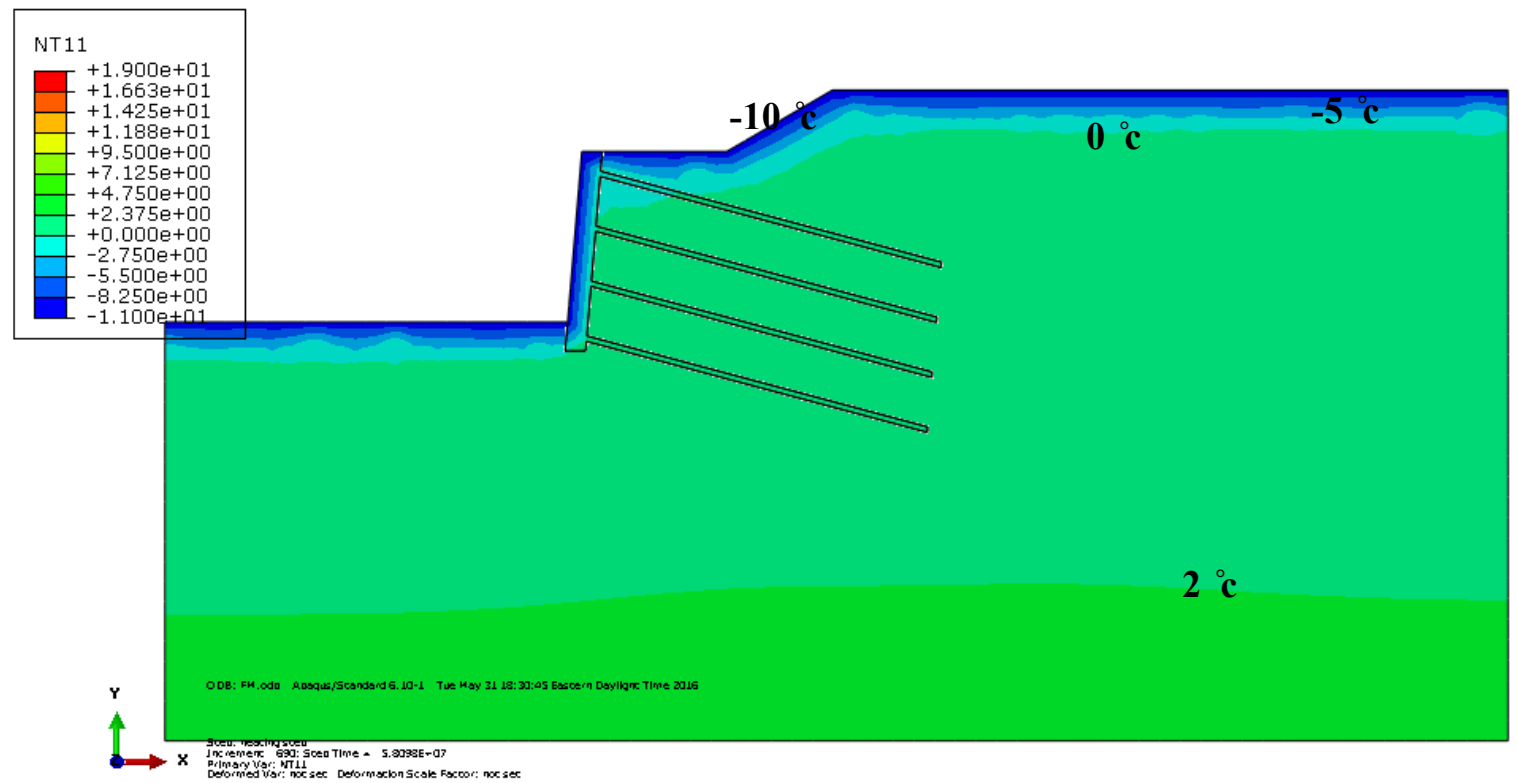

(c) Temperature distribution for cold season, insulated soil nail wall with LFC Figure 4-10 Temperature distribution for cold season in Toronto, ON

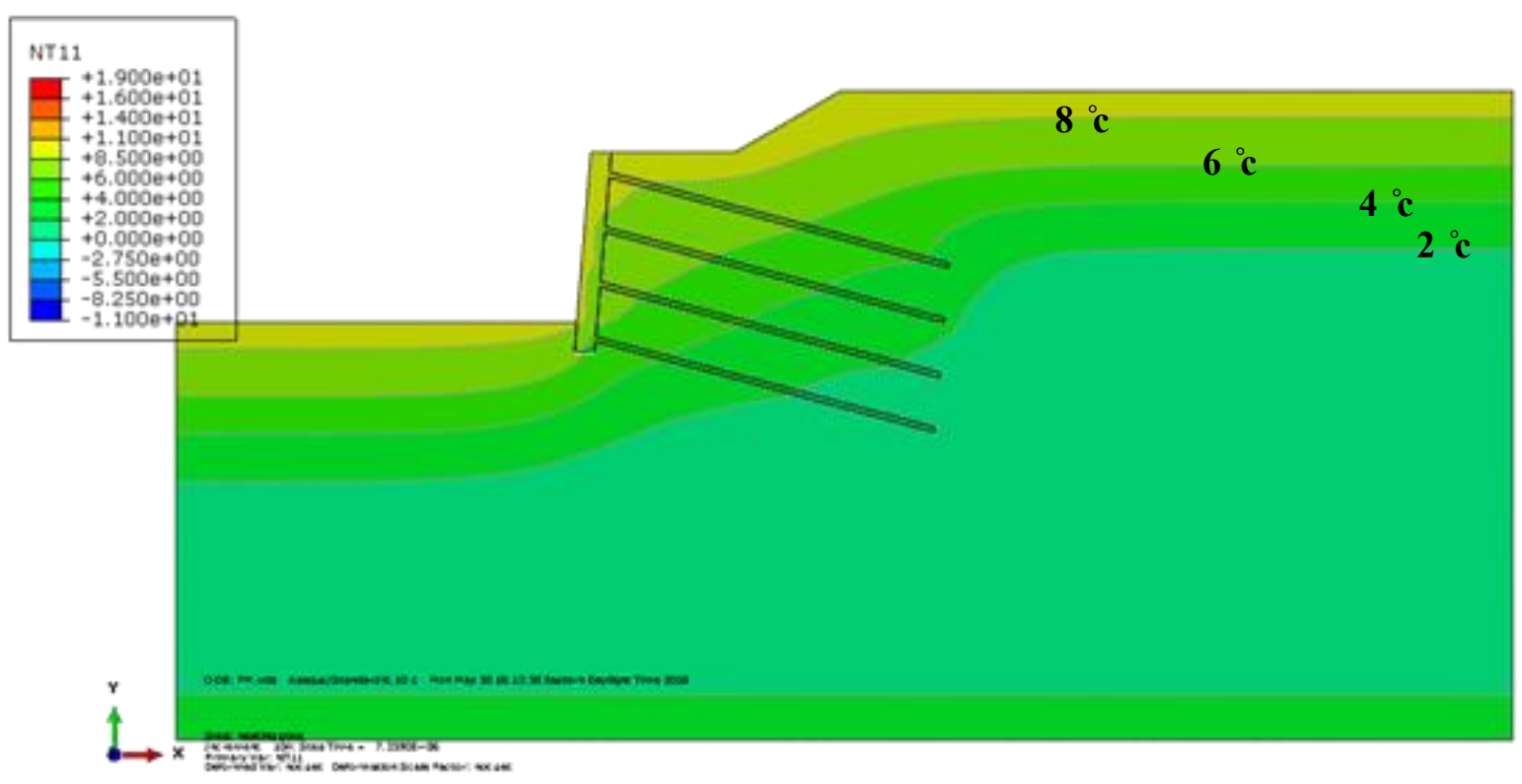

(a) Temperature distribution for warm season, non-insulated soil nail wall 


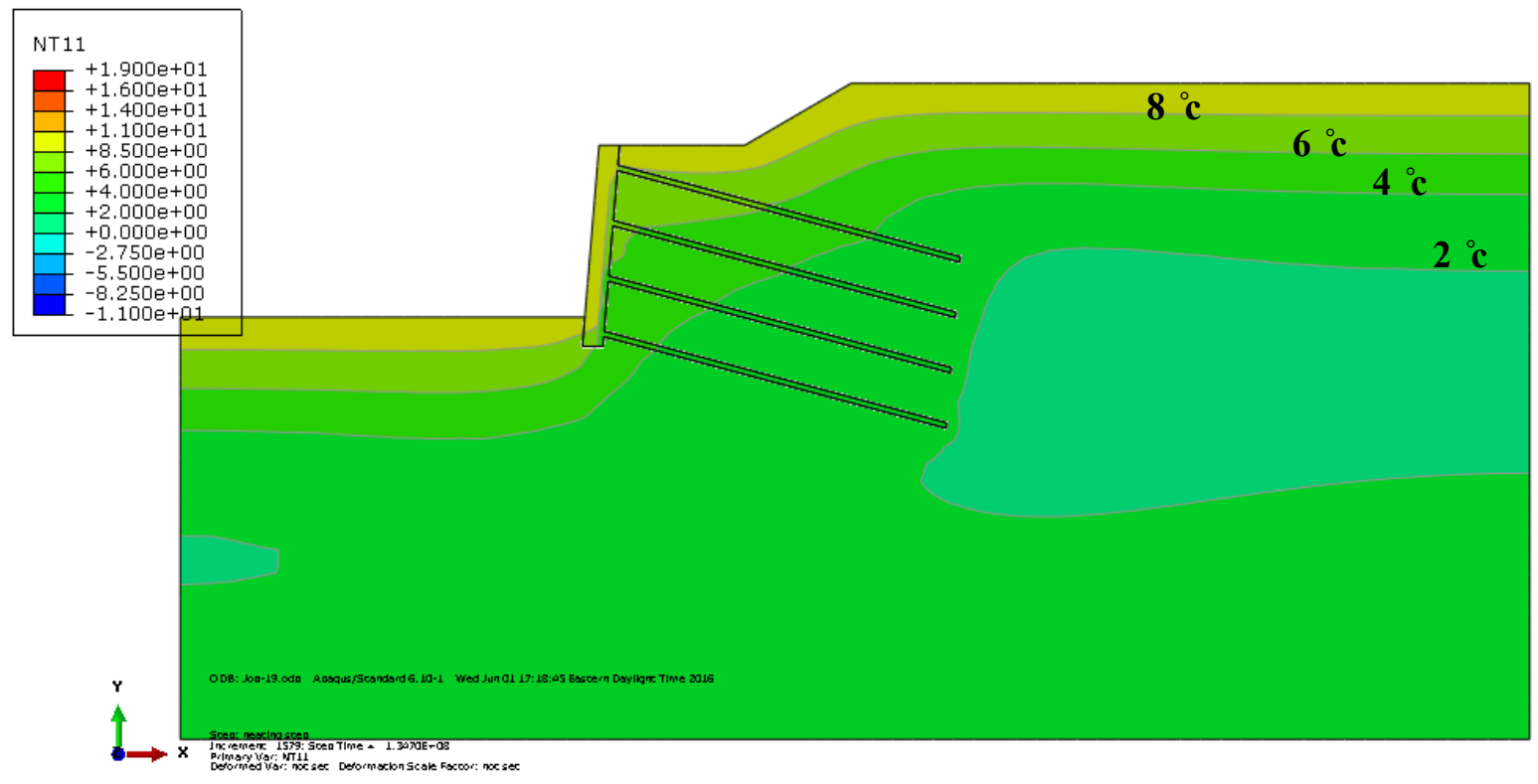

(b) Temperature distribution for warm season, insulated soil nail wall

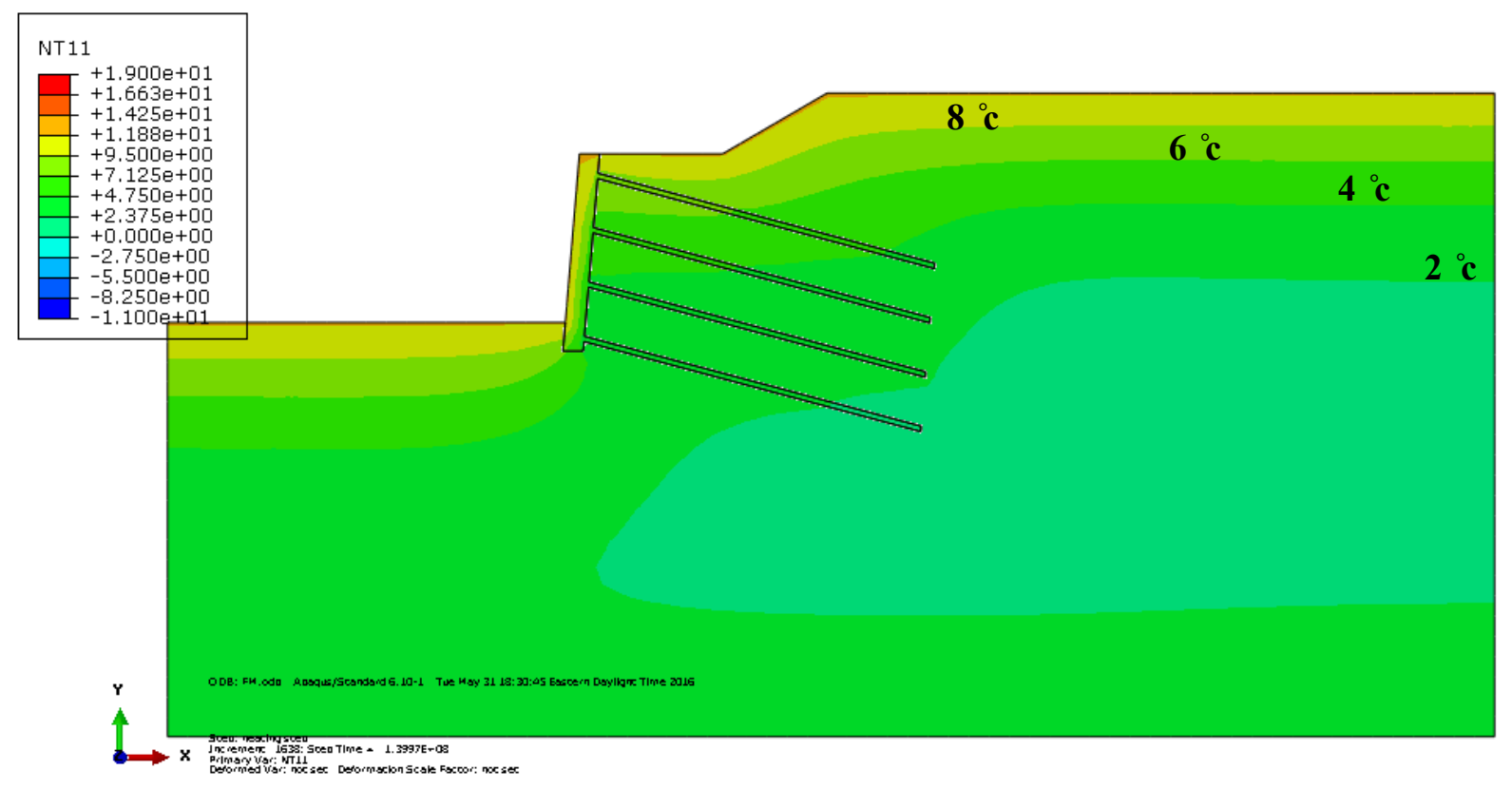

(c)Temperature distribution for warm season, insulated soil nail wall with LFC Figure 4-11 Temperature distribution for warm season in Toronto, ON 
Increased nail stresses and pressures on the wall are attributed to the formation of ice lenses and frost force. Figure 4-12 presents the thermally induced stresses versus time along instrumented nails for the hypothetical insulated and non-insulated SNWs located in Toronto, Ontario.

During the cold season, the highest thermally induced stress on instrumented nail is around 12 $\mathrm{MPa}$, which occurs during the moment of the deepest frost penetration. The peak stress occurs in the nail located closest to the middle of the wall. The stress increase in the third row nail is slightly higher than nail in the second row. A much lower stress increase is found in the bottom row of nails compared to those in the nails in the middle of the wall.

Figure 4-12 denotes that the insulation layer lowers the thermally induced stresses for the nails $\mathrm{N} 2, \mathrm{~N} 3$ and $\mathrm{N} 4$ by approximately $12 \%, 17 \%$ and $31 \%$, respectively in compare to non-insulated wall. However, for insulated wall with LFC the thermally induced stresses for the nails N2, N3 and N4 is diminished by around 34\%, 39\% and 57\%, respectively. It could be noted that the insulation system reduces the effect of frost action over the nails by preventing frost from penetrating into the backfill.

As shown in 4-12 a, b and c, the insulation systems contribute to the overall reduction of freezing front penetration behind the wall. However, the facial insulation shows its usefulness for the nails at the lower part of the wall, where little stress increase occurs in nails during cold season, in compare to the non-insulated wall, where nails experience a large increase. 


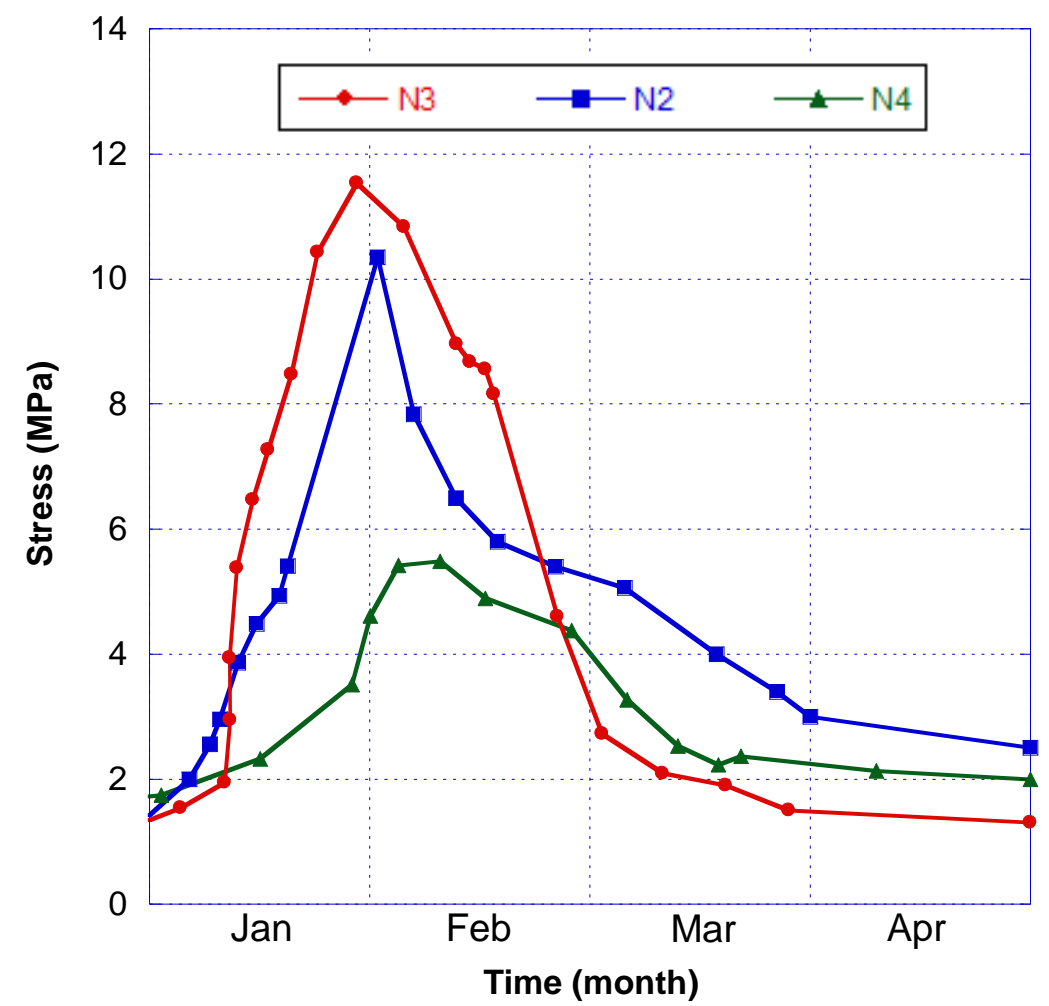

(a) Thermally induced stresses versus time for non-insulated soil nail wall

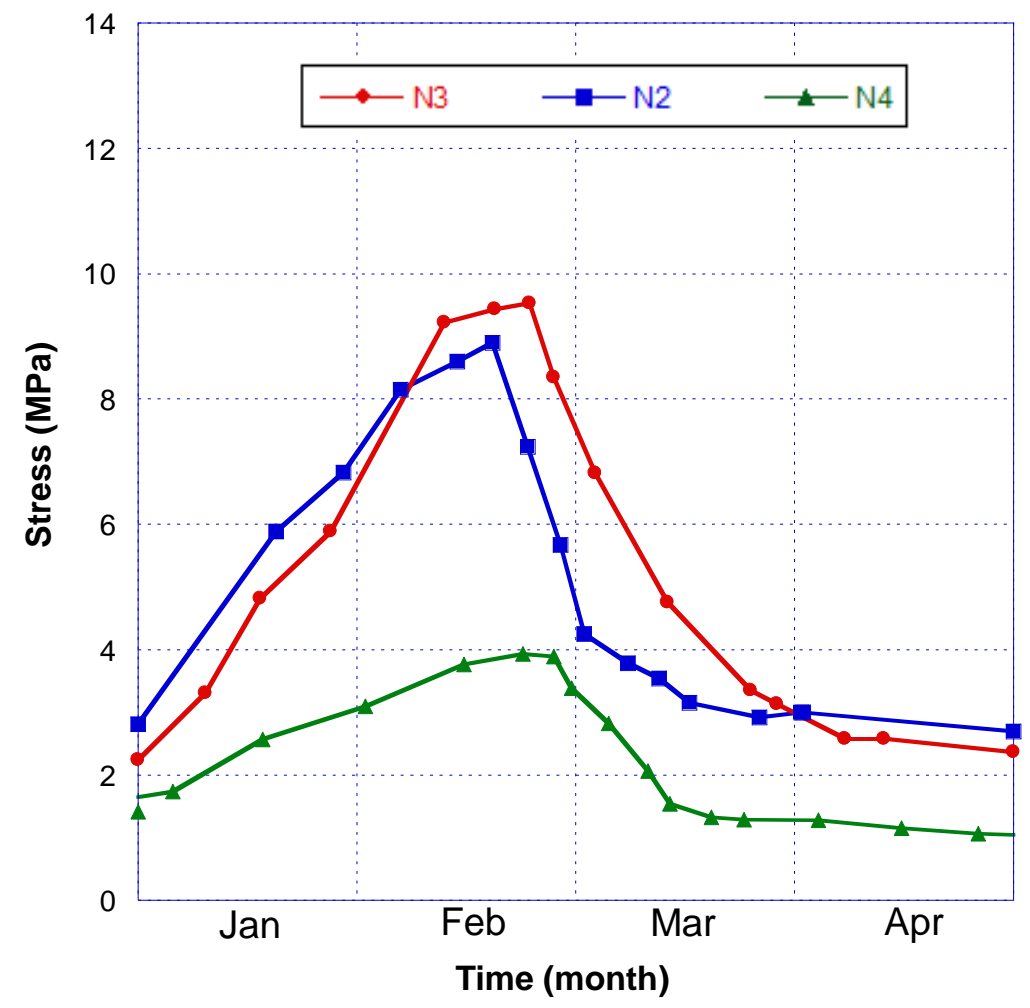

(b) Thermally induced stresses versus time for insulated soil nail wall 


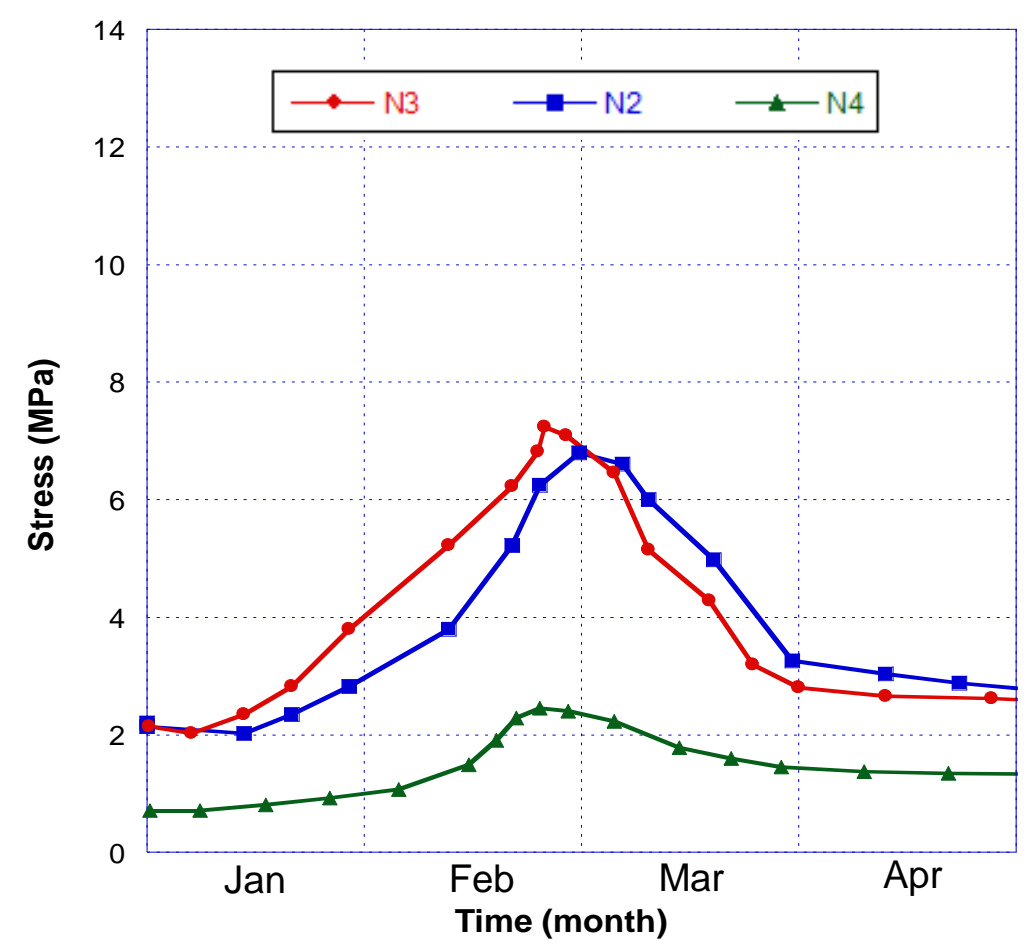

(c) Thermally induced stresses versus time for insulated soil nail wall with LFC

Figure 4-12 Thermally induced stress change versus time for a hypnotical soil nail wall in Toronto, ON

The lateral earth pressure increased on the wall with time during heaving for the insulated and noninsulated SNW are compared in Figure 4-13. During the cold season, the maximum facing pressure increase on the wall is about $0.004 \mathrm{MPa}$, which occurs during the time of the deepest frost penetration.

The insulation systems are proved to be very efficient in reducing the frost induced earth pressure on the wall (Figure 4-13). With the insulation layer, the maximum earth pressure on the wall, during the cold season is reduced to about $18 \%$. However, for the built wall with the LFC, a reduction of nearly $30 \%$ is obtained from FE simulation. Hence, it could be noted that using LFC for facial insulation has a significant effect on the frost heave prevention by impeding the freezing frost penetration.

In the middle of March, the frost induced earth pressure on the wall starts leveling off, indicating that the soil begins thawing and shows no more reaction to temperature variation. 


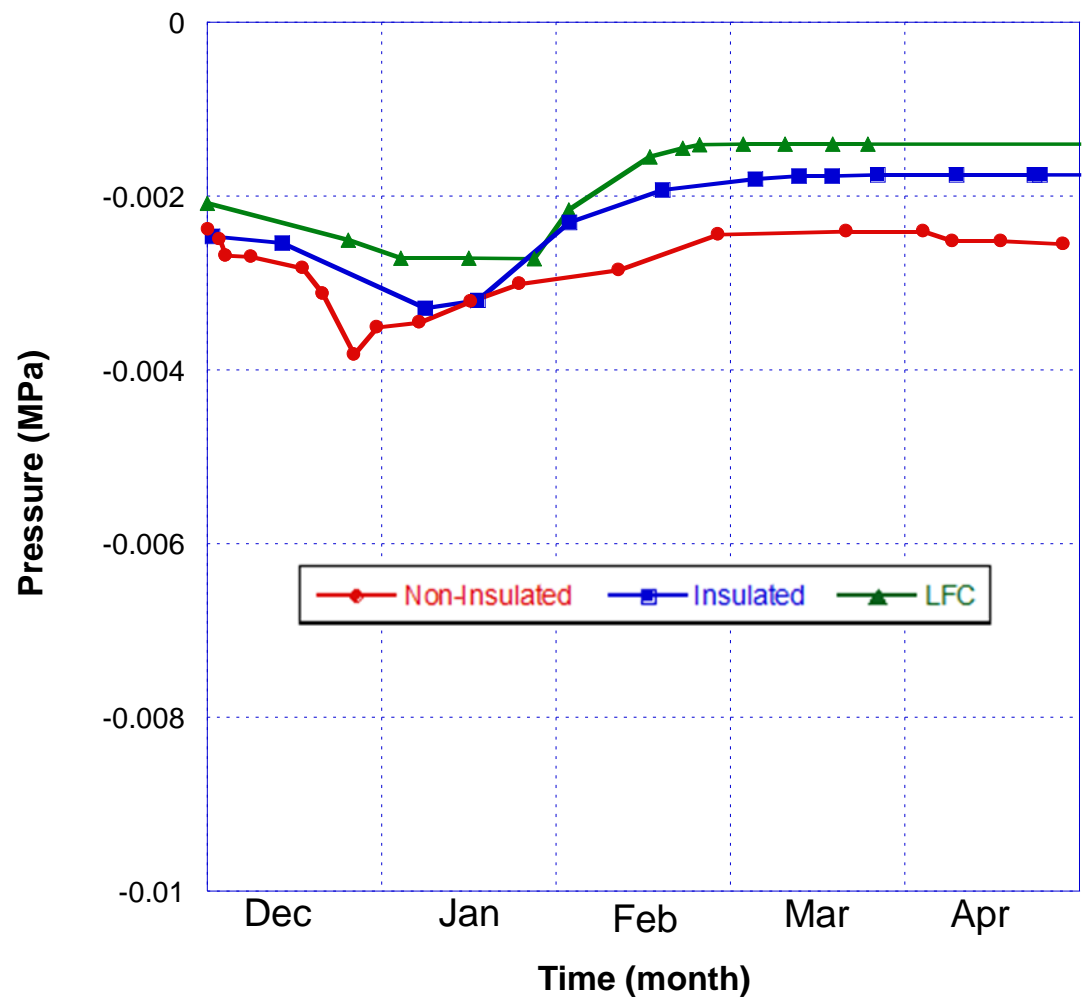

Figure 4-13 Lateral earth pressure increase on the wall versus time in Toronto, ON

To study the influence of the insulation systems on the horizontal movement of the wall, similar insulation systems as previous case are used. The effectiveness of the insulation systems could be evaluated from Figure 4-14.

For the non-insulated wall, the horizontal displacement at the top of the wall occurs when the ambient temperature reaches its lowest value and the freezing front propagates to around $1.2 \mathrm{~m}$ during the freezing season. It is as expected that the wall movement closely corresponds to the seasonal temperature changes. The maximum wall movement is around $0.01 \mathrm{~m}$; roughly $0.2 \%$ of the wall height within the expected range for a SNW, based on the survey by Juran and Elias (1987) on the performance of nailed soil wall in cold regions.

Taking into account that both insulation systems cause similar changes in the thermal regime behind the wall, the maximum outward wall movement is similarly reduced by nearly $41 \%$ for both insulation systems. 
The FE results denoted that the insulation systems are efficient at reducing the wall displacement by limiting the freezing temperature advancement inward from the face of the wall. Hence, the application of insulation systems could protect the SNW against potential damage resulting from frost heave.

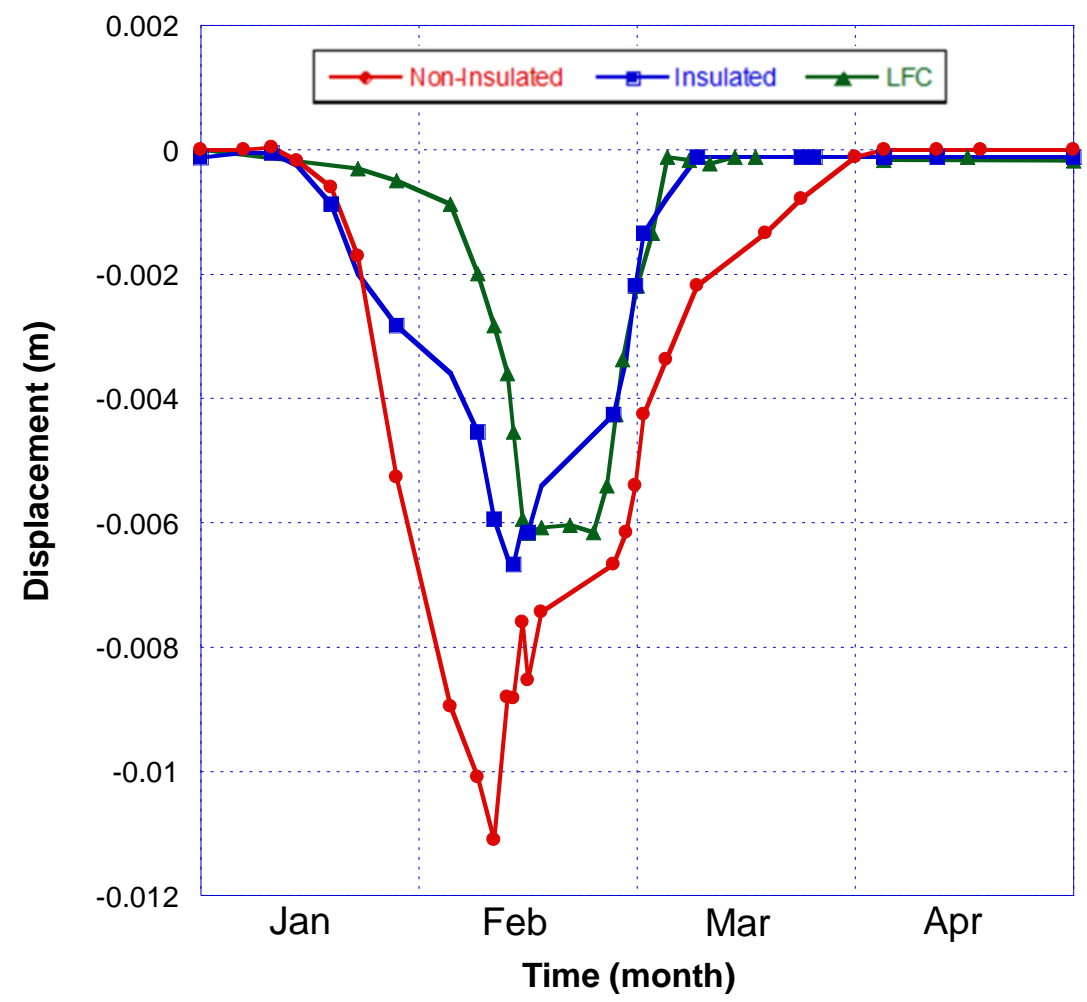

Figure 4-14 Horizontal displacement profile of a hypothetical SNW in Toronto, ON

Vertical displacements of the wall are on the same order of magnitude as the horizontal movements measured at the top of the wall.

The usefulness of the different insulation systems on the vertical wall movement caused by the heave force is studied. Insulation systems included: a $0.01 \mathrm{~m}$ thick facial insulation with the thermal conductivity of $\mathrm{k}=0.02 \mathrm{~W} / \mathrm{m} .{ }^{\circ} \mathrm{C}$ and, LFC for facial insulation with the thermal conductivity of $\mathrm{k}=0.16 \mathrm{~W} / \mathrm{m} .{ }^{\circ} \mathrm{C}$. The FE results of the comparison for the insulated and noninsulated SNW are presented in the Figure 4-15. 
For the non-insulated wall, the vertical displacement of the wall occurs when the ambient temperature reaches its lowest value and the frost front penetrates to around $1.2 \mathrm{~m}$ during the winter month. The heaving force causes the wall to displace downward by about $0.015 \mathrm{~m}$ and tilt. It could be noted that the wall movement, correlates strongly with freezing conditions behind the SNW. With the thermal insulation layer, the maximum vertical movement of the wall is reduced by approximately 56\%. However, using LFC for wall construction reduces the peak vertical movement by roughly $63 \%$.

The FE results indicated the insulation systems are effective at decreasing the wall displacement by slowing down the frost progress behind the SNW.

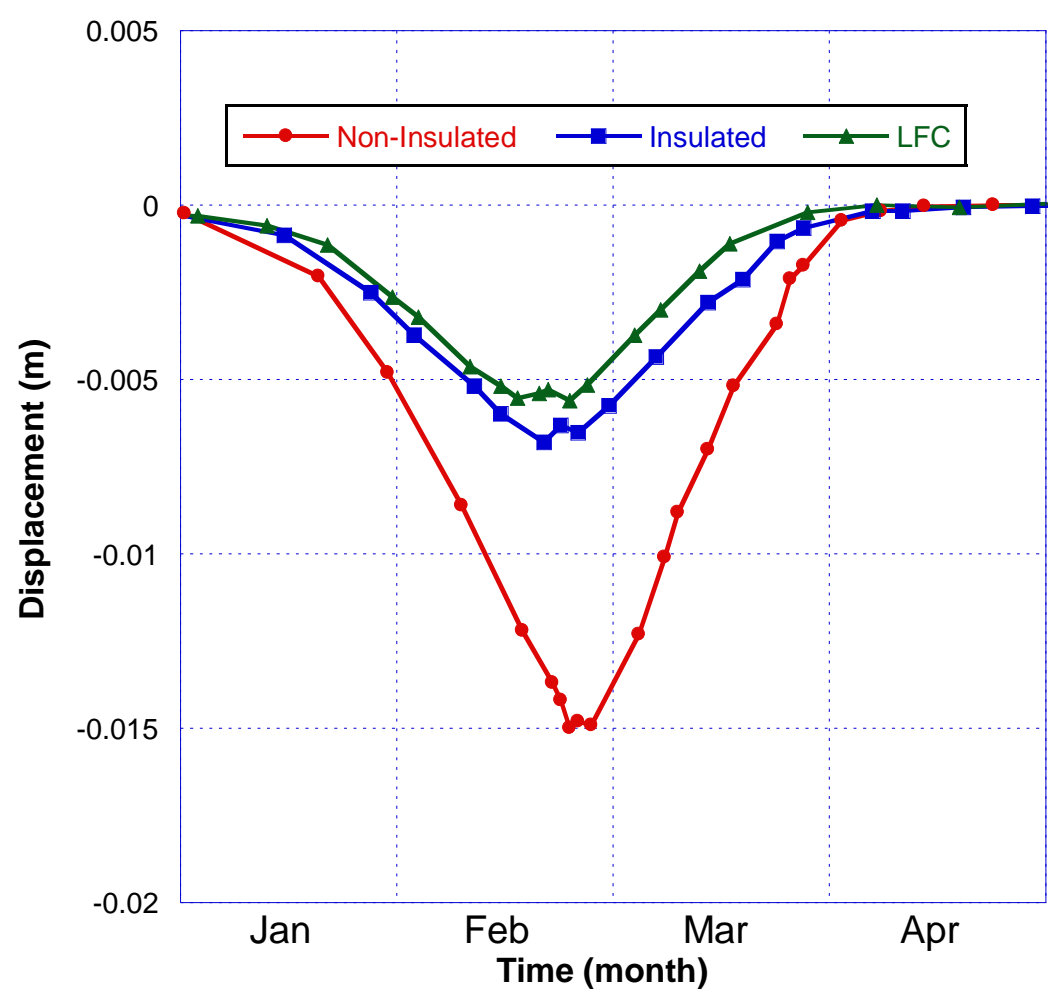

Figure 4-15 Vertical displacement of a hypothetical soil nail wall in Toronto, ON 


\section{Chapter 5 : Conclusions and Future Work}

\subsection{Summary}

In the presented study, a numerical investigation is conducted by using FE package, ABAQUS, to evaluate the influence of freezing conditions on a SNW in terms of frost penetration, wall displacement, lateral earth pressure increase on the wall, and the stress increase along the nail. The model takes into account the effect of latent heat and the variation of thermo-mechanical properties with temperature for frost susceptible soil.

The numerical model is first validated using field measurement from an instrumented SNW in Brunswick, Maine, U.S. The developed model could predict the deformation and stress values similar to field measurements. In the second stage, the developed model is subjected to temperature fluctuations found in Timmins, Ontario and Toronto, Ontario to simulate the coupled processes of thermal loading and soil deformation in two-dimensional cold region problems. These analyses produce interesting results which would improve the understanding of thermal loading on the performance of SNWs in cold regions.

\subsection{Conclusions}

In regards to the thermo-mechanical analysis, the most significant results are the following:

- Frost front penetrates deeper along the soil nailed slope than in the native slope mainly due to high thermal conductivity of steel tendons.

- The mass of soil between the nails freezes slower than the nails due to the differences in the thermal conductivities of these two materials.

- The stress distribution along the nail is not uniform and reached its peak value at a short distance behind the facing wall, approximately $1.5 \mathrm{~m}$ from the nail head. However, it could 
be noted from FE analysis that the zone of deepest frost penetration would not exactly correlate to the maximum thermally induced nail stress.

- The maximum stress increase is found in the nails in the middle of wall. The main reason is the two-dimensional front propagation from both the top and front of the wall, and more restraints at the lower portion of the wall.

- The lateral earth pressure increase on the wall is not very considerable even during sever weather conditions. The main reason is owing to the restraint from densely spaced nails.

- The heaving pressures developed during freezing weather, and the wall movement closely reflect the seasonal temperature variation. As a result of ice lensing, and soil expansion during the cold season, the wall would move outward horizontally and tilt. The maximum horizontal displacements are found at the top of the wall, and it is an important measure, that resonates the intensity of frost action. Vertical displacements of the wall are on the same order of magnitude as the horizontal movements measured at the top of the wall.

- A significant stress increase is obtained in nails due to thermal loading. The nail tendon should be designed properly considering the thermal loads in addition to other loadings.

- In this study, by end of April, the frost induced pressure on the wall has leveled off, indicating that the soil has thawed and presented no more reaction to the temperature variation.

- The FE analysis results indicated that, as facial insulation system devotes to the total reduction of frost propagation along the facing wall, colder weather conditions would induce deeper frost penetration from the top of the wall, which could considerably produce the stress increases in nails within its frost front. However, the facial insulation shows its efficiency for the nails at the lower part of the wall by preventing frost from penetrating into the backfill. Moreover, the results reveal that little stress increase occurs in nail during 
cold season, though the non-insulated wall experiences a large increase in the stress for the nails.

- By limiting the freezing temperature advancement inward from the face of the wall, the insulation systems are proved to be very efficient in reducing the lateral earth pressure on the wall, and consequently wall movements resulting from heaving force are decreased.

- It could be concluded that application of LFC for wall construction would have a considerable effect in the reduction of frost action owing to delay in freezing frost penetration; hence, it can effectively protect the SNW against potential damage resulting from frost heave.

- Although using facial insulation changed the thermal profile behind the wall, its influence on the freezing front advancement for the open ground surface is negligible.

- During the warm season, the insulation system plays a role in delaying the increase in temperature profile for the SNW.

\subsection{Recommendations for Future Research}

More research shall be conducted to thoroughly investigate the influence of freezing conditions on SNWs, and other retention systems.

- Complex thermo-mechanical process shall be modelled in the future. In this study, the main focus is on the conductive heat transfer. Other heat transfer mechanisms, such as heat convection due to water flux, and complex soil property change during temperature variation shall be also examined. 
- It is well known that soil is heterogeneous. The variation of soil parameters particularly thermal properties and its spatial variation should have significant influence on the results. More research shall be conducted in this area.

- More instrumentation scheme and comprehensive numerical analysis may be needed to investigate the performance of SNWs in cold weather regions in terms of reinforcement size, and its layout, various types of surcharge loading, and geometrical dimensions.

- Three dimensional numerical analysis shall be carried out in order to study its effects on the thermo-mechanical fields, in comparison with a 2D plane strain analysis.

- Thermal cyclic loading shall also be included in the future numerical modeling to investigate its influence on the overall stability of SNWs in frost prone regions.

- The equivalent nail-grout system is used in this study. The complex soil-grout interface and its degradation during thermal loading are not considered in the current study. More study or measurement shall be performed to better understand its influence.

- Based on the present analysis, a part of wall movements is irrecoverable. With increasing freezing and thawing cycles, the wall will accumulate more deformation, which will jeopardize the safe operation or maybe even lead to an ultimate failure of the SNW system. More research shall be conducted.

- In the current 2D analysis, the usefulness of two different types of facial insulation systems is examined. The effects of frost action in other frost susceptible soils, cold weather climate with various AFI, groundwater conditions, and the characteristics of the insulation system, shall be investigated to indicate how these factors will influence the performance of a SNW in cold regions. 
Appendices 


\section{Appendix A: ABAQUS inputs for thermo-mechanical analysis with insulation layer}

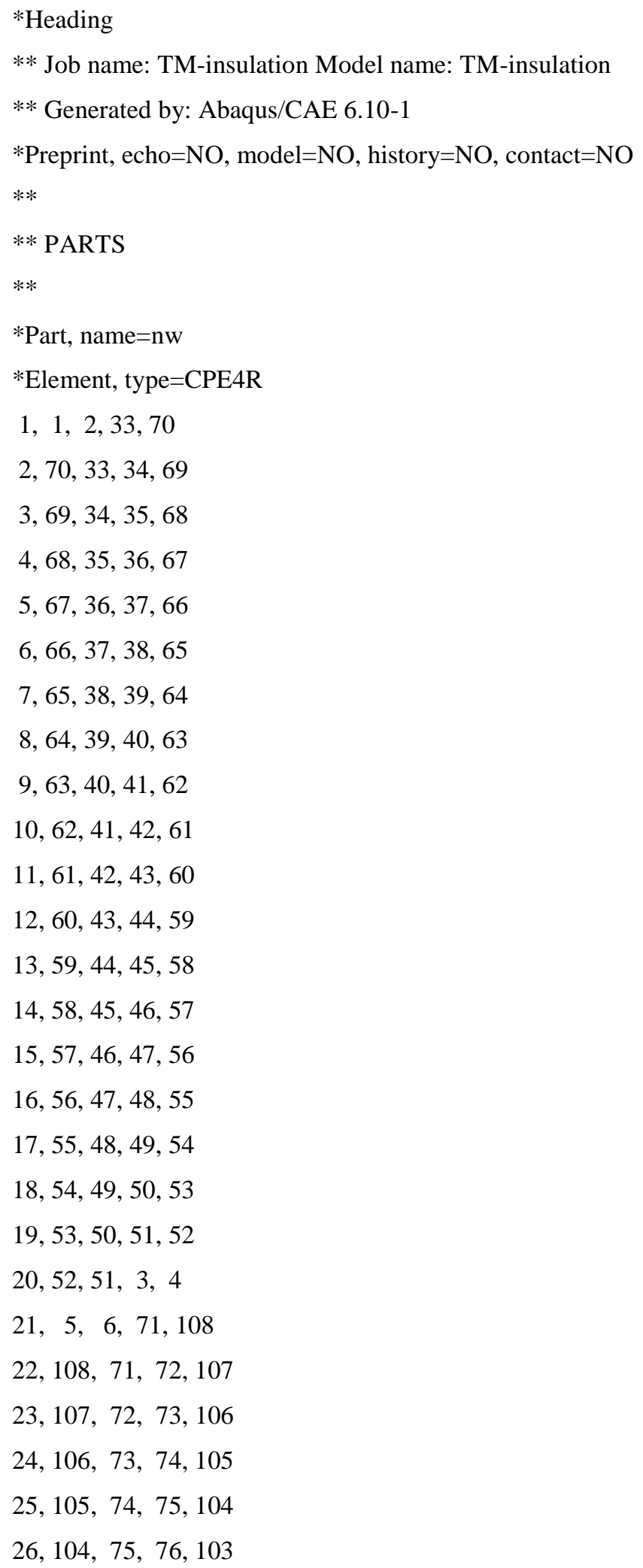


$27,103,76,77,102$

$28,102,77,78,101$

29, 101, 78, 79, 100

$30,100,79,80,99$

$31,99,80,81,98$

32, 98, 81, 82, 97

33, 97, 82, 83, 96

34, 96, 83, 84, 95

$35,95,84,85,94$

$36,94,85,86,93$

37, 93, 86, 87, 92

$38,92,87,88,91$

$39,91,88,89,90$

$40,90,89,7,8$

41, 9, 10, 109, 146

42, 146, 109, 110, 145

$43,145,110,111,144$

$44,144,111,112,143$

$45,143,112,113,142$

$46,142,113,114,141$

47, 141, 114, 115, 140

$48,140,115,116,139$

49, 139, 116, 117, 138

$50,138,117,118,137$

51, 137, 118, 119, 136

$52,136,119,120,135$

$53,135,120,121,134$

$54,134,121,122,133$

$55,133,122,123,132$

$56,132,123,124,131$

$57,131,124,125,130$

$58,130,125,126,129$

$59,129,126,127,128$

$60,128,127,11,12$

$61,13,14,147,184$

$62,184,147,148,183$

$63,183,148,149,182$ 
64, 182, 149, 150, 181

$65,181,150,151,180$

66, 180, 151, 152, 179

67, 179, 152, 153, 178

$68,178,153,154,177$

69, 177, 154, 155, 176

70, 176, 155, 156, 175

71, 175, 156, 157, 174

$72,174,157,158,173$

$73,173,158,159,172$

74, 172, 159, 160, 171

$75,171,160,161,170$

76, 170, 161, 162, 169

$77,169,162,163,168$

$78,168,163,164,167$

79, 167, 164, 165, 166

$80,166,165,15,16$

85, 196, 21, 198, 199

86, 21, 197, 1, 198

87, 191, 9, 187, 190

88, 190, 187, 188, 189

$89,19,20,5,17$

90, 193, 185, 186, 192

91, 194, 13, 185, 193

92, 22, 23, 2, 197

93, 10, 191, 192, 186

$94,189,188,6,20$

95, 194, 195, 14, 13

96, 195, 196, 199, 14

$97,19,18,24,25$

$98,25,26,20,19$

99, 189, 200, 201, 190

100, 20, 26, 200, 189

101, 27, 208, 197, 21

102, 22, 197, 208, 28

103, 190, 201, 202, 191

104, 202, 203, 192, 191 
105, 203, 204, 193, 192

106, 193, 204, 205, 194

107, 194, 205, 206, 195

108, 195, 206, 207, 196

109, 21, 196, 207, 27

$111,24,29,218,25$

112, 30, 219, 218, 29

113, 223, 224, 204, 203

114, 229, 28, 208, 230

$115,217,229,228,31$

116, 209, 220, 219, 30

117, 31, 228, 227, 216

118, 27, 207, 227, 231

119, 216, 227, 226, 215

120, 215, 226, 225, 214

121, 213, 224, 223, 212

122, 221, 222, 202, 201

123, 220, 221, 201, 200

124, 210, 221, 220, 209

$125,32,28,229,217$

126, 200, 26, 219, 220

$127,203,202,222,223$

128, 205, 204, 224, 225

129, 206, 205, 225, 226

130, 207, 206, 226, 227

131, 26, 25, 218, 219

132, 221, 210, 211, 222

133, 222, 211, 212, 223

134, 224, 213, 214, 225

135, 230, 208, 27, 231

136, 231, 228, 229, 230

*Nset, nset=_PickedSet5, internal

$1,2,5,6,9,10,13,14,17,18,19,20,21,22,23,185$

186, 187, 188, 189, 190, 191, 192, 193, 194, 195, 196, 197, 198, 199

*Elset, elset=_PickedSet5, internal, generate

$81,96,1$

*Nset, nset=_PickedSet6, internal 
$1,2,3,4,5,6,7,8,9,10,11,12,13,14,15,16$

$33,34,35,36,37,38,39,40,41,42,43,44,45,46,47,48$

$49,50,51,52,53,54,55,56,57,58,59,60,61,62,63,64$

$65,66,67,68,69,70,71,72,73,74,75,76,77,78,79,80$

$81,82,83,84,85,86,87,88,89,90,91,92,93,94,95,96$

97, 98, 99, 100,101, 102, 103, 104, 105, 106, 107, 108, 109, 110, 111, 112

$113,114,115,116,117,118,119,120,121,122,123,124,125,126,127,128$

129, 130, 131, 132, 133, 134, 135, 136, 137, 138, 139, 140, 141, 142, 143, 144

$145,146,147,148,149,150,151,152,153,154,155,156,157,158,159,160$

$161,162,163,164,165,166,167,168,169,170,171,172,173,174,175,176$

$177,178,179,180,181,182,183,184$

*Elset, elset=_PickedSet6, internal, generate

$1,80,1$

*Nset, nset=_PickedSet7, internal

$24,25,26,27,28,29,30,31,32,200,201,202,203,204,205,206$

207, 208, 209, 210, 211, 212, 213, 214, 215, 216, 217, 218, 219, 220, 221, 222

$223,224,225,226,227,228,229,230,231$

*Elset, elset=_PickedSet7, internal, generate

$110,136,1$

*Nset, nset=_PickedSet8, internal

$18,19,20,21,22,24,25,26,27,28,189,190,191,192,193,194$

195, 196, 197, 200, 201, 202, 203, 204, 205, 206, 207, 208

*Elset, elset=_PickedSet8, internal, generate

97, 109, 1

** Section: nail

*Solid Section, elset=_PickedSet6, material=nail

,

** Section: wall

*Solid Section, elset=_PickedSet5, material=wall

,

** Section: ins

*Solid Section, elset=_PickedSet8, material=insulation

** Section: wall

*Solid Section, elset=_PickedSet7, material=wall

*End Part 
*Part, name=soil

*Nset, nset=_PickedSet18, internal, generate

$1,2165, \quad 1$

*Elset, elset=_PickedSet18, internal, generate

1, 3992, 1

** Section: soil

*Solid Section, elset=_PickedSet18, material=soil

,

*End Part

$* *$

$* *$

** ASSEMBLY

**

*Assembly, name=Assembly

**

*Instance, name=s-1, part=soil

*End Instance

$* *$

*Instance, name $=$ nw-1, part=nw

*End Instance

**

*Nset, nset=_PickedSet175, internal, instance $=\mathrm{s}-1$

$13,14,15,16,17,18,19,20,43,44,45,46,47,48,49,50$

$51,52,53,54,530,531,532,533,534,535,536,537,538,539,540,541$

542, 543, 587, 588, 589, 590, 591, 592, 593, 594, 595, 596, 597, 598, 599, 600

$601,602,603,604,605,606,607$

*Elset, elset=_PickedSet175, internal, instance=s-1

69, 71, 140, 144, 154, 228, 294, 313, 332, 333, 334, 710, 914, 925, 927, 931

933, 935, 936, 937, 938, 981, 982, 984, 988, 993, 997, 1001, 1126, 1155, 1160, 1162

1188, 1190, 1211, 1214, 1216, 1217, 1219, 1221, 1353, 1358, 1378, 1380, 1386, 1476, 1478, 1484

$1486,1494,1496,1502,1504$

*Nset, nset=_PickedSet176, internal, instance=s-1

$20,21,22,23,24,25,26,27,28,29,30,31,32,33,34,35$

$36,37,38,39,40,41,42,43,544,545,546,547,548,549,550,551$

$552,553,554,555,556,557,558,559,560,561,562,563,564,565,566,567$ 
$568,569,570,571,572,573,574,575,576,577,578,579,580,581,582,583$

$584,585,586$

*Elset, elset=_PickedSet176, internal, instance=s-1

$14,62,80,152,155,160,162,163,188,189,203,205,238,255,293,310$

312, 925, 941, 945, 946, 947, 949, 950, 951, 954, 955, 959, 962, 963, 964, 967

968, 972, 973, 976, 977, 978, 981, 1118, 1130, 1131, 1158, 1165, 1167, 1171, 1172, 1174

1175, 1178, 1181, 1198, 1202, 1206, 1356, 1404, 1406, 1426, 1432, 1439, 1447, 1449, 1453, 1458

1461,1469

*Nset, nset=_PickedSet177, internal, instance=s-1, generate

$1,2165, \quad 1$

*Nset, nset=_PickedSet177, internal, instance=nw-1, generate

$1,231, \quad 1$

*Elset, elset=_PickedSet177, internal, instance=s-1, generate

$1,3992, \quad 1$

*Elset, elset=_PickedSet177, internal, instance=nw-1, generate

$1,136,1$

*Nset, nset=_PickedSet178, internal, instance $=$ nw-1

$1,2,3,4,5,6,7,8,9,10,11,12,13,14,15,16$

$33,34,35,36,37,38,39,40,41,42,43,44,45,46,47,48$

$49,50,51,52,53,54,55,56,57,58,59,60,61,62,63,64$

$65,66,67,68,69,70,71,72,73,74,75,76,77,78,79,80$

$81,82,83,84,85,86,87,88,89,90,91,92,93,94,95,96$

97, 98, 99, 100,101, 102, 103, 104, 105, 106, 107, 108, 109, 110, 111, 112

$113,114,115,116,117,118,119,120,121,122,123,124,125,126,127,128$

129, 130, 131, 132, 133, 134, 135, 136, 137, 138, 139, 140, 141, 142, 143, 144

$145,146,147,148,149,150,151,152,153,154,155,156,157,158,159,160$

$161,162,163,164,165,166,167,168,169,170,171,172,173,174,175,176$

$177,178,179,180,181,182,183,184$

*Elset, elset=_PickedSet178, internal, instance=nw-1, generate

$1,80,1$

*Nset, nset=_PickedSet179, internal, instance $=$ s-1, generate

$1,2165,1$

*Elset, elset=_PickedSet179, internal, instance $=$ s-1, generate

1, 3992, 1

*Nset, nset=WALL-DIS, instance $=$ nw-1

17,29

*Nset, nset=NAIL-2, instance $=$ nw-1 
$110,111,144,145$

$*$ Nset, nset=NAIL-3, instance $=$ nw- 1

$148,149,182,183$

*Nset, nset=nail-4, instance $=$ nw-1

$34,35,68,69$

*Nset, nset=WALL-pressuremeter, instance $=\mathrm{s}-1$

704 ,

** Constraint: Constraint-1

*Embedded Element, host elset=_PickedSet179

_PickedSet178

*End Assembly

*Amplitude, name=fullcycle, time=TOTAL TIME

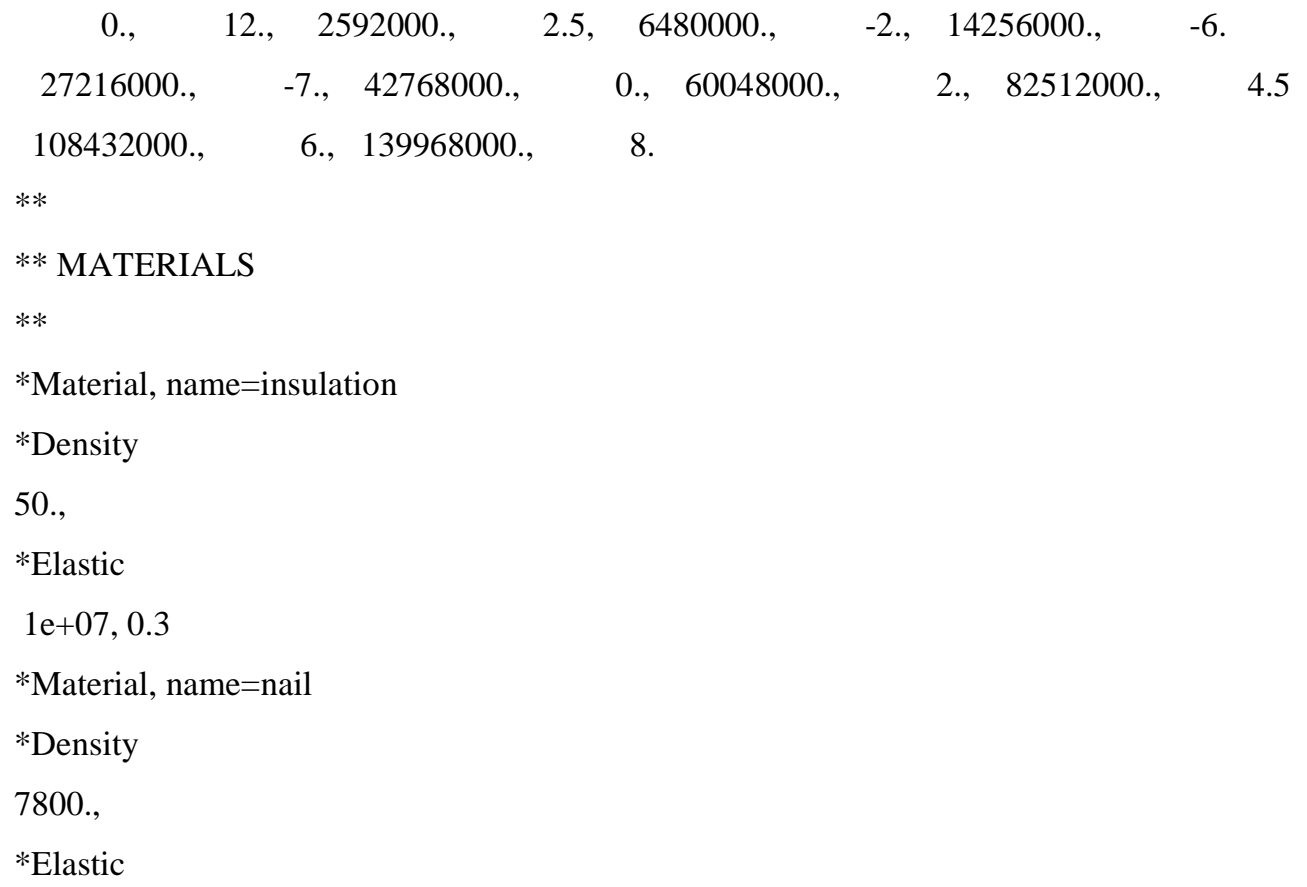


$5.5 \mathrm{e}+07,0.3,-1$.

$2.8 \mathrm{e}+07,0.3,0$.

$2.8 \mathrm{e}+07,0.3,5$.

$2.8 \mathrm{e}+07,0.3,19$.

*Expansion

$-0.00084,-11$.

$-0.00168,-7$.

$-0.00267,-3$.

$-0.00476,-1$.

$0 ., 0$.

$0 ., 5$.

$0 ., 19$.

*Mohr Coulomb

$36 ., 0.1,-11$.

34., $0.1,-7$.

32., $0.1,-3$.

$31 ., 0.1,-1$.

30., $0.1,0$.

30., 0.1, 5 .

30., 0.1, 19 .

$*$ Material, name $=$ wall

*Density

2240 .,

*Elastic

$4.9 \mathrm{e}+09,0.25$

*Expansion

8e-06,

**

** BOUNDARY CONDITIONS

**

** Name: BC-5 Type: Displacement/Rotation

*Boundary

_PickedSet175, 1, 1

** Name: BC-6 Type: Displacement/Rotation

*Boundary

_PickedSet176, 1, 1

_PickedSet176, 2, 2 


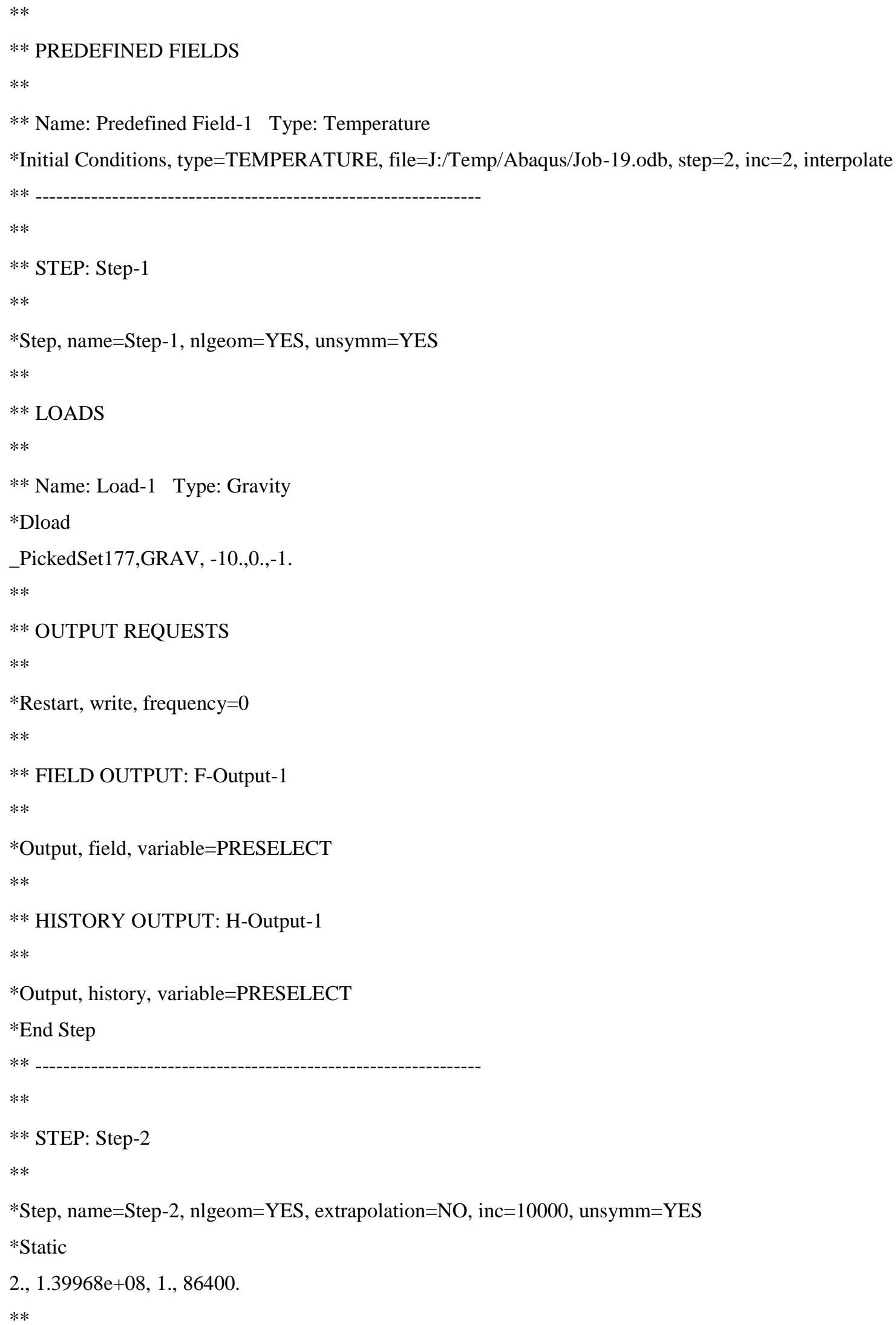


**Name: Load-2 Type: Pressure

*Dsload

_PickedSet193,GRAV,P,14000.

** OUTPUT REQUESTS

**

*Restart, write, frequency $=0$

**

** FIELD OUTPUT: F-Output-8

**

*Output, field

*Node Output

NT,

$* *$

** FIELD OUTPUT: F-Output-3

**

**

** FIELD OUTPUT: F-Output-4

**

**

** FIELD OUTPUT: F-Output-7

**

**

** FIELD OUTPUT: F-Output-6

$* *$

** FIELD OUTPUT: F-Output-5

**

**

** FIELD OUTPUT: F-Output-1

$* *$

*TEMPERATURE, file=J:/Temp/Abaqus/Job-19.odb, bstep=2, estep=2

$*$ Output, field, variable=PRESELECT

**

** HISTORY OUTPUT: H-Output-1

**

*Output, history, variable=PRESELECT

*End Step 


\section{Appendix B: Displacement profiles for non-insulated soil nail wall}

Figure A1 and A2 presented horizontal displacement profiles for a hypothetical non-insulated SNW when the ambient temperature reaches its lowest value for Timmins and Toronto, respectively.

Vertical displacement profiles of a hypothetical non-insulated SNW as a result of frost heave is shown in Figure A2 and A4 for Timmins and Toronto, respectively.

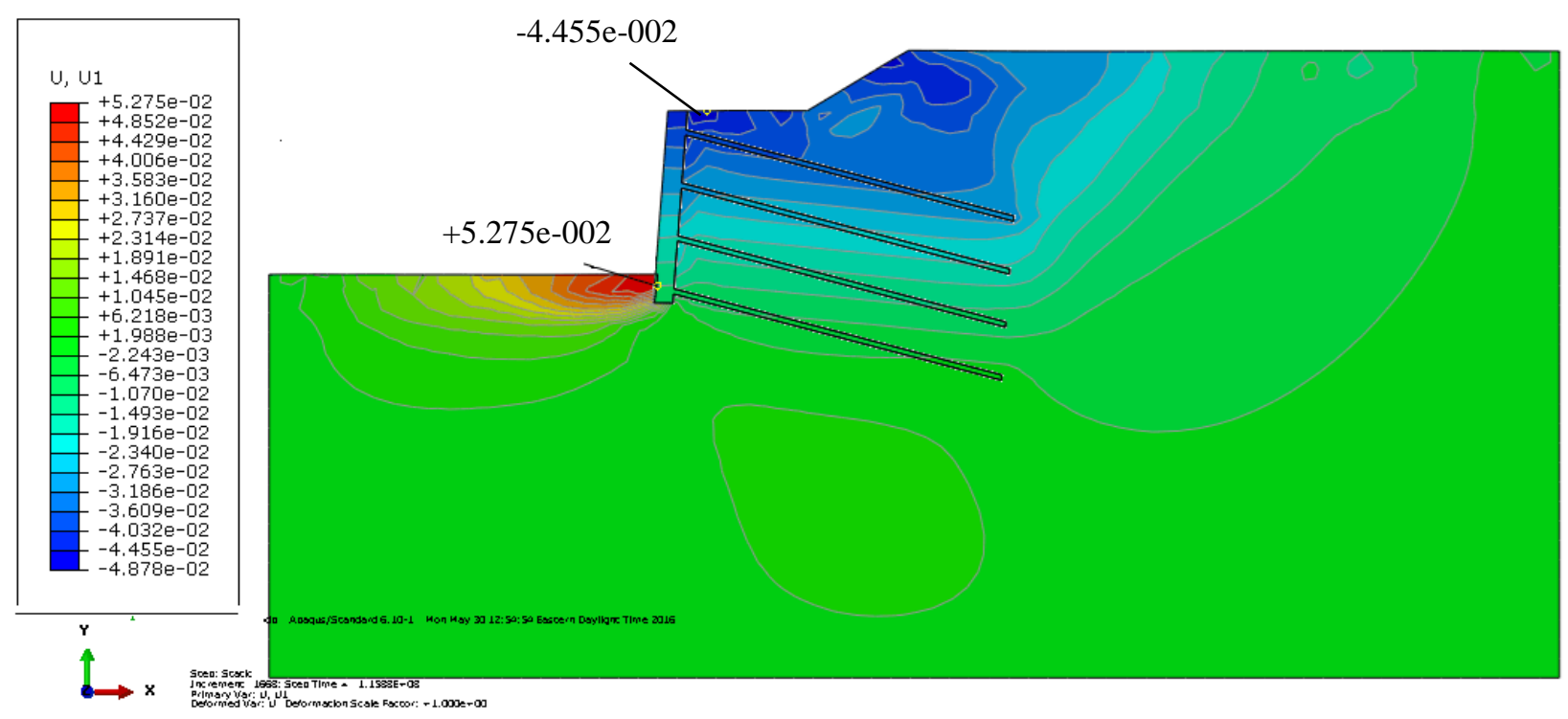

Figure B.1 Horizontal displacement profile of a hypothetical soil nail wall in Timmins, ON 

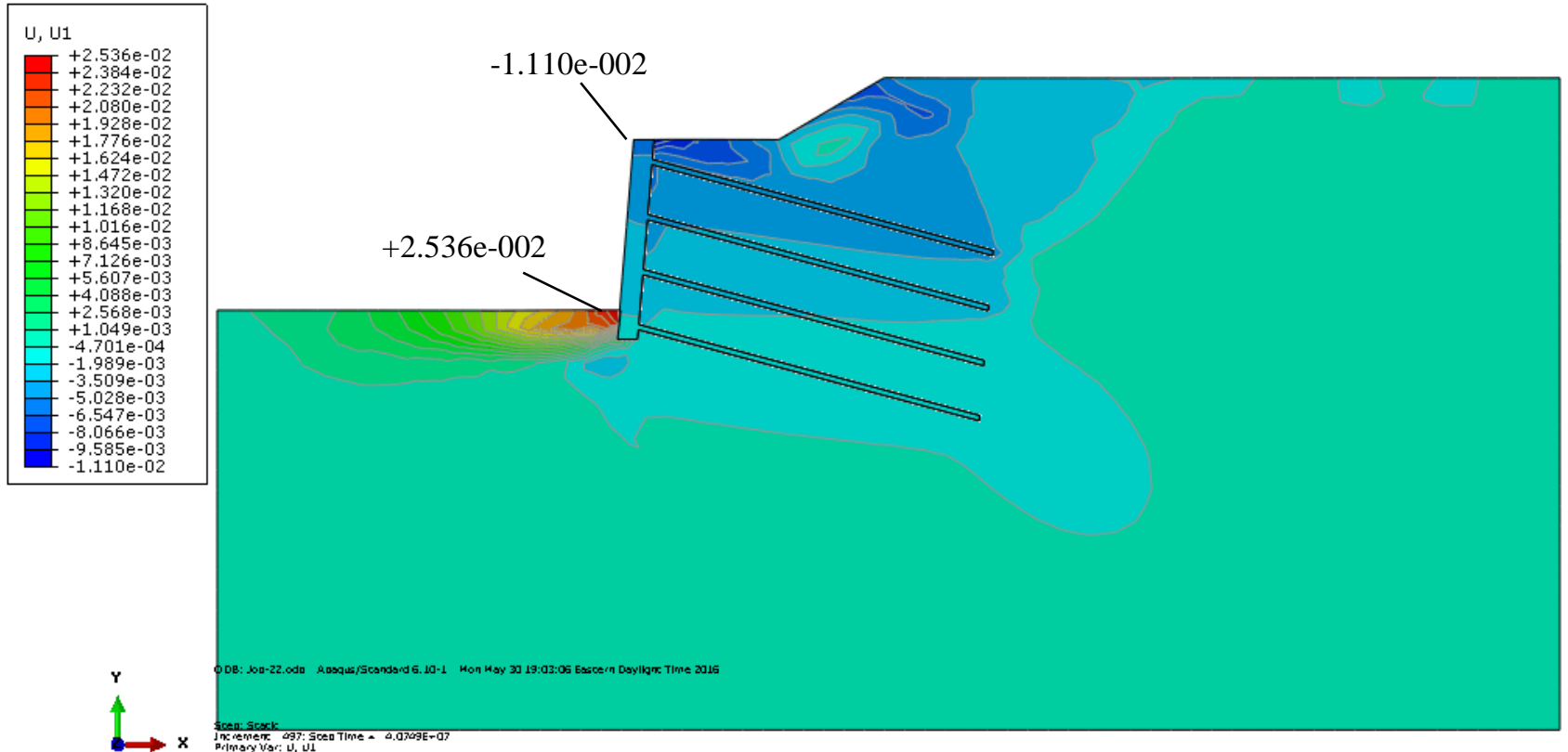

Figure B.2 Horizontal displacement profile of a hypothetical soil nail wall in Toronto, ON

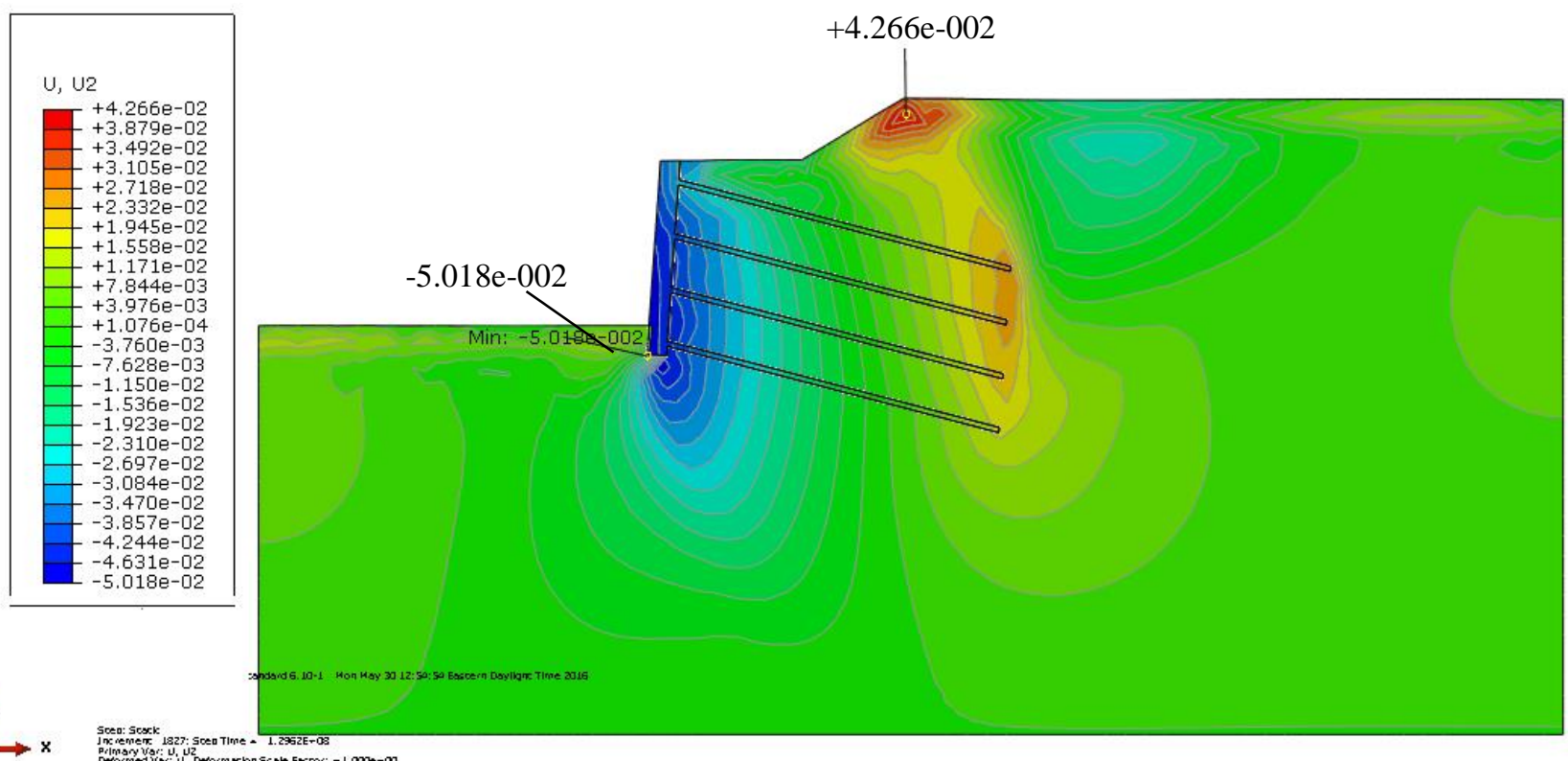

Figure B.3 Vertical displacement profile of a hypothetical soil nail wall in Timmins, ON 


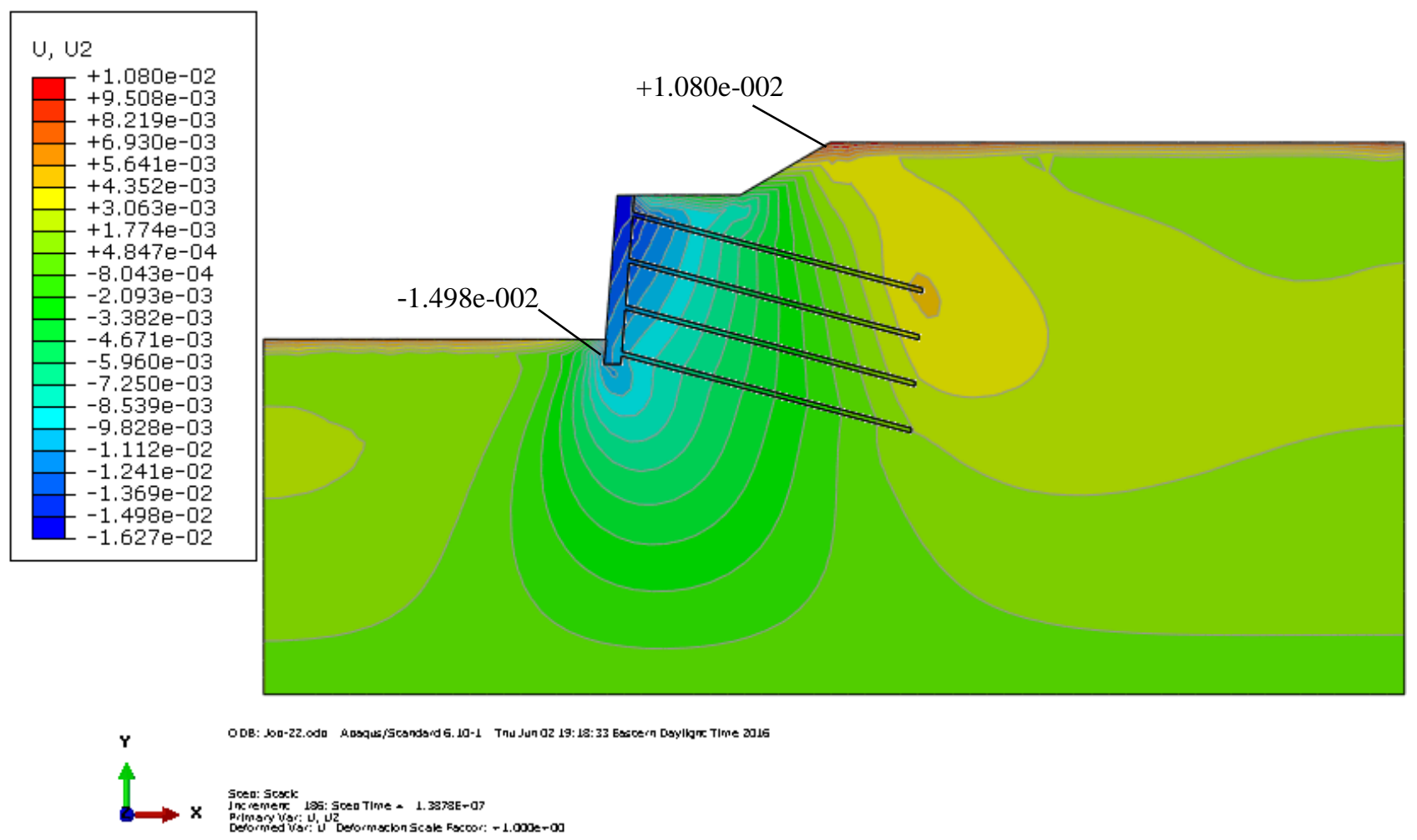

Figure B.4 Vertical displacement profile of a hypothetical soil nail wall in Toronto, ON 


\section{References}

Andersland, O. B., \& Ladanyi, B. (2004). Frozen ground engineering. John Wiley \& Sons.

Aldrich Jr, H. P. (1956). Frost penetration below highway and airfield pavements. Highway Research Board Bulletin, (135).

Alston, C. (1991). Construction of a Geogrid-and Geocomposite-Faced Soil-Nailed Slope Reinforcement Project in Eastern Canada. Transportation Research Record, 1330, 87.

Ansari, N., \& Domitric, C. (1992). Soil Nailing Earth Shoring System. A Ten-Year Update.

Bauchau, O. A., \& Craig, J. I. (2009). Structural analysis: with applications to aerospace structures (Vol. 163). Springer Science \& Business Media.

Blanchard, D., \& Fremond, M. (1985). Soil frost heaving and thaw settlement. In Proc. 4th Int. Symp. on Ground Freezing, Sapporo (Vol. 1, pp. 209-216).

Byrne, R. J., Cotton, D., Porterfield, J., Wolschlag, C., \& Ueblacker, G. (1996). Manual for design and construction monitoring of soil nail walls (No. FHWA-SA-96-069,).

Broms, B. B., \& Ingelson, I. (1971). Earth pressure against the abutments of a rigid frame bridge. Geotechnique, 21(1), 15-28.

Bruce, D. A., \& Jewell, R. A. (1986). Soil nailing: application and practice-part 1. Ground Engineering, 19(8), 10-15.

Berg, R. L., \& Johnson, T. C. (1983). Revised Procedure for Pavement Design under Seasonal Frost Conditions (No. CRREL-SR-83-27). Cold regions research and engineering lab hanover nh.

Boyd, D. W. (1976). Normal freezing and thawing degree-days from normal monthly temperatures. Canadian Geotechnical Journal, 13(2), 176-180.

Cekerevac, C., \& Laloui, L. (2004). Experimental study of thermal effects on the mechanical behavior of a clay. International journal for numerical and analytical methods in geomechanics, 28(3), 209228.

Caine, T. N. (2012). Changing Cold Environments: a Canadian Perspective. Arctic, Antarctic, and Alpine Research, 44(4), 520-521.

Canadian Geotechnical Society. Foundations Committee. (2006). Canadian foundation engineering manual. Canadian geotechnical society, 185-196. 
Chen, L., Li, G., and Huang, W. (1996). Full-scale test studies on prevention of frost damage for retaining wall reinforced with geotextile. In Cold Regions Engineering@ sThe Cold Regions Infrastructure-An International Imperative for the 21st Century (pp. 724-735). ASCE.

Duchesne, S. M. (2003). Effects of Frost Heave on a Soil Nail Wall in Brunswick, Maine (Doctoral dissertation, Northeastern University).

Elias, V. and Juran, I. (1991). Soil nailing for stabilization of highway slopes and excavations. Final report (No. FHWA-RD-89-198).

Eigenbrod, K. D., \& Burak, J. P. (1992). Field measurement of anchor forces, ground temperatures, and pore-water pressures behind a retaining structure in northwestern Ontario. Canadian Geotechnical Journal, 29(1), 112-116.

Everett, D.H. (1961). The thermodynamics of frost dam age to porous solids. Transactions of the Faraday Society, 57, 1541-1551.

Farouki, O. T. (1981). Thermal properties of soils (No. CRREL-MONO-81-1). Cold regions research and engineering lab hanover nh.

Freitag, D.R. and McFadden, T. (1997). Introduction to cold regions engineering. Published by ASCE Press, New York, pp. 209-211.

Fukuda, M., Kim, H., \& Kim, Y. (1997). Preliminary results of frost heave experiments using standard test sample provided by TC8. In Proceedings of the international symposium on ground freezing and frost action in soils, Lulea, Sweden (Vol. 25, p. 30).

French, H. M., \& Slaymaker, O. (1993). Canada's cold environments (Vol. 1). McGill-Queen's PressMQUP.

Guilloux, A., Notte, G., \& Gonin, H. (1983). Experiences on retaining a structure by nailing in marine soils. Proceeding of European conference on soil mechanics and foundation engineering.

Gudehus, G., \& Schwing, E. (1988). Soil-nailing, Design and application to modern and ancient retaining walls. In Proceedings International Geotechnical Symposium on Theory and Practice of Earth Reinforcement, Fukuoka, Japan, Balkema (pp. 605-610).

Haynes, F. D. (1978). Strength and deformation of frozen silt. In Proceedings of the Third International Conference on Permafrost, Edmonton, Alberta, Canada (Vol. 1, 656-661).

Haynes, F. D., \& Karalius, J. A. (1977). Effect of temperature on the strength of frozen silt (No. CRREL-77-3). Cold regions research and engineering lab hanover nh.

Henry, K. S. (1998). The use of geosynthetics to mitigate frost heave in soils. 
Henry, K.S., Zhu, M., and Michalowski, R.L. (2005). Evaluation of three frost heave models. In Proceedings of 7th International Conference on the Bearing Capacity of Roads, Railways and Airfields (BCRA'05).

Hibbitt, K. (2010). Sorensen Inc. ABAQUS/standard user's manual, version 6.10. 1. Pawtucket (RI): Hibbitt, Karlsson, \& Sorensen.

Holman, J. P. (1997). Heat Transfer, 8th Edition. McGraw-Hill.

Jumikis, A. R. (1977). The cryogenic system soil-water-temperature. AJP77, 1, 112-120.

Joshi, B. (2003). Behavior of calculated nail head strength in soil-nailed structures. Journal of geotechnical and geoenvironmental engineering, 129(9), 819-828.

Konrad, J. M., \& Morgenstern, N. R. (1982). Effects of applied pressure on freezing soils. Canadian Geotechnical Journal, 19(4), 494-505.

Kingsbury, D., Sandford, T., \& Humphrey, D. (2002). Soil nail forces caused by frost. Transportation Research Record: Journal of the Transportation Research Board, (1808), 38-46.

Konrad, J. M., \& Morgenstern, N. R. (1982). Effects of applied pressure on freezing soils. Canadian Geotechnical Journal, 19(4), 494-505.

Ladanyi, B., \& Shen, M. (1993). Freezing pressure development on a buried chilled pipeline. In Proceedings of the 2nd International Symposium on Frost in Geotechnical Engineering (pp. 23$33)$.

Lazarte, C. A., Robinson, H., Gómez, J. E., Baxter, A., Cadden, A., \& Berg, R. (2015). Soil Nail Walls Reference Manual (No. FHWA-NHI-14-007).

Lunardini, V. J. (1980). Phase change around a circular pipe (No. CRREL-80-27). Cold regions research and engineering lab hanover nh.

Michalowski, R. L. (1993). A constitutive model of saturated soils for frost heave simulations. Cold regions science and technology. 22(1), 47-63.

Michalowski, R. L., and Zhu, M. (2006). Frost heave modelling using porosity rate function, International Journal for Numerical and Analytical Methods in Geomechanics, vol. 30,703-722.

Michalowski, R.L. and Zhu, M. (2004). Constitutive model for heaving of frost susceptible soils. In Numerical Models in Geomechanics: Proceedings of the Ninth International Symposium on 'Numerical Models in Geomechanics-NUMOG IX', Ottawa, Canada, 25 - 27 August 2004 (p. 71). 
McRostie, G. C., \& Schriever, W. R. (1967).Frost pressures in the tie-back system at the national arts center excavation (no. rp-309). National research council of Canada Ottawa (Ontario) div of building research.

Neaupane, K. M., Yamabe, T., \& Yoshinaka, R. (1999). Simulation of a fully coupled thermo-hydromechanical system in freezing and thawing rock. International Journal of Rock Mechanics and Mining Sciences, 36(5), 563-580.

Nixon, J. F., \& McRoberts, E. C. (1973). A study of some factors affecting the thawing of frozen soils. Canadian Geotechnical Journal, 10(3), 439-452.

Nixon, J. F. (1990). The frozen earth: Fundamentals of geocryology. Canadian Geotechnical Journal, 27(4), 530-530.

Nicholson, P. J. (1986). In Situ Ground Reinforcement Techniques. In Proceedings of Conference on Deep Foundations, Deep foundation Institute/Chinese Institute of Ground Improvement and Sciences, Beijing, China, September.

O 'Neill, K and Miller, R.D. (1980). "Numerical solutions for rigid-ice model of secondary frost heave." Proceedings of the 2nd International Symposium on Ground Freezing, Trondheim, Norway, pp. 656-669.

O 'Neill, K and Miller, R.D. (1985). Exploration of a rigid ice model of frost heave. Water Resources Research, 21(3), 281-296.

Ontario Provincial Standards For Roads \& Public Works. (2010). Foundation, Frost Penetration Depths For Northern Ontario, vol 3, Ministry of Transportation of Ontario, Canada, 3090.100.

Panday, S., \& Corapcioglu, M. Y. (1995). Solution and evaluation of permafrost thaw-subsidence model. Journal of engineering mechanics, 121(3), 460-469.

Penner, E. (1959). The mechanism of frost heaving in soils. Highway Research Board Bulletin, (225).

Penner, E., \& Crawford, C. B. (1983). Frost action and foundations.

Pappas, N. D., \& Sexsmith, D. P. (1968). Performance Monitoring of a Deep Cofferdam in Sensitive Clay. Canadian Geotechnical Journal, 5(2), 80-94.

Rajaei, P., \& Baladi, G. Y. (2015). Frost Depth: General Prediction Model. Transportation Research Record: Journal of the Transportation Research Board, (2510), 74-80.

Schlosser, F. (1993). Recommendations Clouterre, (1991) (English Translation), Federal Highway Administration. FHWA-SA-93-026. 
Sandegren, E., Sahlstroem, P. O., \& Stille, H. (1972). Behavior of anchored sheet-pile wall exposed to frost action. In Fifth Eur Conf On Soil Proc/Sp/ (No. Conf Paper).

Shaanxi, Y., (2015). Numerical Simulation Research on the Frost Heaving of Lining Canal with Consideration of Heat-Moisture-Stress Coupling. Northwest A\&F University, China.

Smoltczyk, U., Hilmer, K., Franke, E., \& Schuppener, B. (1977). Earth pressure variations due to temperature change. In Proceedings of the 9th International Conference on Soil Mechanics and Foundation Engineering (Vol. 1, pp. 725-733).

Tsytovich, N. A. (1960). Bases and foundations on frozen soil. Highway Research Board Special Report, (58).

Taber, S. (1929). Frost heaving. The Journal of Geology, 428-461.

Thomas H. R., Rees S. W. (1998). The thermal performance of ground floor slabs - a full scale insitu experiment. Building and Environment 34 (2), 139 - 164.

Unterreiner, P. 1994. Contribution to the Study and Numeric Modeling of Soil Nails: Design Estimates for Deformation of Retaining Structures, Ph.D. dissertation, Paris, 989.

Wanstreet, P. (2007). Finite element analysis of slope stability. ProQuest.

Wulff, J. (Ed.). (1965). Structure and Properties of Materials: Mechanical behavior, by HW Hayden, LG Moffatt, and J. Wulff (Vol. 3). Wiley.

Xu, X. Z., Wang, J. C., Zhang, L. X., (2001). Frozen soil physics. Beijing Science and Technology Press, Beijing.

Xu X., Wang J., Zhang L., (2001). Frozen soil physics [M]. Beijing: Science Press.

Zhou, M. M., \& Meschke, G. (2013). A three-phase thermo-hydro-mechanical finite element model for freezing soils. International Journal for Numerical and Analytical Methods in Geomechanics, 37(18), 3173-3193.

Zhang, Y., \& Michalowski, R. L. (2013). Thermal-mechanical constitutive modeling for freezing and thawing soils. In ISCORD 2013@ sPlanning for Sustainable Cold Regions (pp. 256-267). ASCE. Zhu, M., (2006). Modeling and simulation of frost heave in frost-susceptible soils. University of Michigan.

Zwissler, B., Oommen, T., \& Vitton, S. (2016). Method to Quantify Freeze-Thaw Effects on Temperate Climate Soils: Calvert Cliffs. Journal of Cold Regions Engineering, 06016002. 